Marquette University

e-Publications@Marquette

9-1-2015

Does Koopmans' Paradigm for 1-Electron Oxidation Always Hold? Breakdown of IP/Eox Relationship for $\mathrm{p}$-Hydroquinone Ethers and the Role of Methoxy Group Rotation

Marat R. Talipov

Marquette University

Anitha Boddeda

Marquette University, anitha.boddeda@marquette.edu

Sergey Lindeman

Marquette University, sergey.lindeman@marquette.edu

Rajendra Rathore

Marquette University

Accepted version. Journal of Physical Chemistry Letters, Vol. 6, No. 17 (September 2015): 3373-3378.

DOI. (C) 2015 American Chemical Society. Used with permission. 


\title{
Does Koopmans' Paradigm for 1- Electron Oxidation Always Hold? Breakdown of IP/Eox Relationship for p-Hydroquinone Ethers and the Role of Methoxy Group Rotation
}

\author{
Marat R. Talipov \\ Department of Chemistry, Marquette University, \\ Milwaukee, WI \\ Anitha Boddeda \\ Department of Chemistry, Marquette University, \\ Milwaukee, WI \\ Sergey V. Lindeman \\ Department of Chemistry, Marquette University, \\ Milwaukee, WI \\ Rajendra Rathore \\ Department of Chemistry, Marquette University, \\ Milwaukee, WI
}




\section{Abstract}

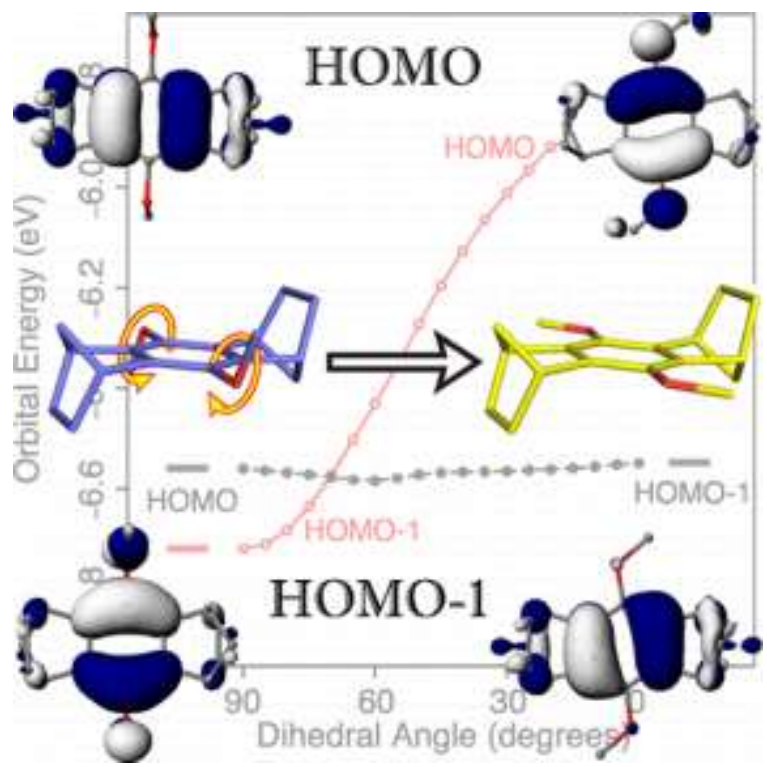

Koopmans' paradigm states that electron loss occurs from HOMO, thus forming the basis for the observed linear relationships between HOMO/IP, $\mathrm{HOMO} / E_{\mathrm{ox}}$, and IP/Eox. In cases where a molecule undergoes dramatic structural reorganization upon 1 -electron oxidation, the IP/E $E_{\text {ox }}$ relationship does not hold, and the origin of which is not understood. For example, X-ray crystallography of the neutral and cation radicals of bicyclo[2.2.1] heptaneannulated $p$-hydroquinone ethers ( ${ }^{\top} \mathbf{H E}$ and ${ }^{\mathrm{M}} \mathbf{H E}$ ) showed that they undergo electron-transfer-induced conformational reorganization and show breakdown of the IP/E ox relationship. DFT calculations revealed that Koopmans' paradigm still holds true because the electron-transfer-induced subtle conformational reorganization, responsible for the breakdown of IP/E $E_{\text {ox }}$ relationship, is also responsible for the reordering of HOMO and HOMO-1. Perceived failure of Koopmans' paradigm in cases of 'HE and ${ }^{\mathrm{M}} \mathbf{H E}$ assumes that both vertical and adiabatic electron detachments involve the same HOMO; however, this study demonstrates that the vertical ionization and adiabatic oxidation occur from different molecular orbitals due to reordering of HOMO/HOMO-1. The underpinnings of this finding will spur widespread interest in designing nextgeneration molecules beyond HQEs, whose electronic structures can be modulated by electron-transfer-induced conformation reorganization.

Keywords: cation radicals; electron-transfer induced conformational reorganization; electronic isomers; IP/E ox relationship; Koopmans' paradigm

p-Hydroquinone ethers (HQEs) are excellent one-electron donors, ${ }^{1,2}$ and they are extensively utilized as components of molecular wires ${ }^{3,4}$ in photovoltaic applications as well as redox shuttle additives in lithium-ion batteries. ${ }^{5-7}$ Because of the potential importance of HQEs as useful one-electron donors, it is essential to 
develop a full understanding of the factors that control their redox potentials and can allow their fine-tuning for future applications. The HQE redox properties can be significantly impacted by the conformation of alkoxy groups, which, in turn, can be modulated by substitution of the hydrogen atoms in the aromatic ring by alkyl/cycloalkyl groups. For example, a careful experimental analysis of the structure-property relationship of a series of HQEs in Chart 1 reveals that bicyclo[2.2.1] heptane-annulated $p$-hydroquinone ethers ( ${ }^{\top}$ HE and ${ }^{M}$ HE) undergo dramatic conformational reorganization of methoxy groups upon 1-electron oxidation, and they show a breakdown of the IP/E $E_{\text {ox }}$ relationship. ${ }^{1}$<smiles>COc1ccc(OC)cc1</smiles>

HE<smiles>COc1c2c(c(OC)c3c1C1CCC3C(F)C1)C1CCC2C1</smiles><smiles>COc1cc(C)c(OC)cc1C</smiles>

Me2 HE<smiles>COc1c2c(c(OC)c3c1C1CCC3CC1)C1CCC2CC1</smiles>

MHE<smiles>COc1c(C)c(C)c(OC)c(C)c1C</smiles>

${ }^{\mathrm{Me} 4} \mathrm{HE}$<smiles>COc1c2c(c(OC)c3c1C1CCC3CC1)C1CCC2CC1</smiles>

${ }^{B} \mathrm{HE}$

Chart 1

It is noted based on the analysis of a number of X-ray crystal structures of neutral electron donors and the corresponding cation radicals (CRs) that the spin/charge distribution in CRs tracks in accordance with the disposition of HOMO; that is, bonds with bonding HOMO lobes undergo elongations, whereas the bonds with antibonding lobes undergo contractions. (See a compilation of the representative examples in the Tables S1-S6 of the Supporting Information. $)^{8-13}$ However, the bicyclo[2.2.1] heptane-annulated $p$-hydroquinone ethers ${ }^{\top} \mathbf{H E}$ and ${ }^{M} \mathbf{H E}$ do not subscribe to this analysis, and their spin/charge distribution corresponds to HOMO-1 rather than HOMO. Interestingly, the energies of HOMO and HOMO-1 of simple benzenoid donors, called hereafter "quinoidal" and "bisallylic", can be easily modulated by altering the arrangement of alkyl substituents or environment. ${ }^{14,15}$ 
Accordingly, herein, we will provide a detailed analysis using experimental redox potentials, vertical ionization potentials (IPs) (obtained by photoelectron spectroscopy), X-ray crystallography of a number of neutral HQEs and their CRs, and DFT calculations to demonstrate that the breakdown of the IP/ $E_{\text {ox }}$ relationship in cases of ${ }^{\top} \mathbf{H E}$ and ${ }^{\mathrm{M}} \mathbf{H E}$ arises due to the geometrical rearrangement upon 1electron oxidation of ${ }^{\top} \mathbf{H E}$ and ${ }^{\mathrm{M}} \mathbf{H E}$, as follows.

A plot of the vertical IPs and the adiabatic oxidation potentials $\left(E_{\text {ox }}\right)$ of a series of hydroquinone ethers (see Chart 1 ) showed that bicyclo[2.2.1] heptane annulated HQEs ${ }^{\top} \mathbf{H E}$ and ${ }^{\mathrm{M}} \mathbf{H E}$ veer away from the expected linear relationship, while the point for structurally similar bicyclo[2.2.2] octane annulated ${ }^{\mathrm{B}} \mathbf{H E}$ lies on the line (Figure 1). ${ }^{1}$

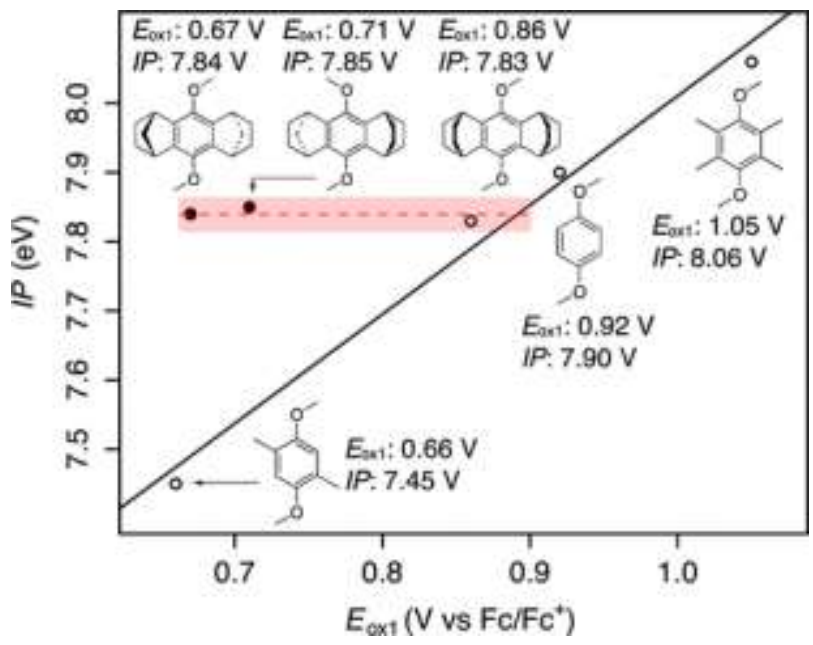

Figure 1. Correlation of the experimental ionization potentials (IPs) and first oxidation potentials $\left(E_{\mathrm{ox} 1}\right)$ of various HQEs.

To probe the breakdown of the IP/ $E_{\text {ox }}$ relationship in cases of ${ }^{\top} \mathbf{H E}$ and ${ }^{M} \mathbf{H E}$, we obtained the precise $X$-ray structures of both neutral and $\mathrm{CR}$ of ${ }^{\mathrm{Me} 2} \mathbf{H E}$, which does not deviate from the linear IP/E $E_{\text {ox }}$ relationship, and of ${ }^{M} \mathbf{H E}$, which does fall off the IP/ $E_{\text {ox }}$ correlation line (Figure 1). A comparison of the X-ray structures of neutral and the corresponding CRs of ${ }^{\mathrm{Me} 2} \mathbf{H E},{ }^{\mathrm{M}} \mathbf{H E}$, and previously reported ${ }^{\mathrm{T}} \mathbf{H E}^{1,16}$ together with the experimental bond length changes, spin/charge distributions, and HOMOs are compiled in Table 1. 
Table 1. ORTEP Diagrams of the Neutral and $C R{ }^{M e 2} \mathbf{H E},{ }^{M} \mathbf{H E}$, and ${ }^{\top} \mathbf{H E}$, the Bond Length Changes, Spin/Charge Distributions, and HOMOs of Neutral HQES

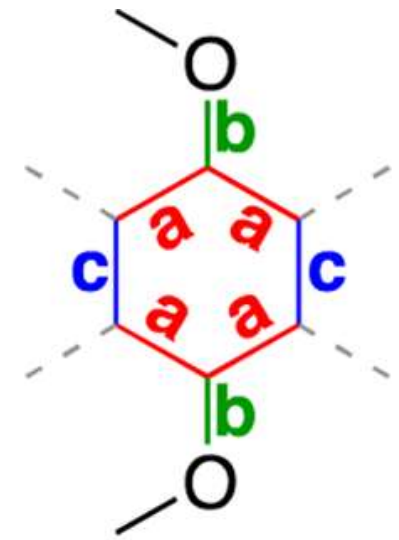

\section{X-ray Structures ${ }^{\mathrm{a}}$}

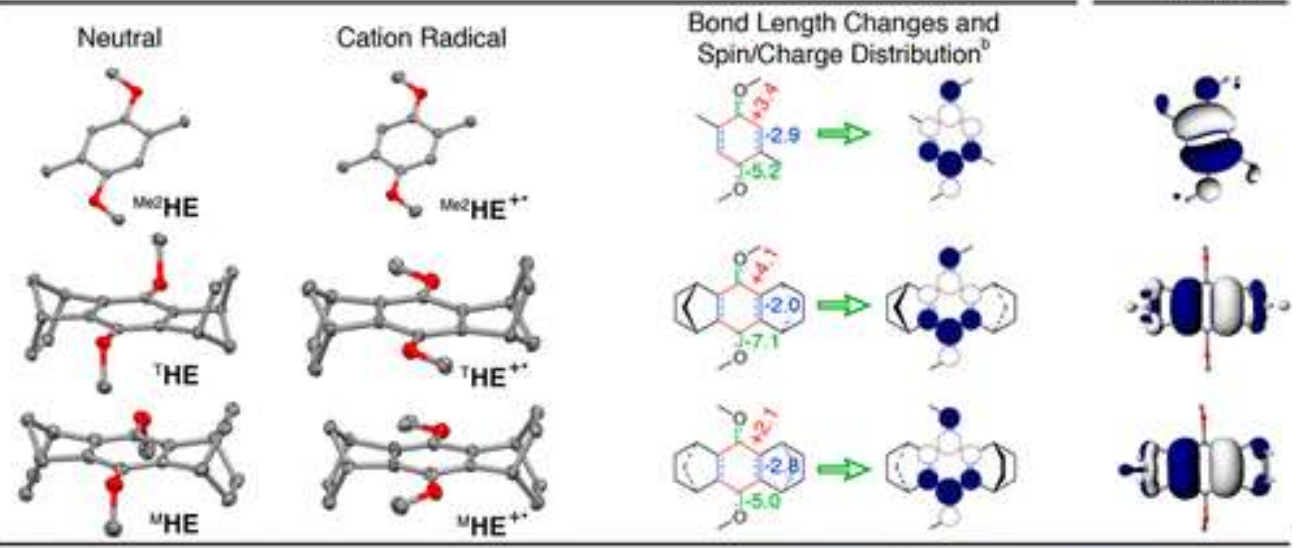

Table aSee Figures S1-S3 and Tables S7-S9 for the additional details of the $X$-ray structures reported herein and Figures S4 and S5 for the X-ray structures of $\mathbf{H E},{ }^{\mathrm{Me}}{ }^{4} \mathbf{H E},{ }^{\mathrm{B}} \mathbf{H E}$, and ${ }^{\mathrm{B}} \mathrm{HE}^{+\bullet}$.

Table bSpin/charge distribution inferred from the observed bond length changes (shown in pm).

Table cHOMOs were obtained from the HF/6-31G(d) calculations.

Thus, the X-ray structures of ${ }^{\mathrm{Me} 2} \mathbf{H E}$ and ${ }^{\mathrm{Me} 2} \mathbf{H E}^{+\bullet} \mathrm{SbCl}_{6}{ }^{-}$, generated using $\mathrm{NOSbCl}_{6}$ as oxidant, ${ }^{17}$ showed that the methoxy groups lie in the aromatic plane both in the neutral and CR and do not undergo rotation upon 1-electron oxidation. Furthermore, a comparison of the bond length changes in neutral $\rightarrow \mathrm{CR}$ transformation of ${ }^{\mathrm{Me}} \mathbf{H E}$ leads to elongation/contractions of the bonds in accordance with the disposition of the bonding/antibonding lobes of HOMO. For example, 4 equiv bonds labeled "a" undergo elongation by 3.4 pm, 
whereas bonds labeled " $b$ " and " $c$ " undergo contractions by 5.2 and $2.9 \mathrm{pm}$, respectively. The observed bond length changes in ${ }^{\mathrm{Me} 2} \mathbf{H E} \rightarrow$ ${ }^{\mathrm{Me} 2} \mathbf{H E}^{+\bullet}$ transformation are also consistent with the "bisallylic" type spin/charge distribution. (See Table 1, row 1.)

Contrastingly, the X-ray structures of neutral bicyclo[2.2.1] heptane-annulated 'HE show that methoxy groups lie perpendicular to the aromatic plane due to the steric repulsion from ortho substituents (Table 1 ). Interestingly, transformation ${ }^{\top} \mathbf{H E} \rightarrow$ ${ }^{\mathrm{T}} \mathrm{HE}^{+\bullet}$ leads to a dramatic conformational change, and the methoxy groups rotate and lie in the aromatic plane. Accommodation of the methoxy groups in ${ }^{\mathrm{T}} \mathbf{H E}^{+\bullet}$ is feasible because the bridgehead hydrogen atoms in bicyclo[2.2.1] heptane fragment point away from the aromatic plane (Table 1, row 2). Note that such an in-plane arrangement of the methoxy groups in ${ }^{B} \mathbf{H E}^{+\bullet}$ is not possible because the bridgehead hydrogens of the bicyclo[2.2.2] octane lie in the aromatic plane, as shown by the superposition of the X-ray structures of neutral ${ }^{\mathrm{B}} \mathrm{HE}$ (gray sticks) and ${ }^{\top} \mathbf{H E}$ (green sticks).

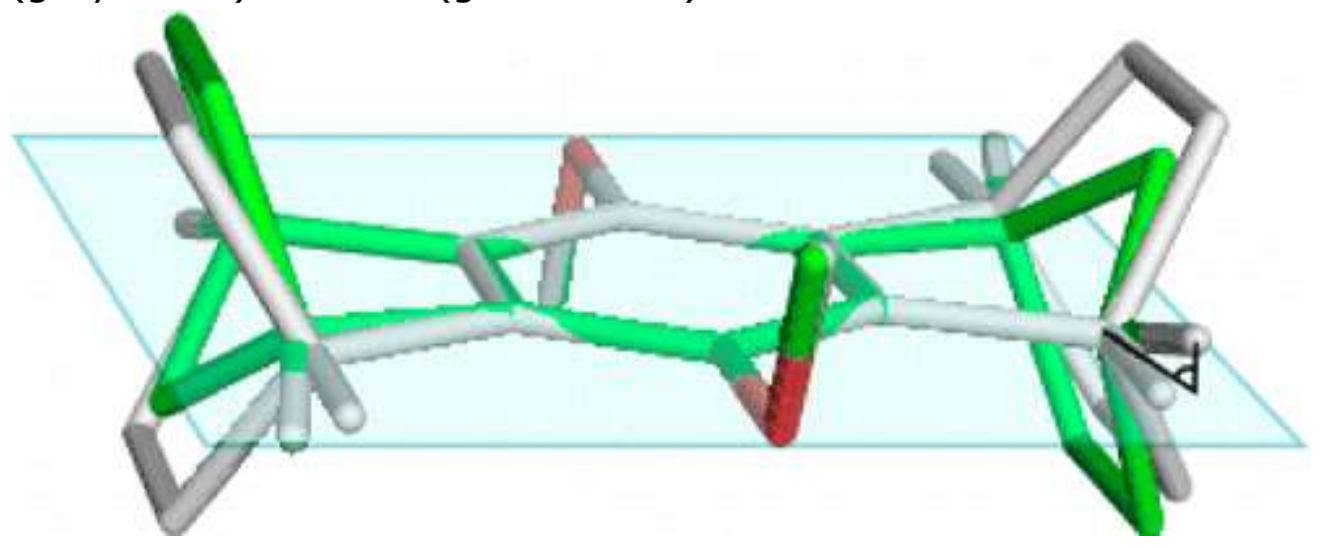

Furthermore, a close examination of the bond length changes in ${ }^{\mathrm{T}} \mathbf{H E} \rightarrow{ }^{\mathrm{T}} \mathbf{H E}^{+\bullet}$ transformation reveals that the observed bond length changes (see Table 1, row 2) are consistent with a "bisallylic" spin/charge distribution and not with the expected "quinoidal" distribution based on the HOMO of THE.

Similarly, in the X-ray structure of neutral ${ }^{M} \mathbf{H E}$, which is a hybrid of ${ }^{\mathrm{T}} \mathbf{H E}$ and ${ }^{\mathrm{B}} \mathrm{HE}$ and contains both bicyclo[2.2.1] heptane and bicyclo[2.2.2] octane fragments, methoxy groups lie perpendicular to the aromatic plane (Table 1, row 3). Interestingly, in neutral ${ }^{\mathrm{M}} \mathbf{H E}$ both methoxy groups point on the same face unlike ${ }^{\mathrm{T}} \mathrm{HE}$ and ${ }^{\mathrm{B}} \mathrm{HE} .{ }^{18}$ The 
electron-transfer-induced ${ }^{\mathrm{M}} \mathbf{H E} \rightarrow{ }^{\mathrm{M}} \mathbf{H E}^{+\bullet}$ transformation rotates the methoxy groups into the aromatic plane, and they adopt syn conformation (Table 1, row 3). The syn arrangement of the methoxy groups in ${ }^{\mathrm{M}} \mathbf{H E}^{+\bullet}$ is expected based on the fact that the methoxy groups can be accommodated in the aromatic plane only by the bicyclo[2.2.1] heptane framework. ${ }^{19}$ Moreover, the bond length changes during the ${ }^{\mathrm{M}} \mathbf{H E} \rightarrow{ }^{\mathrm{M}} \mathbf{H E}^{+\bullet}$ transformation again show that the spin/charge distribution does not follow expected "quinoidal" nodal structure of HOMO (see Table 1, row 3) but is rather consistent with a "bisallylic" spin/charge distribution similar to that observed with the ${ }^{\top} \mathbf{H E} \rightarrow{ }^{\top} \mathbf{H E}^{+\bullet}$ transformation.

Thus, the X-ray crystal structures related to the $\mathbf{H Q E} \rightarrow \mathbf{H Q E}^{+\bullet}$ transformations clearly reveal that the spin/charge distribution in the case of Me2 HE corresponds to the expected "bisallylic" distribution based on the HOMO, whereas in the cases of 'HE and ${ }^{\mathrm{H}} \mathbf{H E}$ the observed spin/charge distribution is again "bisallylic", but it is not in agreement with the "quinoidal" HOMO. Moreover, unlike Me2 HE, 'TE and ${ }^{\mathrm{M}} \mathbf{H E}$ deviate from the IP/E $E_{\text {ox }}$ relationship and expected spin/charge distribution, and they also undergo electron-transfer-induced rotation of the methoxy groups. To account for this discrepancy, we performed computational study of the electronic structures of both neutral and CRs of HQEs, as follows.

The DFT calculations using selected standard functionals ( $\omega$ B97X-D and M06-2X) and B1LYP-4020-22 (see the Supporting Information) accurately reproduced the observed conformations of both neutral and CRs of various HQEs as well as the experimentally observed bond length changes relevant to the HQE $\rightarrow \mathbf{H Q E}^{+\bullet}$ transformations (Figures S8-S11 and Tables S11-S13 in the Supporting Information). Moreover, the calculated (gas-phase) vertical IPs and the free energies of oxidation in solvent $\left(\Delta G_{0 x}\right)$ for HQEs reproduced the experimentally observed linear IP/E $E_{\text {ox }}$ relationship, which again showed that ${ }^{\top} \mathbf{H E}$ and ${ }^{\mathrm{M}} \mathbf{H E}$ fall off the trend line (compare Figure 1 vs Figure S12 in the Supporting Information).

Both experimental (Figure 1, Table 1) and computational data (Figure S12 in the Supporting Information) suggest that the breakdown of the IP/ $E_{\text {ox }}$ relationship must be accompanied by the changes in electronic structures due to the associated structural 
reorganization. Accordingly, we performed a careful DFT analysis of the electronic structures of neutral HQEs, and examination of the occupied frontier molecular orbitals (OFMOs) showed that their energies and ordering are highly dependent on a number of structural factors as discussed below.

First, the methoxy groups in HQEs remove the degeneracy of the "bisallylic"/"quinoidal" OFMOs, found in parent benzene, due to the interaction of the benzenoid orbitals with the orbitals containing lone pairs of oxygens $\left(n_{0}\right)$ or the $\sigma$ orbitals of the $\mathrm{O}-\mathrm{CH}_{3}$ bonds $\left(\sigma_{\mathrm{OCH}}\right)$ and alkyl groups ( $\left.\sigma_{\text {alk }}\right)$. Importantly, the HOMO/HOMO-1 energy gap $(\Delta)$ is critically dependent on the orientation of the methoxy groups with respect to the benzene ring and was found to be highest in cases where methoxy groups lie in the aromatic plane $(\Delta=1.47$ and $1.26 \mathrm{eV}$ for $\mathbf{H E}$ and ${ }^{\mathrm{Me} 2} \mathbf{H E}$, respectively) and as low as $0.1 \mathrm{eV}$ in ${ }^{\mathrm{Me}}{ }^{4} \mathbf{H E}$, where methoxy groups lie perpendicular to the aromatic plane (Figure 2a).

(a)

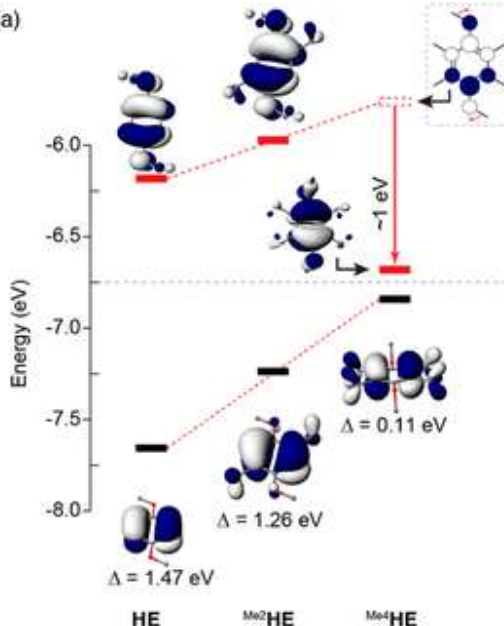

(b)

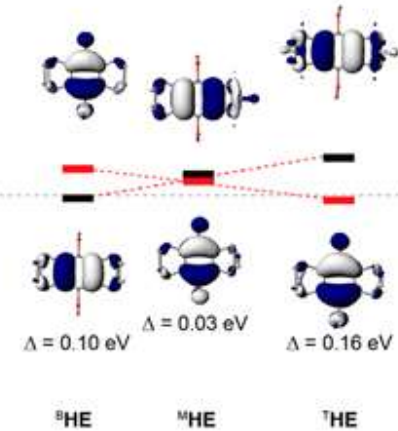

Figure 2. Energies and isovalue plots (0.03 au) of HOMO/HOMO-1 [B1LYP40/6$31 \mathrm{G}(\mathrm{d})+\mathrm{PCM}\left(\mathrm{CH}_{2} \mathrm{Cl}_{2}\right)$ ] of (a) parent $\mathbf{H E}$ and its methylated analogues and (b) bicycloalkane-annulated HQEs. Red and black bars represent energy levels of the "bisallylic" and "quinoidal" orbitals, respectively. The inset in panel a shows that the HOMO of hypothetical ${ }^{\mathrm{Me}} \mathbf{H E}$ (with the methoxy groups lying in the aromatic plane) is expected to be $\sim 1 \mathrm{eV}$ higher in energy than the actual ${ }^{\mathrm{Me}} \mathbf{H E}$. See Figure S13 in the Supporting Information for the Hartree-Fock orbitals of HQEs.

Second, the energies and ordering of the "bisallylic"/"quinoidal" OFMOs can be further modulated by varying the nature of the alkyl substituents (Chart 1 ). For example, the orbital ordering and the HOMO/HOMO-1 energy gap $(\Delta=0.10 \mathrm{eV})$ in ${ }^{\mathrm{B}} \mathrm{HE}$, which has two bicyclo[2.2.2] octane fragments, were similar to those of ${ }^{\mathrm{Me}} \mathrm{HE}$ (Figure

Journal of Physical Chemistry Letters, Vol 6, No. 17 (September 2015): pg. 3373-3378. DOI. This article is @ American Chemical Society and permission has been granted for this version to appear in e-Publications@Marquette. American Chemical Society does not grant permission for this article to be further copied/distributed or hosted elsewhere without the express permission from American Chemical Society. 
2); however, a substitution of one of the bicyclo[2.2.2]octane fragments in ${ }^{\mathrm{B}} \mathbf{H E}$ by the bicyclo[2.2.1] heptane fragment (i.e., ${ }^{\mathrm{M}} \mathbf{H E}$ ) led to the stabilization of the "bisallylic" orbital and destabilization of the "quinoidal" orbital, ${ }^{23}$ thereby leading to the almost degenerate HOMO/HOMO-1 $(\Delta=0.03 \mathrm{eV})$. Substitution of both bicyclo[2.2.2] octanes with bicyclo[2.2.1] heptane frameworks (i.e., ${ }^{\top} \mathrm{HE}$ ) resulted in swapping of the order of HOMO/HOMO-1 with significantly increased energy gap $(\Delta=0.16 \mathrm{eV})$; see Figure $2 \mathrm{~b}$.

The analysis presented in Figure 2 shows that relatively small HOMO/HOMO-1 energy gap in fully substituted HQEs can be modulated by varying the nature of alkyl substituents; however, this energy gap is highly dependent on the conformation of the methoxy groups as it sharply decreases when the methoxy groups rotate from being in the aromatic plane (i.e., $\mathbf{H E}$ and ${ }^{\mathrm{Me}} \mathbf{H E}$ ) to lying perpendicular to the aromatic plane ( $\left.{ }^{\mathrm{Me}} \mathrm{HE}\right)$; see Figure 2 . This analysis thus demands that electron-transfer-induced structural reorganization in cases of ${ }^{\mathrm{M}} \mathbf{H E}$ and THE (Table 1) must involve reordering of the energies of OFMOs.

Accordingly, we performed a Walsh-type analysis(24) of the energies of OFMOs in bicycloalkane-annulated HQEs with respect to varying conformations of methoxy groups. Thus, the orientation of both methoxy groups with respect to the aromatic plane (as measured by dihedral angle $\mathrm{CH}_{3}-\mathrm{O}-\mathrm{C}_{\mathrm{ar} 1}-\mathrm{C}_{\mathrm{ar} 2}$ ) was fixed, while the other geometric parameters were allowed to optimize; the dihedral angles were varied from 0 to $90^{\circ}$, and the energies of HOMO/HOMO-1 are plotted in Figure 3. It is clearly seen from these scans that the energy of the "quinoidal" orbital is virtually independent of the orientation of the methoxy groups. On the contrary, the energy of the "bisallylic" orbital sharply increases (by $\sim 0.8 \mathrm{eV}$ ) when the conformation of methoxy groups was changed from being perpendicular to lying in the plane of the aromatic ring. Moreover, Figure 3 shows that the dramatic changes in the HOMO/HOMO-1 energy gap due to the rotation of methoxy groups also lead to the reordering of the HOMO and HOMO- 1 in ${ }^{\text {M HE }}$ and ${ }^{\top} \mathbf{H E}$ (panels $a$ and $b$ ). Indeed, the reordering of the OFMOs is further attested by the experimental observation (Table 1) and calculated spin/charge distributions ${ }^{25}$ in HQE CRs with respect to the orientation of the methoxy groups; see Figures S15-S17 in the Supporting Information. 
NOT THE PUBLISHED VERSION; this is the author's final, peer-reviewed manuscript. The published version may be accessed by following the link in the citation at the bottom of the page.
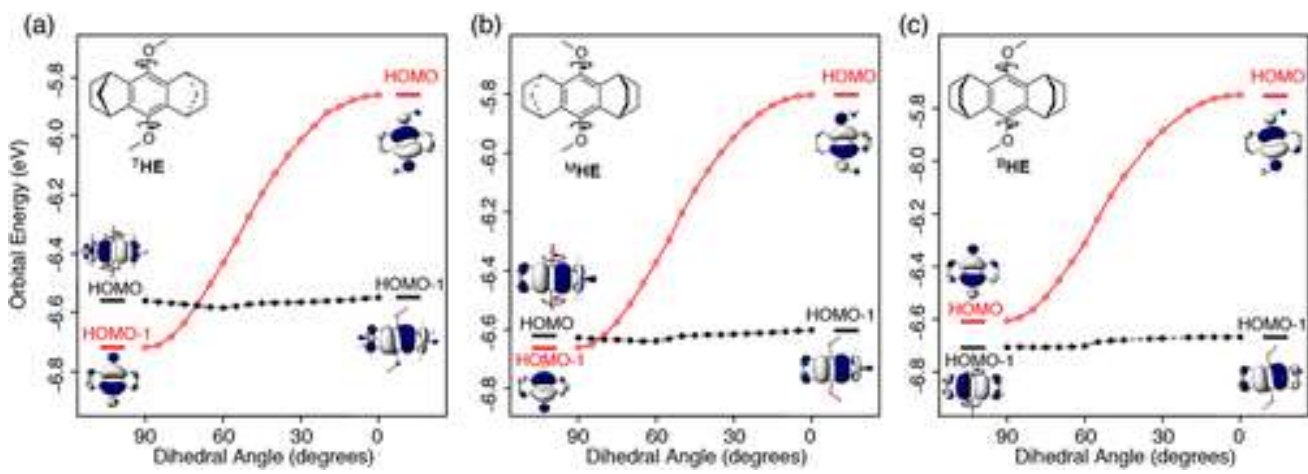

Figure 3. Energies and isovalue plots $(0.03 \mathrm{au})$ of HOMO/HOMO-1 of THE (a), ${ }^{\mathrm{M}} \mathrm{HE}$ (b), and ${ }^{\mathrm{B}} \mathrm{HE}$ (c) as a function of the $\mathrm{CH}_{3}-\mathrm{O}-\mathrm{C}_{\mathrm{ar} 1}-\mathrm{C}_{\text {ar2 }}$ dihedral angle [B1LYP40/6$31 \mathrm{G}(\mathrm{d})+\mathrm{PCM}\left(\mathrm{CH}_{2} \mathrm{Cl}_{2}\right)$ ]. See Figure $\mathrm{S} 14$ for the corresponding energetic profiles.

It is noted that measurement of vertical IPs by photoelectron spectroscopy corresponds to the removal of electron from a frozen rotational state of the molecule on a ultrafast time scale, whereas measurement of thermodynamic oxidation potentials $\left(E_{\mathrm{ox} 1}\right)$ by electrochemistry occurs on a much longer time scale and therefore allows for a necessary structural changes in the resulting CRs. In fact, the similarity of the IPs of ${ }^{\mathrm{T}} \mathbf{H E},{ }^{\mathrm{M}} \mathbf{H E}$, and ${ }^{\mathrm{B}} \mathbf{H E}$ is not surprising because their HOMO energies are also similar. Indeed, Figure 4 shows that the spin/charge distributions in vertically ionized state closely correspond to the HOMOs in their neutral state. ${ }^{26}$ On the contrary, structurally reorganized CRs of ${ }^{\top} \mathbf{H E}$ and ${ }^{\mathrm{M}} \mathbf{H E}$ show reorganization of the spin/charge distribution, which now corresponds to HOMO-1 in the neutral molecules (Figure 4).

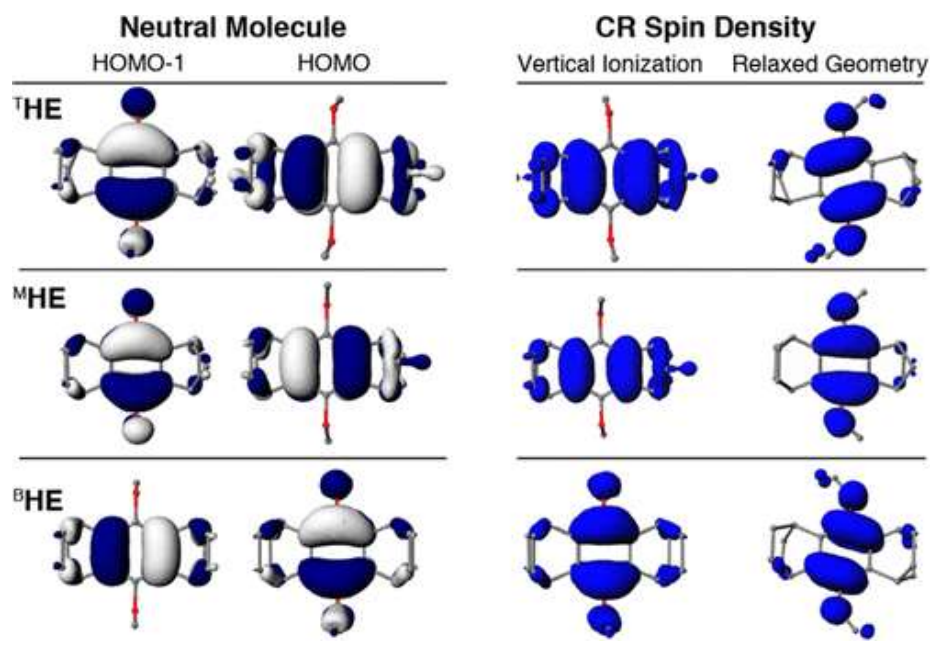

Figure 4. Isovalue plots of the HQE HOMO/HOMO-1 (0.03 au) and spin densities of the CRs at the geometries of the neutral HQEs (vertical ionization) and corresponding

Journal of Physical Chemistry Letters, Vol 6, No. 17 (September 2015): pg. 3373-3378. DOI. This article is (C) American Chemical Society and permission has been granted for this version to appear in e-Publications@Marquette. American Chemical Society does not grant permission for this article to be further copied/distributed or hosted elsewhere without the express permission from American Chemical Society. 
NOT THE PUBLISHED VERSION; this is the author's final, peer-reviewed manuscript. The published version may be accessed by following the link in the citation at the bottom of the page.

(relaxed) CR geometries $\left(E_{\mathrm{ox}}\right)\left[\mathrm{B} 1 \mathrm{LYP} 40 / 6-31 \mathrm{G}(\mathrm{d})+\mathrm{PCM}\left(\mathrm{CH}_{2} \mathrm{Cl}_{2}\right)\right]$. Also see Figure $\mathrm{S} 18$ in the Supporting Information.

Clearly, the breakdown of the IP/ $E_{\text {ox }}$ relationship is associated with the structural reorganization in the CRs induced by 1-electron oxidation, which accompanies the reordering of the HOMO/HOMO-1. As shown in Figure S19 in the Supporting Information, the $\mathrm{HOMO} / E_{\text {ox }}$ relationship does not hold when the energies of the HOMOs are calculated based on the geometries of nonreorganized neutral molecules; however, the HOMO energies of the reorganized (CR) geometries show an excellent linear relationship (Figure S20). Thus, the Koopmans' paradigm does hold true if one takes in account the structural reorganization and reordering of the HOMO/HOMO- 1 in the course of 1-electron oxidation (Figure S20).

In summary, we demonstrate that the breakdown of IP/ $E_{\text {ox }}$ relationship in cases of bicycloheptane annulated hydroquinone ethers ( ${ }^{\top} \mathbf{H E}$ and ${ }^{\mathrm{M}} \mathbf{H E}$ ) arises due to the electron-transfer-induced rotation of the methoxy groups from being perpendicular to the aromatic plane (neutral ${ }^{\mathrm{T}} \mathbf{H E}$ or ${ }^{\mathrm{M}} \mathbf{H E}$ ) to lying in the aromatic plane $\left({ }^{\top} \mathbf{H E}^{+\bullet}\right.$ or ${ }^{\mathrm{M}} \mathbf{H E}^{+\bullet}$ ). A careful analysis of the X-ray structural data of both neutral HQEs and their CRs, together with the DFT calculations, show that the spin/charge distribution in ${ }^{\mathrm{T}} \mathbf{H E}^{+\bullet}$ or ${ }^{\mathrm{M}} \mathbf{H E}^{+\bullet}$ corresponds to the removal of electron from "bisallylic" HOMO-1, as opposed to the expected "quinoidal" HOMO. As such, this finding demands a reordering of the energies of HOMO/HOMO-1 during the conformational reorganization. Indeed, a Walsh-type analysis showed that the reordering of the HOMO/HOMO-1 does occur when methoxy groups are systematically rotated from being perpendicular to being in the aromatic plane (i.e., $\theta_{\mathrm{CH} 3-\mathrm{O}-\mathrm{Car} 1-\mathrm{Car} 2}=90$ to $0^{\circ}$ ). Thus, breakdown of IP/ $E_{\text {ox }}$ relationship suggests the involvement of two different electronic structures of the CRs: (1) ${ }^{\top} \mathbf{H E}^{+\bullet}$ and ${ }^{\mathrm{M}} \mathbf{H E}^{+\bullet}$ (with methoxy groups lying perpendicular to the aromatic plane) formed during vertical ionization (IP) with electron being ejected from "quinoidal" HOMO and (2) reorganized ' $\mathbf{H E}^{+\bullet}$ and ${ }^{M} \mathbf{H E}^{+\bullet}$ (with methoxy groups lying in the aromatic plane) produced by adiabatic electrochemical oxidation $\left(E_{\mathrm{ox}}\right)$ correspond to the electron being ejected from the "bisallylic" HOMO. The perceived failure of Koopmans' paradigm and the breakdown of IP/ $E_{\text {ox }}$ relationship in cases of ${ }^{\mathrm{T}} \mathbf{H E}$ and ${ }^{\mathrm{M}} \mathbf{H E}$ presume that both electron detachment events involved the same HOMO; however, if one takes into account the 
reordering of $\mathrm{HOMO} / \mathrm{HOMO}-1$ energies due to the conformational reorganization in the course of adiabatic 1 -electron oxidation, suggesting that different orbitals are involved for vertical ionization ("quinoidal" HOMO) and adiabatic oxidation ("bisallylic" HOMO), the Koopmans' paradigm will hold true.

The finding herein, which demonstrates that electronic structures of a given CR can be altered by a simple rotation of methoxy groups, together with our previous demonstration of modulation of electronic structures of CRs by varied placement of counteranions, ${ }^{14}$ and substituents suggest high malleability of the spin/charge distribution in CRs. This finding should spur widespread interest in designing novel molecules beyond HQEs, whose electronic structures can be modulated by electron-transfer-induced conformation reorganization. A number of studies are underway in our laboratory to elaborate the role of nuclear motion and alteration of the electronic structures of the CRs in the bond forming or electrontransfer events.

\section{Acknowledgment}

We thank the NSF and NIH for financial support. The calculations were performed on the high-performance computing cluster Père at Marquette University funded by NSF awards OCI-0923037 and CBET-0521602, and the Extreme Science and Engineering Discovery Environment (XSEDE) funded by NSF (TG-CHE130101).

\section{References}

${ }^{1}$ Rathore, R.; Kochi, J. K.Isolation of Novel Radical Cations from Hydroquinone Ethers. Conformational Transition of the Methoxy Group upon Electron Transfer J. Org. Chem. 1995, 60, 4399- 4411, DOI: 10.1021/jo00119a017

2 Rathore, R.; Burns, C. L.; Deselnicu, M. I.Preparation of 1,4:5,8-Dimethano$1,2,3,4,5,6,7,8$-Octahydro-9,10-Dimethoxyanthracenium Hexachloroantimonate $\left(\mathbf{4}^{+\bullet} \mathrm{SbCl}_{6}{ }^{-}\right)$: A Highly Robust Radical-Cation Salt Org. Synth. 2005, 1- 9, DOI: 10.1002/0471264229.0s082.01

3 Hankache, J.; Wenger, O. S.Organic Mixed Valence Chem. Rev. 2011, 111, 5138- 5178, DOI: $10.1021 / \mathrm{cr} 100441 \mathrm{k}$ 
NOT THE PUBLISHED VERSION; this is the author's final, peer-reviewed manuscript. The published version may be

accessed by following the link in the citation at the bottom of the page.

${ }^{4}$ Wenger, O. S.How Donor-Bridge-Acceptor Energetics Influence Electron Tunneling Dynamics and Their Distance Dependences Acc. Chem. Res. 2011, 44, 25- 35, DOI: 10.1021/ar100092v

${ }^{5}$ Wang, Q.; Evans, N.; Zakeeruddin, S. M.; Exnar, I. ; Grätzel, M.Molecular Wiring of Insulators: Charging and Discharging Electrode Materials for High-Energy Lithium-Ion Batteries by Molecular Charge Transport Layers J. Am. Chem. Soc. 2007, 129, 3163-3167, DOI: 10.1021/ja066260j

${ }^{6}$ Fergus, J. W.Recent Developments in Cathode Materials for Lithium Ion Batteries J. Power Sources 2010, 195, 939- 954, DOI: 10.1016/j.jpowsour.2009.08.089

7 Li, T.; Xing, L.; Li, W.; Peng, B.; Xu, M.; Gu, F.; Hu, S.Theoretic Calculation for Understanding the Oxidation Process of 1,4-DimethoxybenzeneBased Compounds as Redox Shuttles for Overcharge Protection of Lithium Ion Batteries J. Phys. Chem. A 2011, 115, 4988- 4994, DOI: 10.1021/jp2004584

${ }^{8}$ Navale, T. S.; Thakur, K.; Vyas, V. S.; Wadumethrige, S. H.; Shukla, R.; Lindeman, S. V.; Rathore, R.Charge delocalization in Self-Assembled Mixed-Valence Aromatic Cation Radicals Langmuir 2012, 28, 71- 83, DOI: $10.1021 / \mathrm{la} 202611 \mathrm{w}$

${ }^{9}$ Chebny, V. J.; Navale, T. S.; Shukla, R.; Lindeman, S. V.; Rathore, R.X-ray Structural Characterization of Charge Delocalization onto the Three Equivalent Benzenoid Rings in Hexamethoxytriptycene Cation Radical Org. Lett. 2009, 11, 2253- 2256, DOI: 10.1021/ol900558s

10 Navale, T. S.; Zhai, L.; Lindeman, S. V.; Rathore, R.Octamethoxydibenzochrysene: Isolation and X-ray Crystallographic Characterization of a Twisted Polyaromatic Cation Radical Chem. Commun. 2009, 2857- 2859, DOI: 10.1039/b903133b

${ }^{11}$ Chebny, V. J.; Shukla, R.; Lindeman, S. V.; Rathore, R.Molecular Actuator: Redox-controlled Clam-like Motion in a Bichromophoric Electron Donor Org. Lett. 2009, 11, 1939-1942, DOI: 10.1021/ol900371m

12 Banerjee, M.; Vyas, V. S.; Lindeman, S. V.; Rathore, R.Isolation and X-ray Structural Characterization of Tetraisopropylpyrene Cation Radical Chem. Commun. 2008, 1889- 1891, DOI: 10.1039/b800168e

${ }^{13}$ Shukla, R.; Wadumethrige, S. H.; Lindeman, S. V.; Rathore, R.Synthesis, Electronic Properties, and X-ray Structural Characterization of Tetrarylbenzo[1,2-b:4,5-b']difuran Cation Radicals Org. Lett. 2008, 10, 3587- 3590, DOI: $10.1021 /$ ol801356e

14 Talipov, M. R.; Timerghazin, Q. K.; Rathore, R.Controlling the Structure of Reactive Intermediates via Incipient Covalent Bonding with the Counterions: Coexistence of Two Distinct Forms of the $\mathrm{C}_{6} \mathrm{~F}_{6}$ Cation Radical in a Single Crystal J. Phys. Chem. C 2013, 117, 23568- 23574, DOI: $10.1021 / j p 408912 \mathrm{~g}$

Journal of Physical Chemistry Letters, Vol 6, No. 17 (September 2015): pg. 3373-3378. DOI. This article is (C) American Chemical Society and permission has been granted for this version to appear in e-Publications@Marquette. American Chemical Society does not grant permission for this article to be further copied/distributed or hosted elsewhere without the express permission from American Chemical Society. 
15 Talipov, M. R.; Hewage, J. S.; Lindeman, S. V.; Gardinier, J. R.; Rathore, R.Comment on "Synthesis, Characterization, and Structures of Persistent Aniline Radical Cation": It Is a Protonated Aniline and Not an Aniline Radical Cation Angew. Chem., Int. Ed. 2014, 53, 938-942, DOI: 10.1002 /anie. 201305293

${ }^{16}$ Sun, D.; Lindeman, S. V.; Rathore, R.; Kochi, J. K.Intramolecular (Electron) Delocalization Between Aromatic Donors and Their Tethered Cationradicals. Application of Electrochemical and Structural Probes J. Chem. Soc. Perk. T. 2001, 2, 1585- 1594, DOI: 10.1039/b103139m

17 Rathore, R.; Burns, C. L.A Practical One-pot Synthesis of Soluble Hexaperi-hexabenzocoronene and Isolation of its Cation-radical Salt J. Org. Chem. 2003, 68, 4071-4074, DOI: 10.1021/jo034271e

18 Observation of the syn-arrangement of the methoxy groups in ${ }^{\mathrm{M}} \mathbf{H E}$ is likely caused by the bicyclo[2.2.1] heptane bridgehead hydrogen atoms which point away from the aromatic plane, thus allowing stabilization of the syn-arrangement.

19 In general, the anti-arrangement of the methoxy groups is preferred in $p$ hydroquinone ethers, which is reflected in the observation of a slightly higher $E_{0 \times 1}$ values of MHE as compared with 'HE. See: O'Neill, P.; Steenken, S.; Schulte-Frohlinde, D. J. Phys. Chem. 1975, 79, 27732779, DOI: $10.1021 / \mathrm{j} 100592 \mathrm{a} 013$

20 Talipov, M. R.; Boddeda, A.; Timerghazin, Q. K.; Rathore, R.Key Role of End-Capping Groups in Optoelectronic Properties of Poly- $p$-phenylene Cation Radicals J. Phys. Chem. C 2014, 118, 21400- 21408, DOI: 10.1021/jp5082752

${ }^{21}$ Renz, M.; Theilacker, K.; Lambert, C.; Kaupp, M.A Reliable QuantumChemical Protocol for the Characterization of Organic Mixed-valence Compounds J. Am. Chem. Soc. 2009, 131, 16292-16302, DOI: 10.1021/ja9070859

22 Renz, M.; Kess, M.; Diedenhofen, M.; Klamt, A.; Kaupp, M.Reliable Quantum Chemical Prediction of the Localized/Delocalized Character of Organic Mixed-Valence Radical Anions. From Continuum Solvent Models to Direct-COSMO-RS J. Chem. Theory Comput. 2012, 8, 41894203, DOI: $10.1021 / \operatorname{ct300545x}$

23 Destabilization of the "quinoidal" orbital by bicyclo[2.2.1] heptane bridge as compared with bicyclo[2.2.2] octane or methyl substitutions is apparent in the oxidation potentials of the corresponding benzenoid derivatives without methoxy groups. See: Rathore, R.; Lindeman, S. V.; Kochi, J. K. J. Am. Chem. Soc. 1997, 119, 9393-9404, DOI: 10.1021/ja9720319

${ }^{24}$ Buenker, R. J.; Peyerimhoff, S. D. Molecular Geometry and the MullikenWalsh Molecular Orbital Model. Ab Initio Study Chem. Rev. 1974, 74, 127- 188, DOI: $10.1021 / \mathrm{cr} 60288 \mathrm{a002}$ 
NOT THE PUBLISHED VERSION; this is the author's final, peer-reviewed manuscript. The published version may be accessed by following the link in the citation at the bottom of the page.

25 Note that spin density and charge density distributions closely correspond to each other in HQE CRs. See Figure S15 in the Supporting Information.

${ }^{26}$ Visual similarity between the spatial distribution of HOMOs of neutral HQEs and spin densities of their CRs arises from the fact that 1-electron oxidation leads to only marginal distortion of alpha- and betaspinorbitals of CRs as compared with the counterparts from neutral HQEs; therefore, the spin density is mostly determined by the singly occupied molecular orbital, which in turn closely matches the HOMO.

\section{Supporting Information}

The Supporting Information is available free of charge on the ACS Publications website at DOI: 10.1021/acs.jpclett.5b01532.

- X-ray crystallography data, computational details, Tables S1S13, Figures S1-S20, and the coordinates and energies of the calculated structures. (PDF)

- Archive entries from the DFT calculations. (PDF) 


\section{Supporting Information}

Does Koopmans' Paradigm for 1-Electron

Oxidation Always Hold?

Breakdown of IP $/ E_{\text {ox }}$ Relationship for

$p$-Hydroquinone Ethers and the Role of

Methoxy Group Rotation

Marat R. Talipov, Anitha Boddeda, Sergey V. Lindeman, Rajendra Rathore*

Department of Chemistry

Marquette University

P.O. Box 1881, Milwaukee, WI 53201-1881

\section{Corresponding Author}

*E-mail: rajendra.rathore@marquette.edu 


\section{Table of contents}

S1. Correspondence between the HOMO shape and CR spin/charge

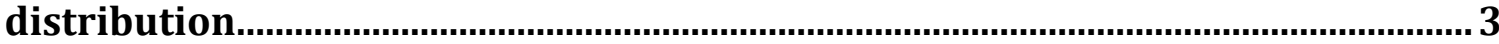

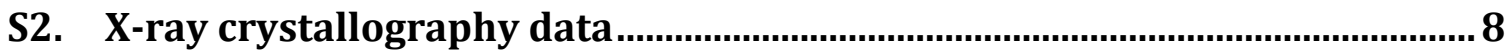

S2.1. Me2 $\mathrm{HE}^{+}{ }^{\circ}$.....................................................................................................................8

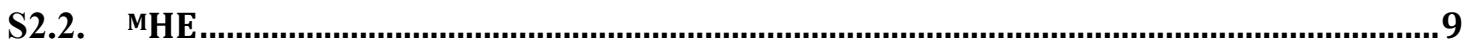

S2.3. MHE ${ }^{\circ}$......................................................................................................................... 10

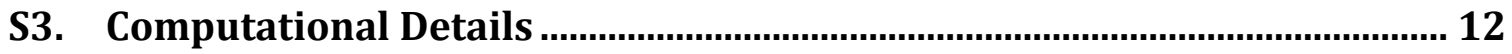

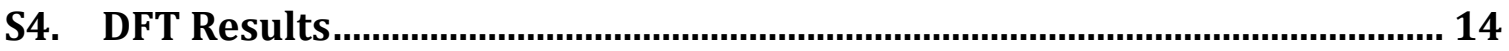

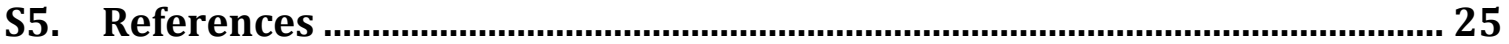




\section{S1. Correspondence between the HOMO shape and CR spin/charge distribution}

Table S1. The experimental (X-ray) and calculated [B3LYP/6-31G(d)] bond lengths of the neutral and cation radical of octamethoxydibenzochrysene DBC presented in picometers (pm). ${ }^{1}$

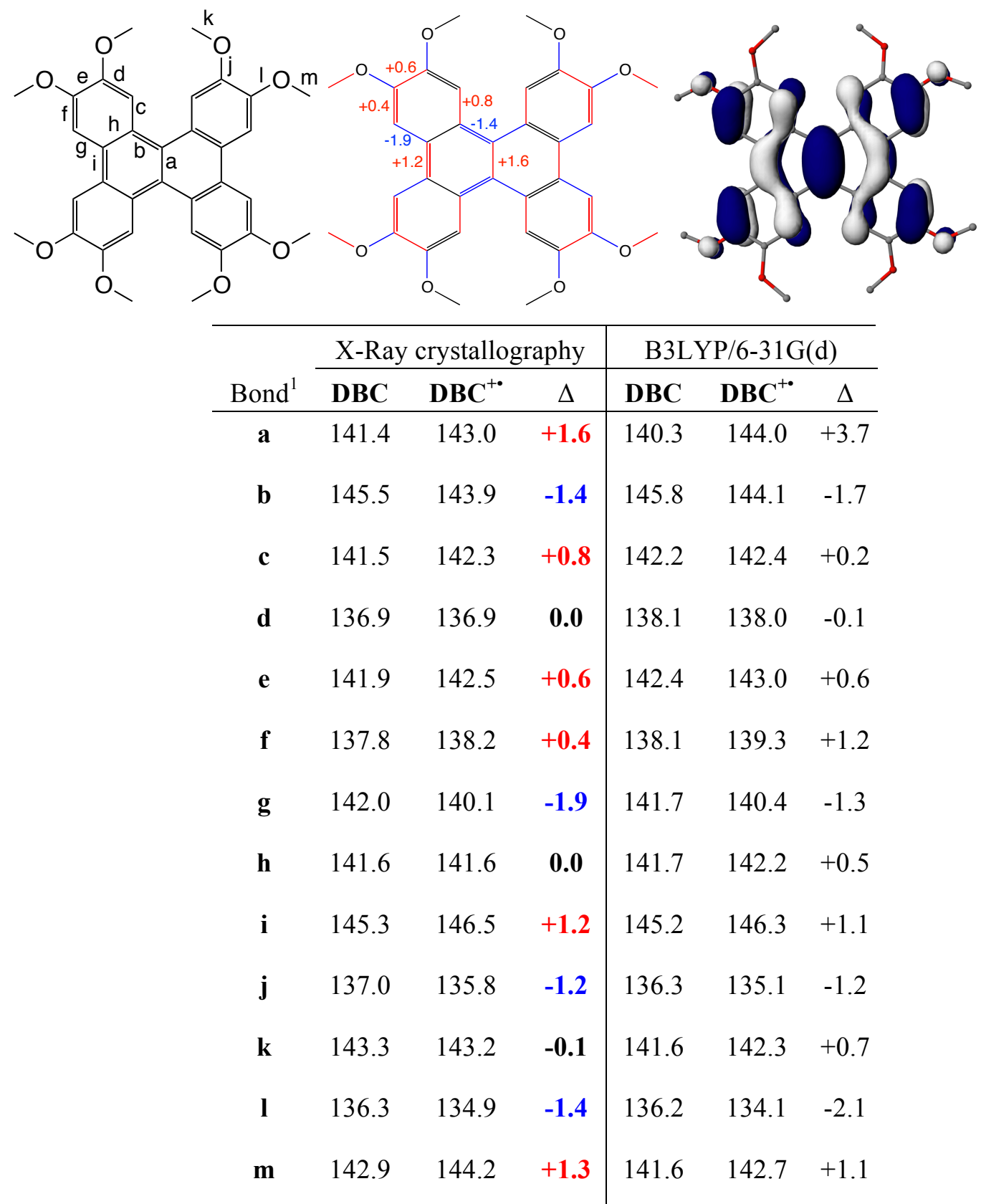

${ }^{1}$ Average of equivalent bonds. 
Table S2. The experimental (X-ray) and calculated [B3LYP/6-31G(d,p)] bond lengths of the neutral and cation radical of 1,3,6,8-tetraisopropylpyrene TIP presented in picometers (pm). ${ }^{2}$

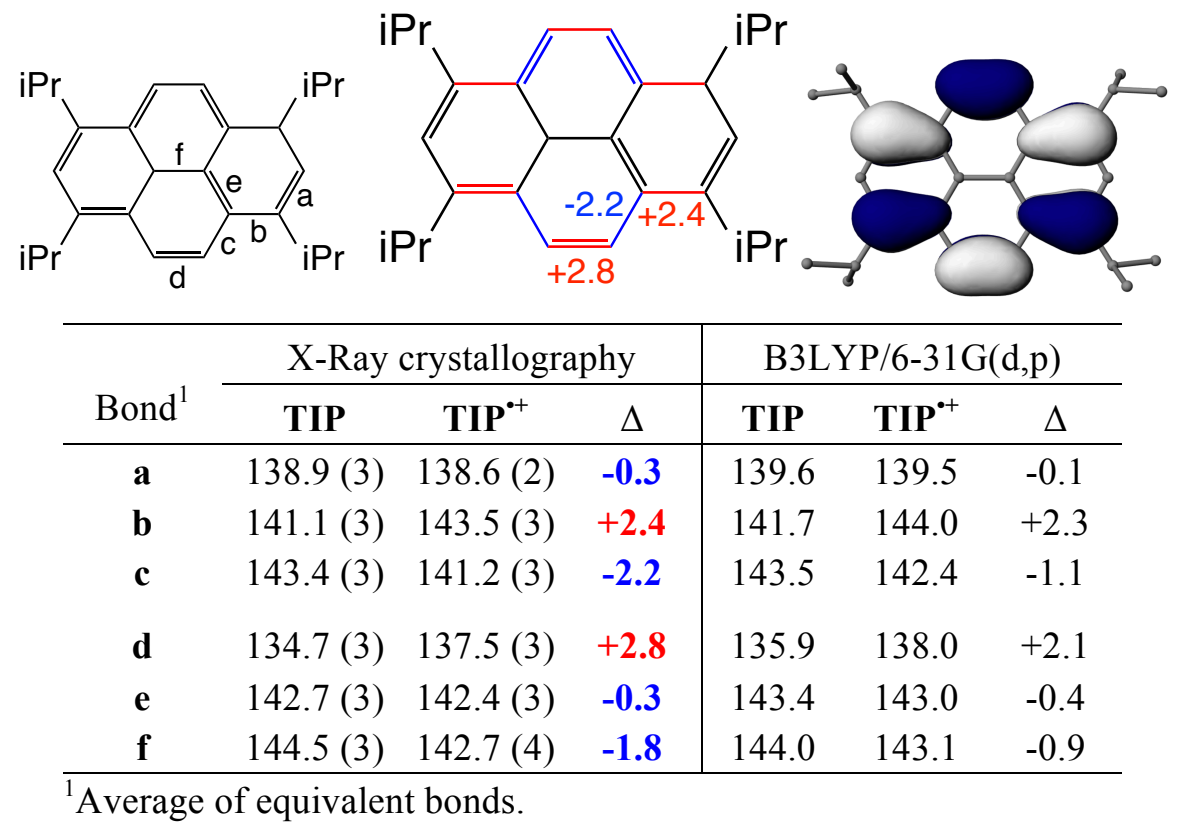

Table S3. The experimental (X-ray) and calculated [B3LYP/6-31G(d)] bond lengths of the neutral and cation radicals of hexamethoxytriptycene $\mathbf{T} 3$ in picometers $(\mathrm{pm}){ }^{3}$
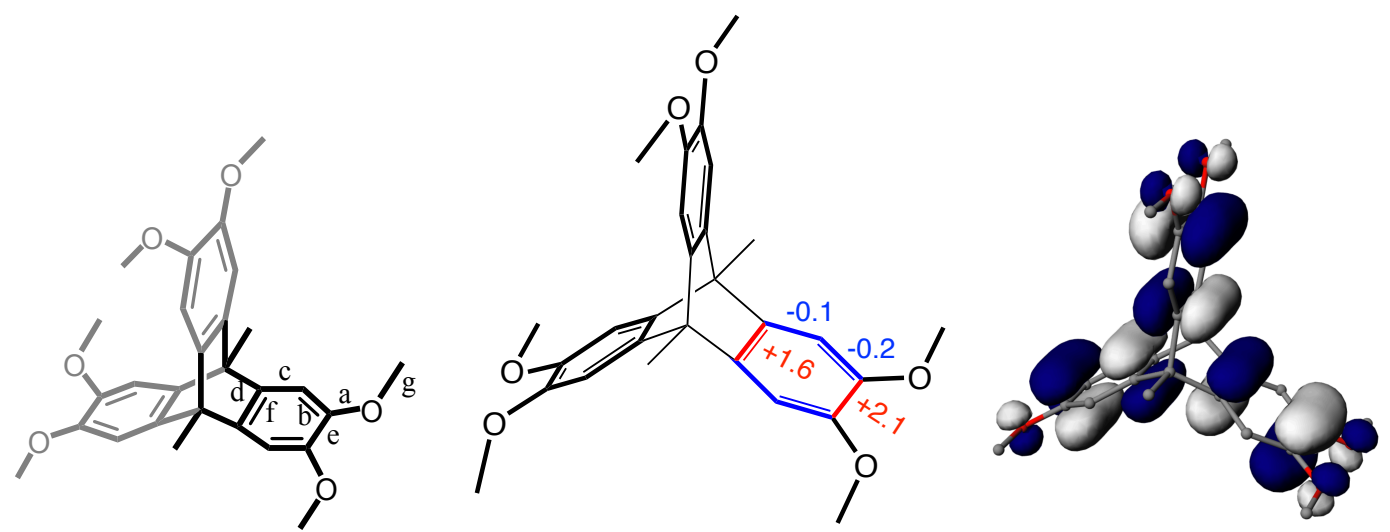

\begin{tabular}{cccc|ccc}
\hline & \multicolumn{3}{c|}{ X-Ray crystallography } & \multicolumn{3}{|c}{ B3LYP/6-31G(d) } \\
\cline { 2 - 7 } Bond $^{1}$ & $\mathbf{T 3}$ & $\mathbf{T 3}^{+\bullet}$ & $\Delta$ & $\mathbf{T 3}$ & $\mathbf{T 3}^{+\bullet}$ & $\Delta$ \\
\hline a & 136.6 & 134.3 & $\mathbf{- 2 . 3}$ & 137.2 & 135.0 & -2.2 \\
b & 139.8 & 139.6 & $\mathbf{- 0 . 2}$ & 139.2 & 138.4 & -0.8 \\
c & 139.6 & 139.5 & $\mathbf{- 0 . 1}$ & 139.0 & 138.9 & -0.1
\end{tabular}




\begin{tabular}{lrrr|rrr} 
d & 154.2 & 153.4 & $\mathbf{- 0 . 8}$ & 154.0 & 153.0 & -1.0 \\
$\mathbf{e}$ & 141.3 & 143.4 & $\mathbf{+ 2 . 1}$ & 141.1 & 142.3 & +1.2 \\
$\mathbf{f}$ & 139.6 & 141.2 & $+\mathbf{1 . 6}$ & 138.8 & 140.5 & +1.7 \\
$\mathbf{g}$ & 141.5 & 142.7 & $+\mathbf{1 . 2}$ & 142.7 & 143.8 & +1.1 \\
\hline
\end{tabular}

${ }^{1}$ Average of equivalent bonds.

Table S4. The experimental (X-ray) and calculated [B3LYP/6-31G(d)] bond lengths of the neutral, monomer and dimer cation radicals of octamethylbiphenylene (OMB) in picometers (pm). ${ }^{4}$

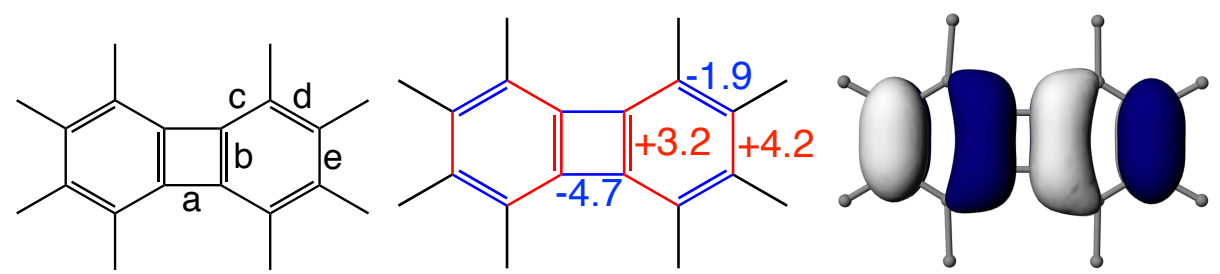

\begin{tabular}{|c|c|c|c|c|c|c|}
\hline \multirow[b]{2}{*}{ bond $^{1}$} & \multicolumn{3}{|c|}{ X-ray crystallography } & \multicolumn{3}{|c|}{ B3LYP/6-31G(d) } \\
\hline & OMB & $\mathrm{OMB}^{+\bullet}$ & $(\mathrm{OMB})_{2}^{+\bullet}$ & OMB & $\mathrm{OMB}^{+\bullet}$ & $(\mathrm{OMB})_{2}^{+\bullet}$ \\
\hline $\mathbf{a}$ & 152.2 & $\begin{array}{l}147.5 \\
(-4.7)\end{array}$ & $\begin{array}{l}149.5 \\
(-2.7)\end{array}$ & 151.6 & $\begin{array}{l}147.4 \\
(-4.2)\end{array}$ & $\begin{array}{l}149.4 \\
(-2.2)\end{array}$ \\
\hline b & 141.8 & $\begin{array}{l}145.0 \\
(+3.2)\end{array}$ & $\begin{array}{l}143.2 \\
(+1.4)\end{array}$ & 142.3 & $\begin{array}{l}144.6 \\
(+2.3)\end{array}$ & $\begin{array}{l}143.4 \\
(+\mathbf{1 . 1})\end{array}$ \\
\hline c & 136.5 & $\begin{array}{l}138.6 \\
(+2.1)\end{array}$ & $\begin{array}{l}138.0 \\
(+1.5)\end{array}$ & 137.7 & $\begin{array}{l}138.6 \\
(+\mathbf{0 . 9})\end{array}$ & $\begin{array}{l}138.1 \\
(+\mathbf{0 . 4})\end{array}$ \\
\hline d & 143.5 & $\begin{array}{l}141.6 \\
\mathbf{( - 1 . 9 )}\end{array}$ & $\begin{array}{l}142.4 \\
\mathbf{( - 1 . 1 )}\end{array}$ & 143.7 & $\begin{array}{l}142.0 \\
\mathbf{( - 1 . 7 )}\end{array}$ & $\begin{array}{l}142.8 \\
(\mathbf{- 0 . 9 )}\end{array}$ \\
\hline $\mathbf{e}$ & 139.1 & $\begin{array}{l}143.3 \\
(+4.2)\end{array}$ & $\begin{array}{l}142.0 \\
(+2.9)\end{array}$ & 140.3 & $\begin{array}{l}143.8 \\
(+\mathbf{3 . 5})\end{array}$ & $\begin{array}{l}142.0 \\
(+1.7)\end{array}$ \\
\hline
\end{tabular}

${ }^{1}$ Average of equivalent bonds. ${ }^{2}$ Numbers in parenthesis indicate the bond length changes relative to neutral OMB. 
Table S5. The experimental (X-ray) and calculated [B3LYP/6-31G(d)] bond lengths of the (centrosymmetric) neutral and cation radicals of BDF1 and BDF2 in picometers (pm). ${ }^{5}$

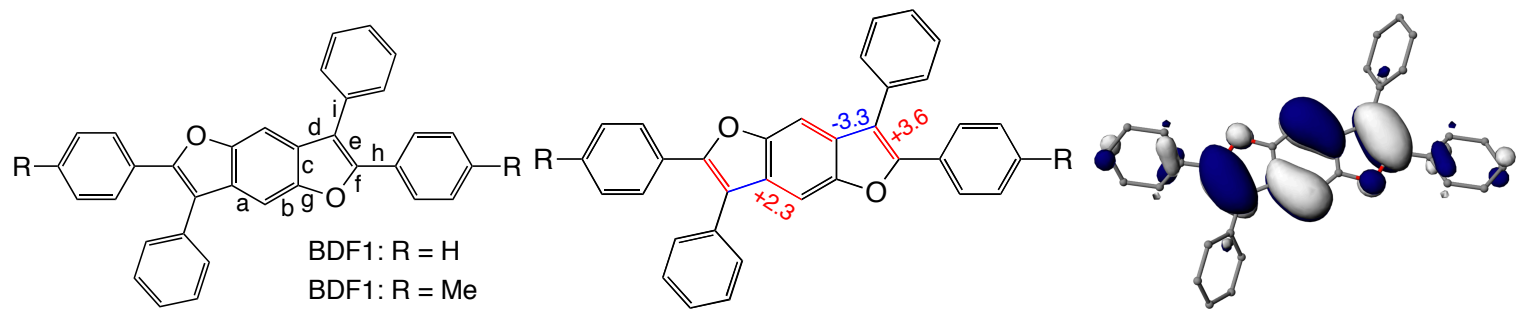

\begin{tabular}{|c|c|c|c|c|c|c|}
\hline \multirow[b]{2}{*}{ Bond $^{1}$} & \multicolumn{3}{|c|}{ X-Ray crystallography } & \multicolumn{3}{|c|}{ B3LYP/6-31G(d) } \\
\hline & BDF1 & BDF1 $^{\circ+}$ & $\Delta$ & BDF1 & BDF1 $^{\circ+}$ & $\Delta$ \\
\hline $\mathbf{a}$ & $139.9(1)$ & $142.2(5)$ & +2.3 & 140.3 & 141.8 & +1.5 \\
\hline b & $137.8(1)$ & $135.3(5)$ & -2.5 & 138.5 & 137.1 & -1.4 \\
\hline c & $140.7(1)$ & $142.1(5)$ & +1.4 & 141.6 & 142.6 & +1.0 \\
\hline d & $144.9(1)$ & $141.6(5)$ & -3.3 & 144.8 & 142.0 & -2.8 \\
\hline e & $136.7(1)$ & $140.3(5)$ & +3.6 & 137.7 & 141.1 & +3.4 \\
\hline $\mathbf{f}$ & $138.6(1)$ & $136.7(4)$ & -1.9 & 138.4 & 136.7 & -1.7 \\
\hline g & $137.5(1)$ & $137.9(4)$ & +0.4 & 136.8 & 137.1 & +0.3 \\
\hline $\mathbf{h}$ & $146.4(1)$ & $144.9(5)$ & -1.5 & 146.3 & 144.5 & -1.8 \\
\hline \multirow[t]{2}{*}{$\mathbf{i}$} & $147.4(1)$ & $147.5(5)$ & +0.1 & 147.8 & 147.3 & -0.5 \\
\hline & BDF2 & BDF2 $^{\circ+}$ & $\Delta$ & BDF2 & BDF2 $^{\circ+}$ & $\Delta$ \\
\hline $\mathbf{a}$ & $140.0(1)$ & $141.7(2)$ & +1.7 & 140.3 & 141.5 & +1.2 \\
\hline b & 138.1(1) & $136.5(2)$ & -1.6 & 138.5 & 137.3 & -1.2 \\
\hline c & $140.9(1)$ & $141.7(2)$ & +0.8 & 141.5 & 142.4 & +0.9 \\
\hline d & $144.7(1)$ & $141.7(2)$ & -3.0 & 144.8 & 142.5 & -2.3 \\
\hline $\mathbf{e}$ & 137.1(1) & $139.9(2)$ & +2.8 & 137.7 & 140.8 & +3.1 \\
\hline f & $138.6(1)$ & $137.3(2)$ & -1.3 & 138.5 & 137.2 & -1.3 \\
\hline g & $137.3(1)$ & $137.8(2)$ & +0.5 & 136.9 & 137.0 & +0.1 \\
\hline h & $145.9(1)$ & $144.3(2)$ & -1.6 & 146.1 & 144.0 & -2.1 \\
\hline i & $147.8(1)$ & $145.8(2)$ & -2.0 & 147.7 & 147.0 & -0.7 \\
\hline
\end{tabular}

${ }^{1}$ Average of equivalent bonds. 
Table S6. The experimental (X-ray) and calculated [B3LYP/6-31G(d)] bond lengths of the neutral and cation radical of tetramethoxydibenzobicyclo[4.4.1] undecane BA presented in picometers. ${ }^{6}$

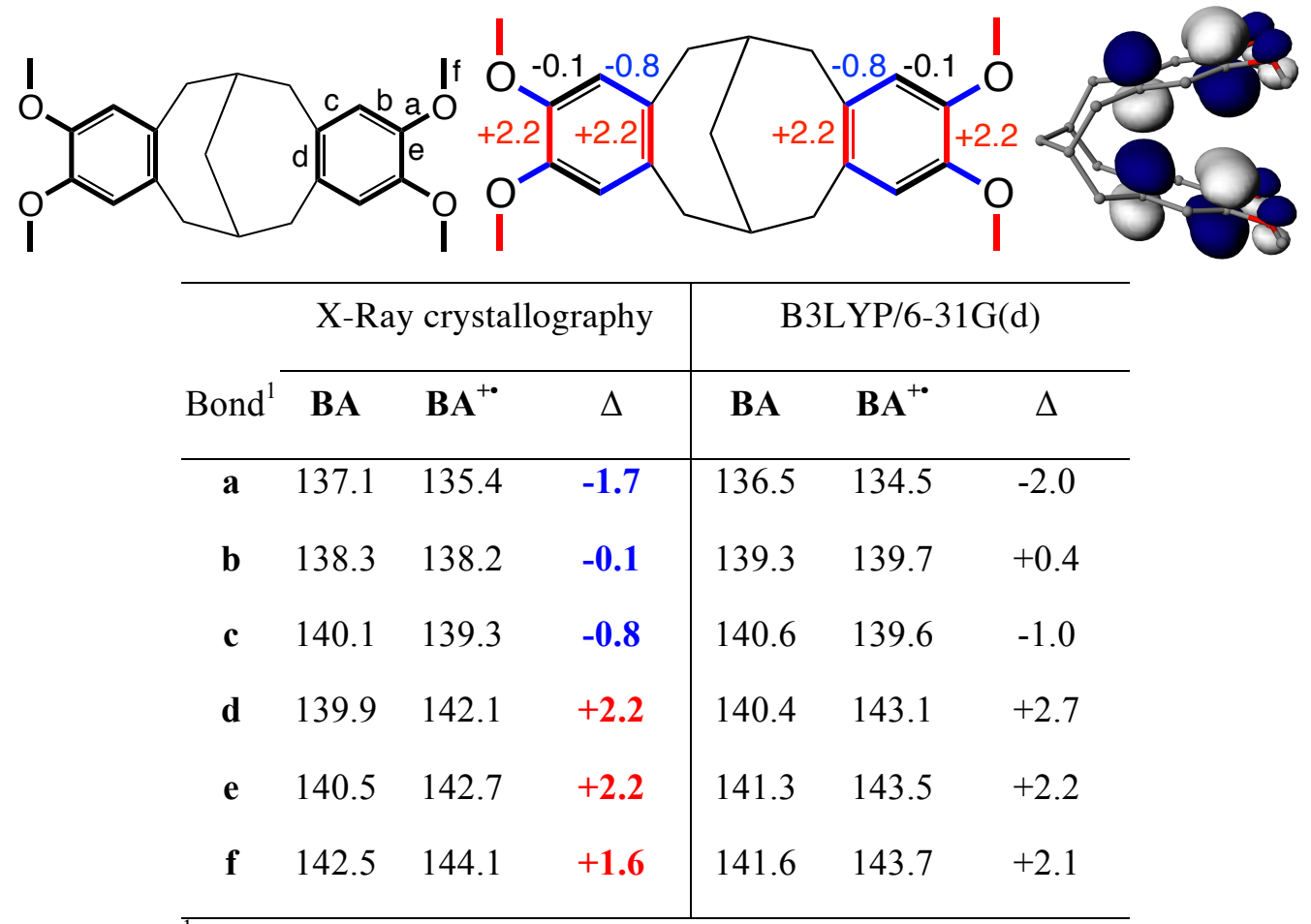

${ }^{1}$ Average of equivalent bonds. 


\section{S2. X-ray crystallography data}

\section{S2.1. X-ray structure of ${ }^{\mathrm{Me} 2} \mathrm{HE}^{+}$}
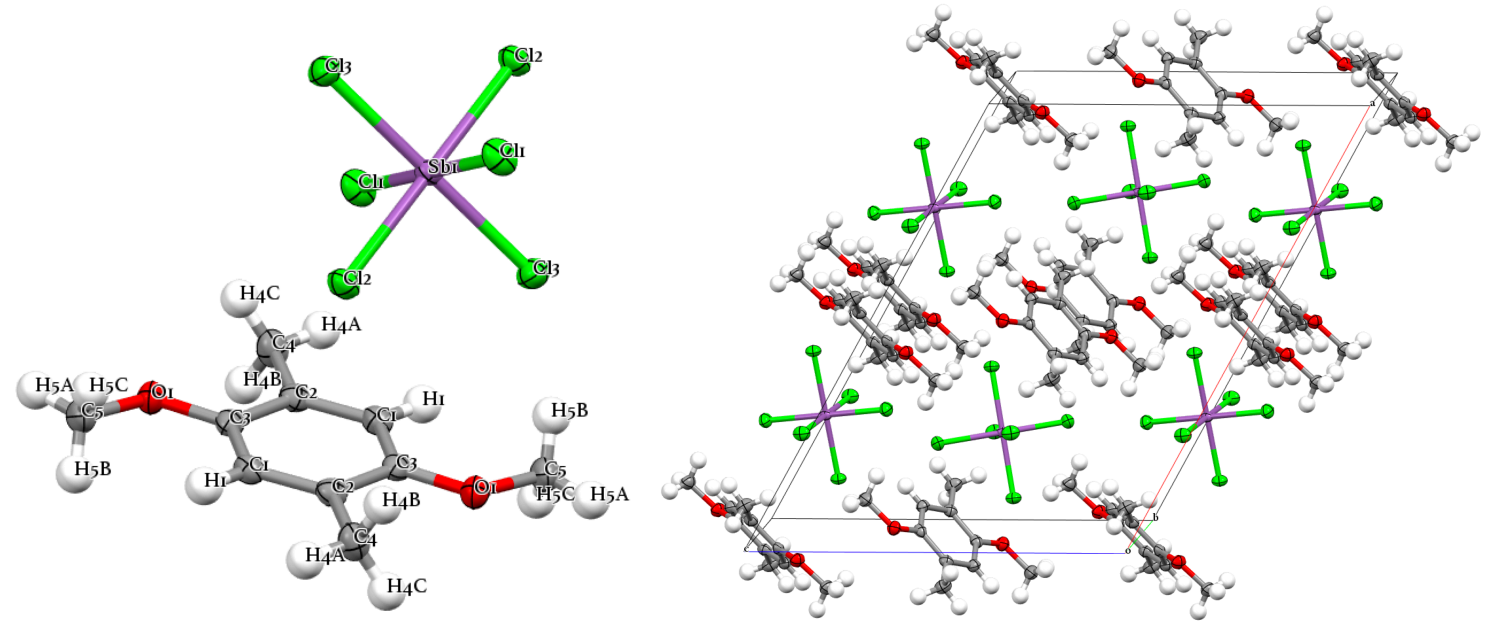

Figure S1. ORTEP and packing diagrams of ${ }^{\mathrm{Me}^{2}} \mathrm{HE}^{+{ }^{+}} \mathrm{SbCl}_{6}{ }^{-}$.

Table S7. Crystal data and structure refinement for ${ }^{\mathrm{Me} 2} \mathbf{H E}^{+{ }^{+} \mathrm{SbCl}_{6}}{ }^{-}$

Identification code

Empirical formula

Formula weight

Temperature

Wavelength

Crystal system

Space group

Unit cell dimensions

Volume

$\mathrm{Z}$

Density (calculated)

Absorption coefficient

$\mathrm{F}(000)$

Crystal size

Theta range for data collection

Index ranges

Reflections collected

Independent reflections

Completeness to theta $=66.76^{\circ}$

Absorption correction

Max. and min. transmission

Refinement method

Data / restraints / parameters

Goodness-of-fit on $\mathrm{F}^{2}$

Final $\mathrm{R}$ indices [I $>2 \operatorname{sigma}(\mathrm{I})]$

$\mathrm{R}$ indices (all data)

Largest diff. peak and hole raj7w

C10 H14 Cl6 O2 Sb

500.66

$100(2) \mathrm{K}$

$1.54178 \AA$

Monoclinic

C $2 / \mathrm{c}$

$\mathrm{a}=18.5274(4) \AA$

$\mathrm{b}=7.7885(2) \AA$

$\mathrm{c}=13.6927(3) \AA$

$\mathrm{a}=90^{\circ}$.

$\mathrm{b}=119.1760(10)^{\circ}$.

$\mathrm{g}=90^{\circ}$.

$1725.18(7) \AA^{3}$

4

$1.928 \mathrm{Mg} / \mathrm{m}^{3}$

$21.205 \mathrm{~mm}^{-1}$

972

$0.22 \times 0.20 \times 0.06 \mathrm{~mm}^{3}$

5.47 to $66.76^{\circ}$.

$-21<=\mathrm{h}<=19,0<=\mathrm{k}<=8,0<=\mathrm{l}<=16$

6990

$1426[\mathrm{R}(\mathrm{int})=0.0269]$

$98.3 \%$

Numerical

0.3627 and 0.0895

Full-matrix least-squares on $\mathrm{F}^{2}$

1426 / 0 / 116

1.122

$\mathrm{R} 1=0.0200, \mathrm{wR} 2=0.0507$

$\mathrm{R} 1=0.0209, \mathrm{wR} 2=0.0513$

0.602 and -0.342 e. $\AA^{-3}$ 


\section{S2.2. X-ray structure of ${ }^{\mathrm{M}} \mathrm{HE}$}
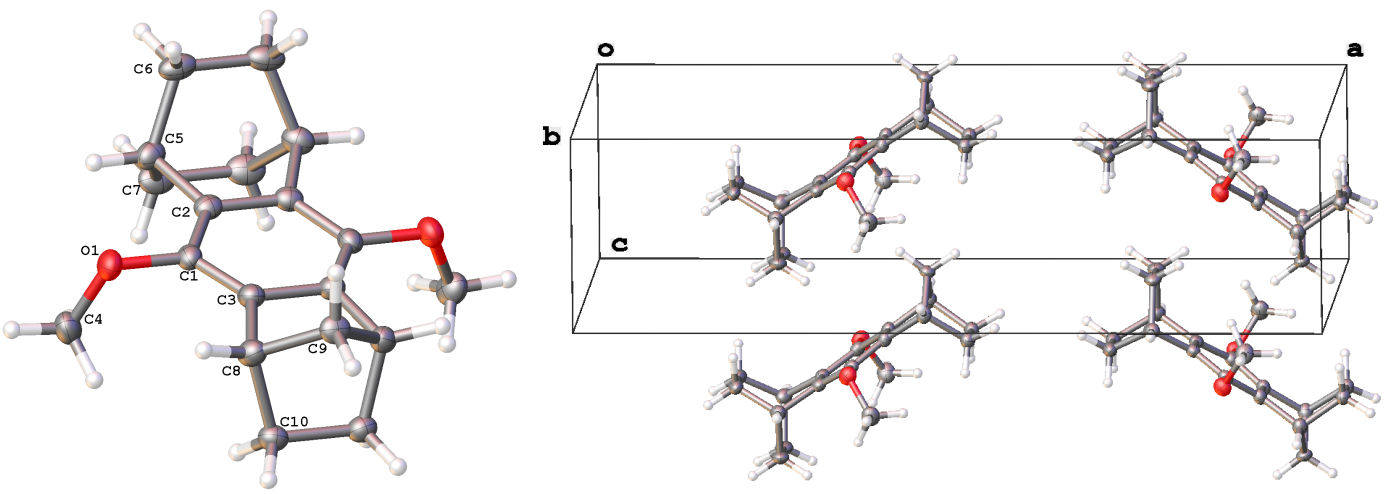

Figure S2. ORTEP and packing diagrams of ${ }^{\mathrm{M}} \mathbf{H E}$.

Table S8. Crystal data and structure refinement for ${ }^{\mathrm{M}} \mathbf{H E}$

Identification code

Empirical formula

Formula weight

Temperature/K

Crystal system

Space group

$\mathrm{a} / \AA ̊$

$\mathrm{b} / \AA$

c/Å

$\alpha /^{\circ}$

$\beta /{ }^{\circ}$

$\gamma /{ }^{\circ}$

Volume $/ \AA^{3}$

$\mathrm{Z}$

$\varrho_{\text {calc }} \mathrm{g} / \mathrm{cm}^{3}$

$\mu / \mathrm{mm}^{-1}$

$\mathrm{F}(000)$

Crystal size $/ \mathrm{mm}^{3}$

Radiation

Index ranges

Reflections collected

Independent reflections

Data/restraints/parameters

Goodness-of-fit on $\mathrm{F}^{2}$

Final $R$ indexes $[\mathrm{I}>=2 \sigma(\mathrm{I})]$

Final $\mathrm{R}$ indexes [all data]

Largest diff. peak/hole / e $\AA^{-3} 0.39 /-0.24$ raj25h

$\mathrm{C}_{19} \mathrm{H}_{23} \mathrm{O}_{2}$

283.37

100.00(10)

orthorhombic

Pnma

22.1332(4)

$11.5650(2)$

$5.82560(9)$

90.00

90.00

90.00

1491.18(4)

4

1.262

0.625

612.0

$0.34 \times 0.05 \times 0.04$

$\mathrm{CuK} \alpha(\lambda=1.54184)$

${ }^{\circ} 7.98$ to 147.56

$-27 \leq \mathrm{h} \leq 19,-12 \leq \mathrm{k} \leq 14,-6 \leq 1 \leq 7$

7656

$1575\left[\mathrm{R}_{\mathrm{int}}=0.0261, \mathrm{R}_{\text {sigma }}=0.0158\right]$

$1575 / 0 / 102$

1.044

$\mathrm{R}_{1}=0.0496, \mathrm{wR}_{2}=0.1376$

$\mathrm{R}_{1}=0.0548, \mathrm{wR}_{2}=0.1450$ 


\section{S2.3. X-ray structure of ${ }^{\mathrm{M}} \mathrm{HE}^{+}$}

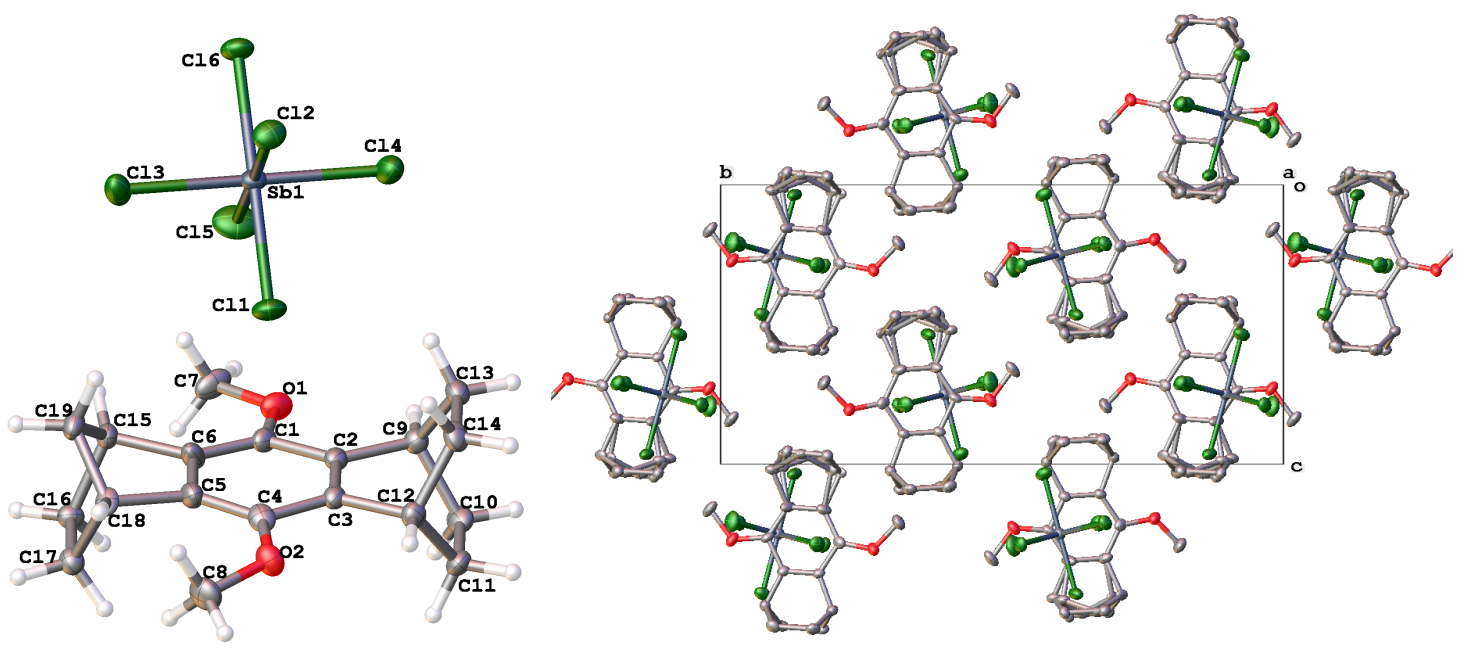

Figure S3. ORTEP and packing diagrams of ${ }^{\mathrm{M}} \mathrm{HE}^{+{ }^{+} \mathrm{SbCl}_{6}}$.

Table S9. Crystal data and structure refinement for ${ }^{\mathrm{M}} \mathrm{HE}^{+{ }^{+} \mathrm{SbCl}_{6}}{ }^{-}$.

Identification code

raj25a

Empirical formula

$\mathrm{C}_{19} \mathrm{H}_{24} \mathrm{O}_{2} \mathrm{Cl}_{6} \mathrm{Sb}$

Formula weight

618.83

Temperature/K

$100.00(10)$

Crystal system

monoclinic

Space group

$\mathrm{P} 2{ }_{1} / \mathrm{n}$

$\mathrm{a} / \AA$

$10.07958(17)$

$\mathrm{b} / \AA$

21.4803(4)

c/Å

10.71257(17)

$\alpha /^{\circ}$

90.00

$\beta /{ }^{\circ}$

96.3692(16)

$\gamma^{\circ}$

90.00

Volume $/ \AA^{3}$

2305.08(7)

Z

4

$\varrho_{\text {calc }} \mathrm{g} / \mathrm{cm}^{3}$

1.783

$\mu / \mathrm{mm}^{-1}$

16.012

$\mathrm{F}(000)$

1228.0

Crystal size $/ \mathrm{mm}^{3}$

$0.413 \times 0.0353 \times 0.0234$

Radiation

$\mathrm{CuK} \alpha(\lambda=1.54184)$

$2 \Theta$ range for data collection $/{ }^{\circ} 8.24$ to 148.34

Index ranges

$-8 \leq \mathrm{h} \leq 12,-26 \leq \mathrm{k} \leq 26,-13 \leq 1 \leq 13$

Reflections collected

22323

Independent reflections

$4597\left[\mathrm{R}_{\mathrm{int}}=0.0464, \mathrm{R}_{\text {sigma }}=0.0323\right]$

Data/restraints/parameters

$4597 / 10 / 271$

Goodness-of-fit on $\mathrm{F}^{2}$

1.139

Final $\mathrm{R}$ indexes $[\mathrm{I}>=2 \sigma(\mathrm{I})]$

Final $R$ indexes [all data]

$\mathrm{R}_{1}=0.0439, \mathrm{wR}_{2}=0.1170$

$\mathrm{R}_{1}=0.0495, \mathrm{wR}_{2}=0.1201$

Largest diff. peak/hole / e $\AA^{-3} 1.71 /-1.04$ 


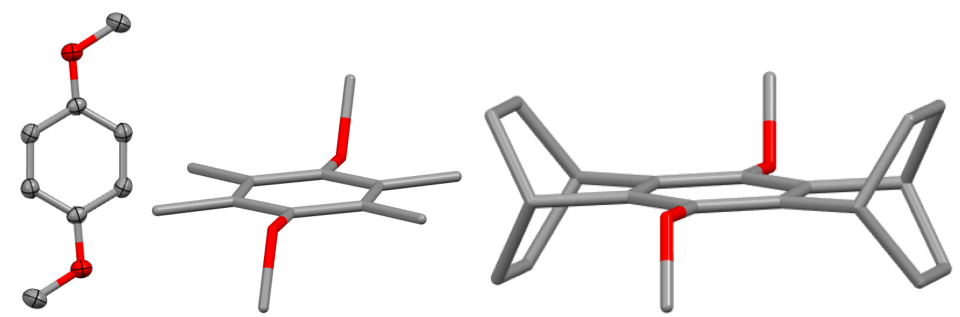

Figure S4. X-ray structures of $\mathbf{H E},{ }^{7}{ }^{\mathrm{Me} 4} \mathbf{H E},{ }^{8}$ and ${ }^{\mathrm{B}} \mathbf{H E}$ (left to right) ${ }^{9}$.

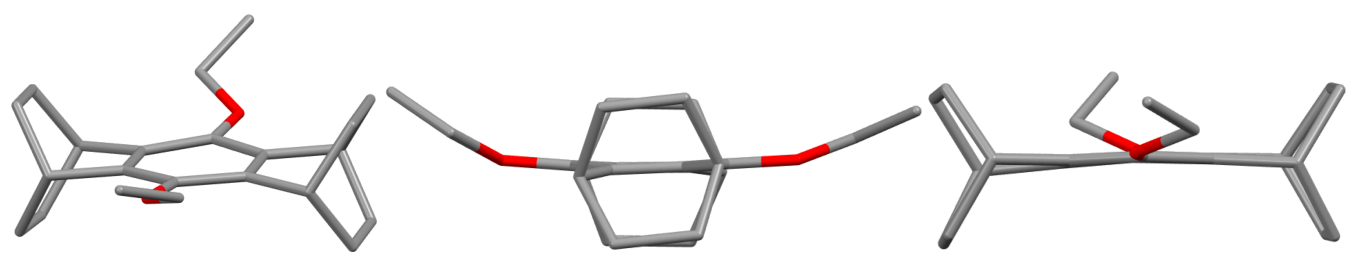

Figure S5. Different views of the ${ }^{\mathrm{B}} \mathbf{H E}^{+\bullet}$ ethoxy-analog X-ray structure. ${ }^{10}$ 


\section{S3. Computational Details}

Electronic structure calculations were performed with the Gaussian 09 package, revision D01. ${ }^{11}$ For the density functional theory (DFT) calculations we used calibrated (see Ref. ${ }^{12}$ for details) B1LYP functional ${ }^{13}$ that contains $40 \%$ contribution of the exact exchange with $6-31 \mathrm{G}(\mathrm{d})$ basis set by Pople and co-workers. ${ }^{14}$ Note that $\mathrm{we}^{12}$ and others ${ }^{15,16}$ have earlier demonstrated that alteration of the exact exchange contribution is essential to mitigate the self-interaction error ${ }^{17,18}$ that causes artificial delocalization of spin/charge in the calculations of $\pi$-conjugated cation radicals. In this study, we found that B1LYP-40 functional provides the free energies of oxidation of various HQEs (Chart 1 in the manuscript) in slightly better agreement with the measured oxidation potentials as compared with the standard functionals $\mathrm{M} 06-2 \mathrm{X}^{19}$ and $\omega \mathrm{B} 97 \mathrm{X}-\mathrm{D}^{20,21}$ (Figures S6 and S7). For this reason as well as for the sake of consistency with our previous studies, ${ }^{12}$ the calculations reported in this manuscript were based on the B1LYP40 functional.

Solvent effects were included using the implicit integral equation formalism polarizable continuum model (IEF-PCM, also referred as PCM) ${ }^{22-26}$ with the dichloromethane solvent parameters $(\varepsilon=8.93)$. In all DFT calculations, ultrafine Lebedev's grid was used with 99 radial shells per atom and 590 angular points in each shell. For cation radical calculations, wave function stability tests ${ }^{27,28}$ was performed to ensure absence of solutions with lower energy. The values of $\left\langle S^{2}\right\rangle$ operator after spin annihilation were confirmed to be close to the expectation value of 0.75 . Unpaired spin density plots were rendered using isovalue of 0.001 a.u. Tight cutoffs on forces and atomic displacements were used to determine convergence in geometry optimization procedure. Harmonic vibrational frequency calculations were performed for the optimized structures to confirm absence of imaginary frequencies. Free energies were computed within the harmonic oscillator approximation for $T=298.15 \mathrm{~K}$ and $P=1 \mathrm{~atm}$. 
Table S10. Solution-phase (PCM) adiabatic oxidation potentials and gas-phase vertical ionization potentials, obtained by means of B1LYP-40/6-31G(d).

\begin{tabular}{ccc}
$\mathrm{HQE}$ & $\Delta G_{\text {ox }}, \mathrm{eV}$ & $I P, \mathrm{eV}$ \\
\hline $\mathbf{H E}$ & 5.358 & 7.265 \\
${ }_{\mathrm{Me} 2} \mathbf{H E}$ & 5.144 & 6.931 \\
${ }^{\mathrm{Me} 4} \mathbf{H E}$ & 5.560 & 7.586 \\
${ }^{\mathrm{B}} \mathbf{H E}$ & 5.429 & 7.394 \\
${ }^{\mathrm{M}} \mathbf{H E}$ & 5.268 & 7.418 \\
${ }^{\mathrm{T}} \mathbf{H E}$ & 5.234 & 7.367 \\
\hline
\end{tabular}
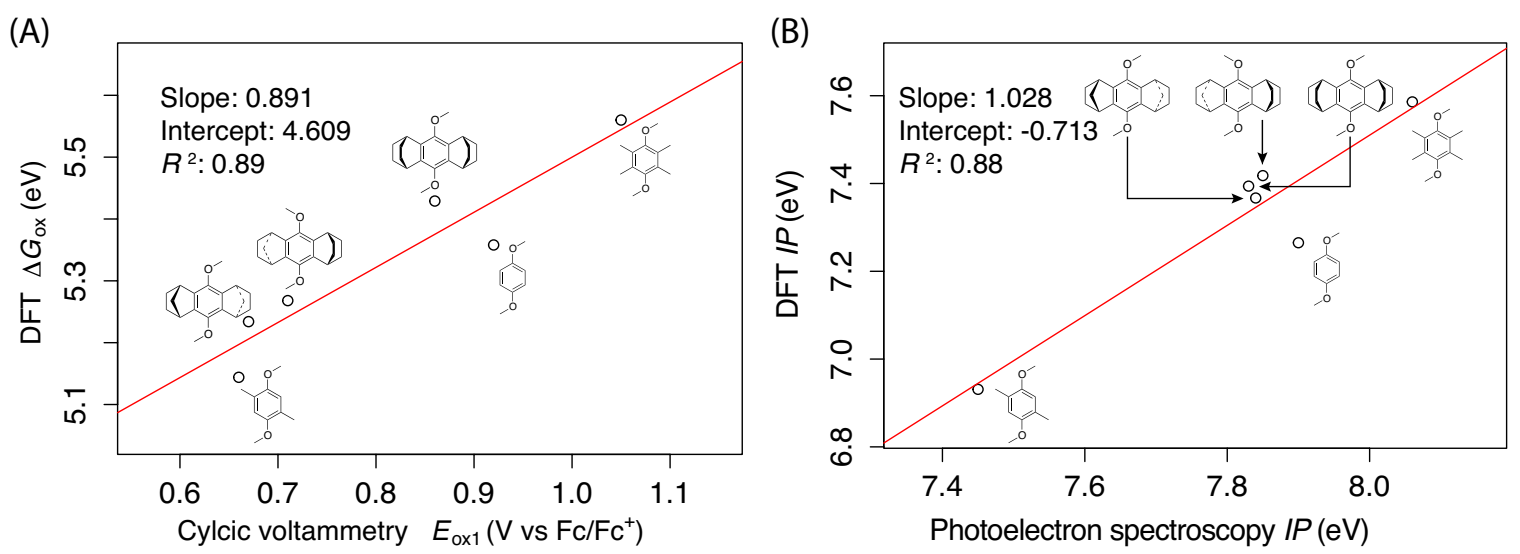

Figure S6. Comparison of the solution-phase adiabatic oxidation potentials (A) and gas-phase vertical ionization potentials (B), obtained experimentally and by means of B1LYP-40/6-31G(d).
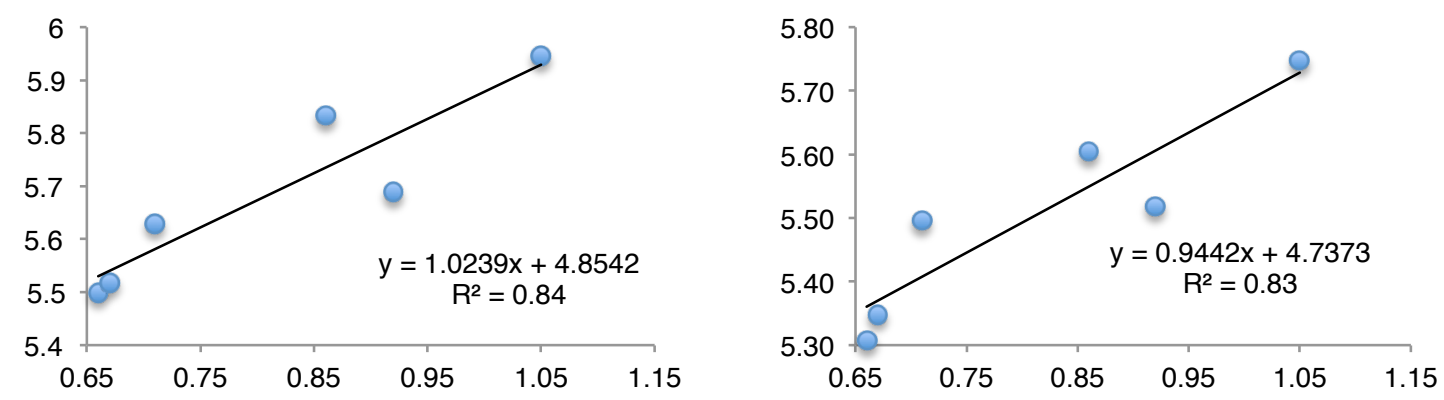

Figure S7. Comparison of the solution-phase adiabatic oxidation potentials obtained experimentally (ordinate) and by means of DFT functionals M06-2X ${ }^{19}$ (left) and $\omega$ B97X-D ${ }^{20,21}$ (right) using the 6-31G(d) basis set and the PCM(dichloromethane) solvation model. 


\section{S4. DFT Results}

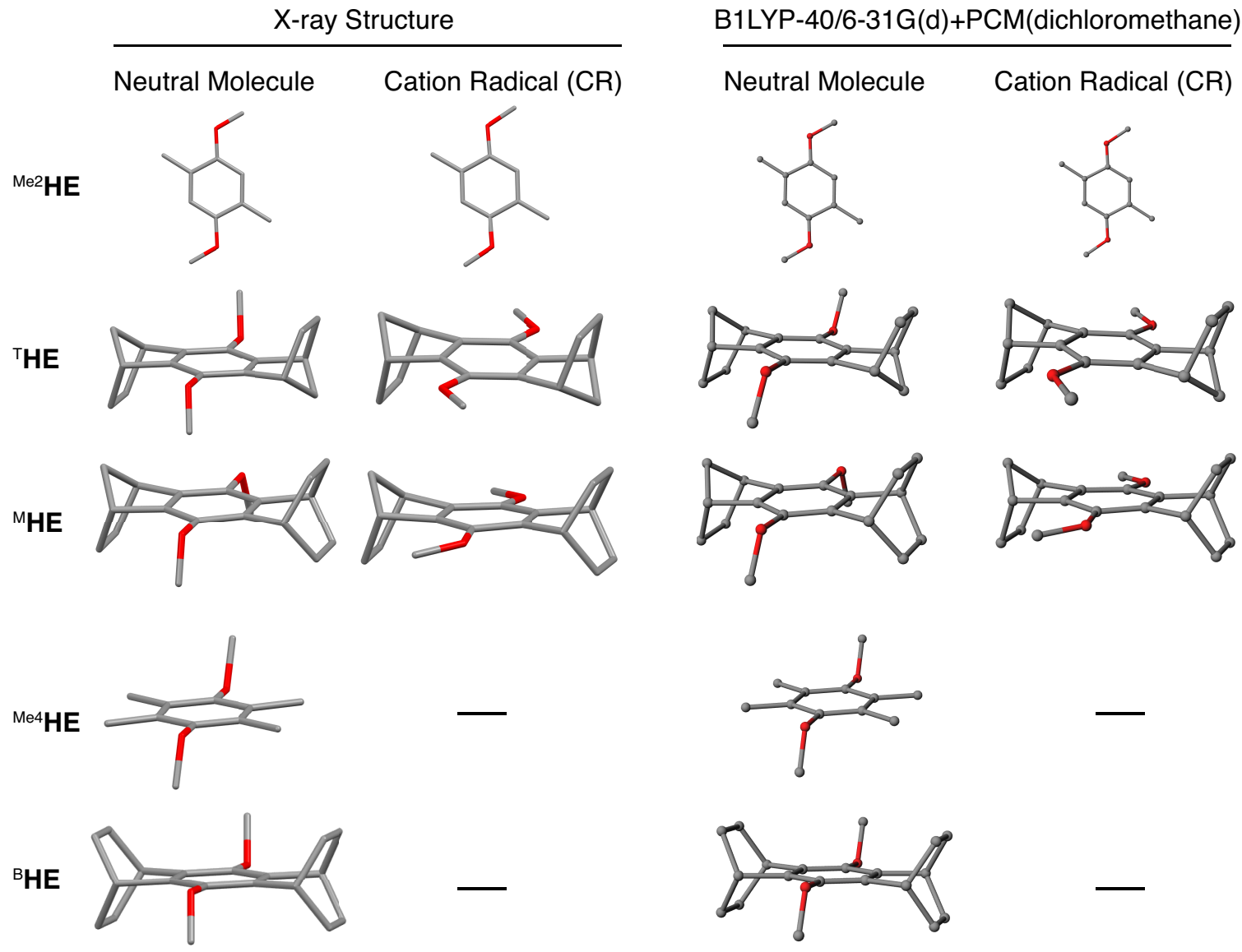

Figure S8. Comparison of the conformations of the neutral and CR HQEs obtained from X-ray crystallography vs those from the DFT calculations. 
Table S11. X-ray structural parameters of neutral $(\mathrm{N})^{29,30}$ and cation radical (CR) ${ }^{\mathrm{Me} 2} \mathbf{H E}$ as well as the corresponding values obtained from the DFT calculations. Bond lengths are given in $\AA$

\begin{tabular}{|c|c|c|c|c|c|c|}
\hline \multirow{2}{*}{ Bond } & \multicolumn{3}{|c|}{ X-Ray } & \multicolumn{3}{|c|}{ DFT } \\
\hline & $\mathrm{N}$ & $\mathrm{CR}$ & $\Delta$ & $\mathrm{N}$ & CR & $\Delta$ \\
\hline $\mathrm{C} 1-\mathrm{O} 1$ & 1.426 & 1.450 & 0.024 & 1.411 & 1.436 & 0.025 \\
\hline $\mathrm{O} 1-\mathrm{C} 2$ & 1.380 & 1.328 & -0.052 & 1.365 & 1.310 & -0.055 \\
\hline $\mathrm{C} 2-\mathrm{C} 3$ & 1.401 & 1.435 & 0.034 & 1.397 & 1.441 & 0.044 \\
\hline $\mathrm{C} 3-\mathrm{C} 4$ & 1.396 & 1.367 & -0.029 & 1.392 & 1.368 & -0.024 \\
\hline $\mathrm{C} 4-\mathrm{C} 5$ & 1.505 & 1.493 & -0.012 & 1.504 & 1.495 & -0.009 \\
\hline
\end{tabular}

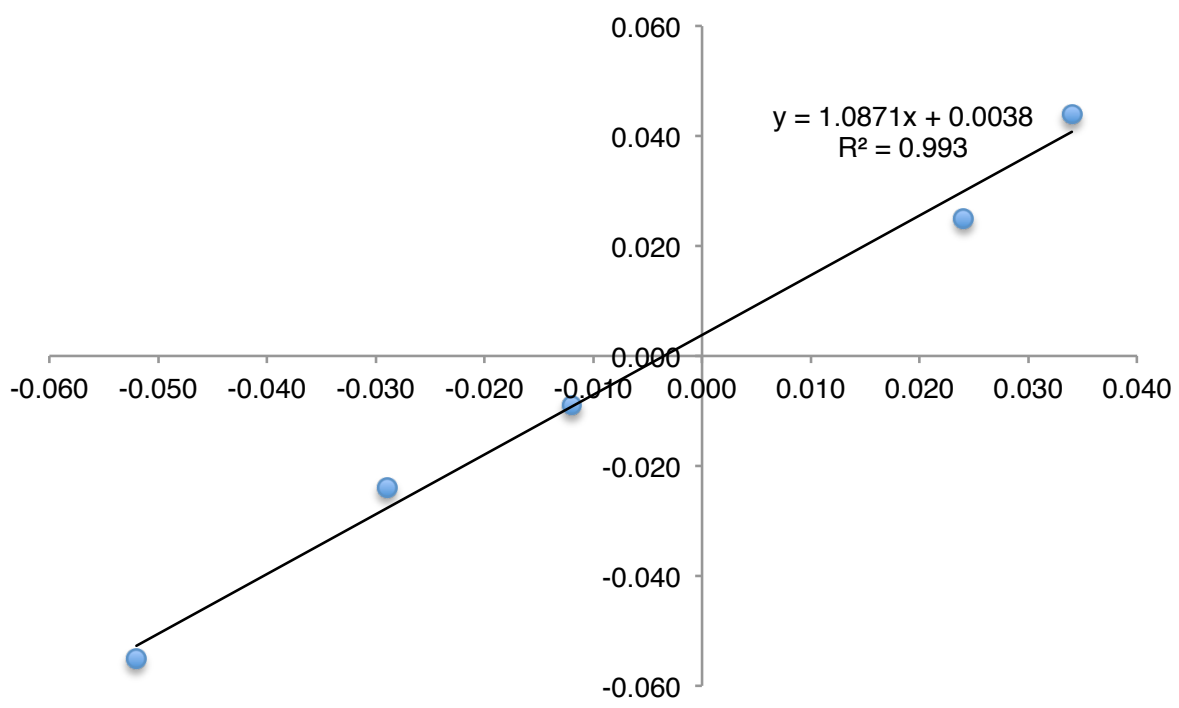

Figure S9. Comparison of the oxidation-induced bond length changes in ${ }^{\mathrm{Me}} \mathbf{H E}$ obtained by means of X-ray crystallography (abscissa) and DFT calculations (ordinate). 
Table S12. X-ray structural parameters of neutral (N) ${ }^{9}$ and cation radical (CR) ${ }^{9}{ }^{\mathrm{T}} \mathbf{H E}$ as well as the corresponding values obtained from the DFT calculations. Bond lengths are given in $\AA$<smiles>COc1c2c(c(OC)c3c1C1CCC3C1C1CCCC1)C1CCC2C1CO</smiles>

\begin{tabular}{ccccccc} 
Bond & \multicolumn{3}{c}{ X-Ray } & \multicolumn{3}{c}{ DFT } \\
& $\mathrm{N}$ & $\mathrm{CR}$ & $\Delta$ & $\mathrm{N}$ & $\mathrm{CR}$ & $\Delta$ \\
\hline C1-C2 & 1.516 & 1.529 & 0.013 & 1.513 & 1.524 & 0.011 \\
C1-C6 & 1.398 & 1.378 & -0.020 & 1.400 & 1.378 & -0.022 \\
C5-C6 & 1.518 & 1.506 & -0.012 & 1.513 & 1.504 & -0.009 \\
C6-C8 & 1.389 & 1.430 & 0.041 & 1.389 & 1.431 & 0.042 \\
C8-O & 1.391 & 1.320 & -0.071 & 1.377 & 1.314 & -0.063 \\
C9-O & 1.414 & 1.442 & 0.028 & 1.419 & 1.432 & 0.013 \\
\hline
\end{tabular}

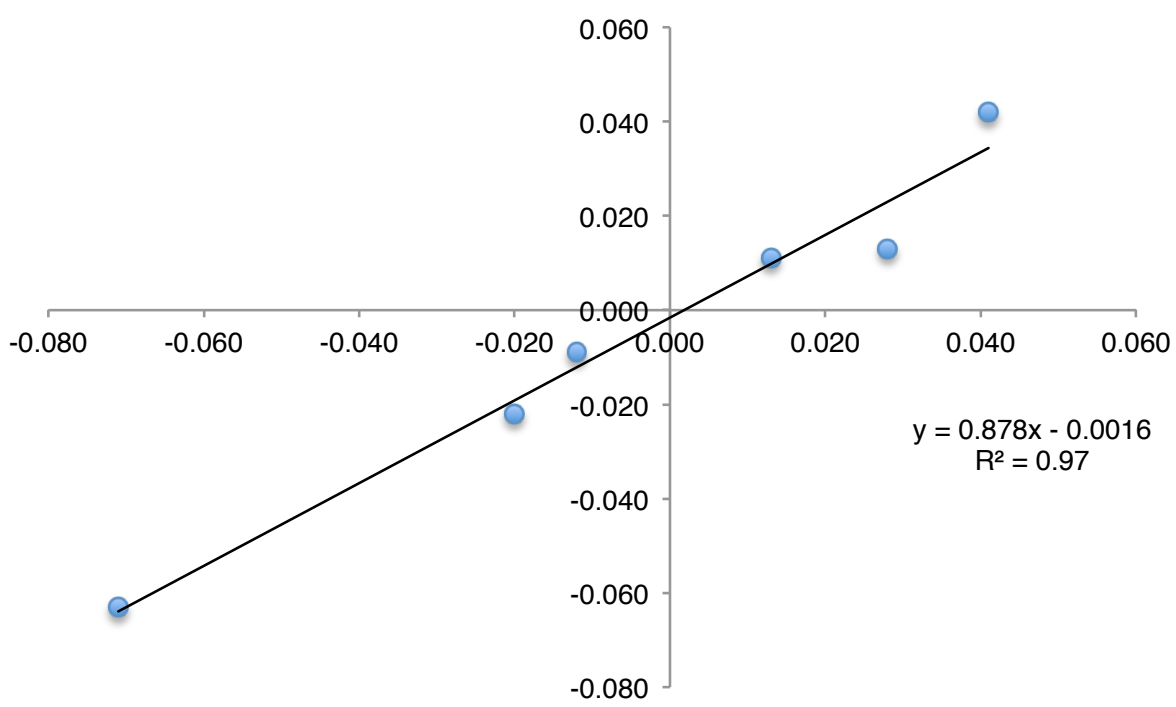

Figure S10. Comparison of the oxidation-induced bond length changes in ${ }^{\mathrm{T}} \mathbf{H E}$ obtained by means of X-ray crystallography (abscissa) and DFT calculations (ordinate). 
Table S13. X-ray structural parameters of neutral (N) and cation radical (CR) ${ }^{\mathrm{M}} \mathbf{H E}$ as well as the corresponding values obtained from the DFT calculations. Bond lengths are given in $\AA$<smiles>COc1c2c(c(OC)c3c1C1CCCC3C1)C1CCC2CC1</smiles>

\begin{tabular}{cccc} 
Bond & \multicolumn{3}{c}{ X-Ray } \\
& $\mathrm{N}$ & $\mathrm{CR}$ & $\Delta$ \\
\hline C1-C4 & 1.504 & 1.491 & -0.013
\end{tabular}

$\begin{array}{llll}\mathrm{C} 1-\mathrm{C} 3 & 1.405 & 1.367 & -0.038\end{array}$

C3-C5 $1.504 \quad 1.503 \quad-0.001$

$\begin{array}{llll}\mathrm{C} 2-\mathrm{C} 3 & 1.392 & 1.422 & 0.030\end{array}$

C2-01 $1.397 \quad 1.344 \quad-0.053$

$\begin{array}{llll}\mathrm{C} 1-01 & 1.422 & 1.436 & 0.014\end{array}$

$\begin{array}{llll}\mathrm{C} 6-\mathrm{C} 7 & 1.386 & 1.393 & 0.007\end{array}$

$\begin{array}{llll}\mathrm{C} 7-\mathrm{C} 8 & 1.406 & 1.388 & -0.018\end{array}$

$\begin{array}{llll}\mathrm{C} 8-\mathrm{C} 9 & 1.515 & 1.547 & 0.032\end{array}$

$\begin{array}{llll}\mathrm{C} 7-\mathrm{C} 10 & 1.515 & 1.533 & 0.018\end{array}$

$\begin{array}{llll}\mathrm{C} 6-\mathrm{O} 2 & 1.397 & 1.351 & -0.046\end{array}$

$\begin{array}{llll}\mathrm{O} 2-\mathrm{C} 11 & 1.422 & 1.448 & 0.026\end{array}$

$\begin{array}{llll}\mathrm{C} 6-\mathrm{C} 1 & 1.392 & 1.396 & 0.004\end{array}$

$\begin{array}{llll}\mathrm{C} 2-\mathrm{C} 8 & 1.386 & 1.429 & 0.043\end{array}$

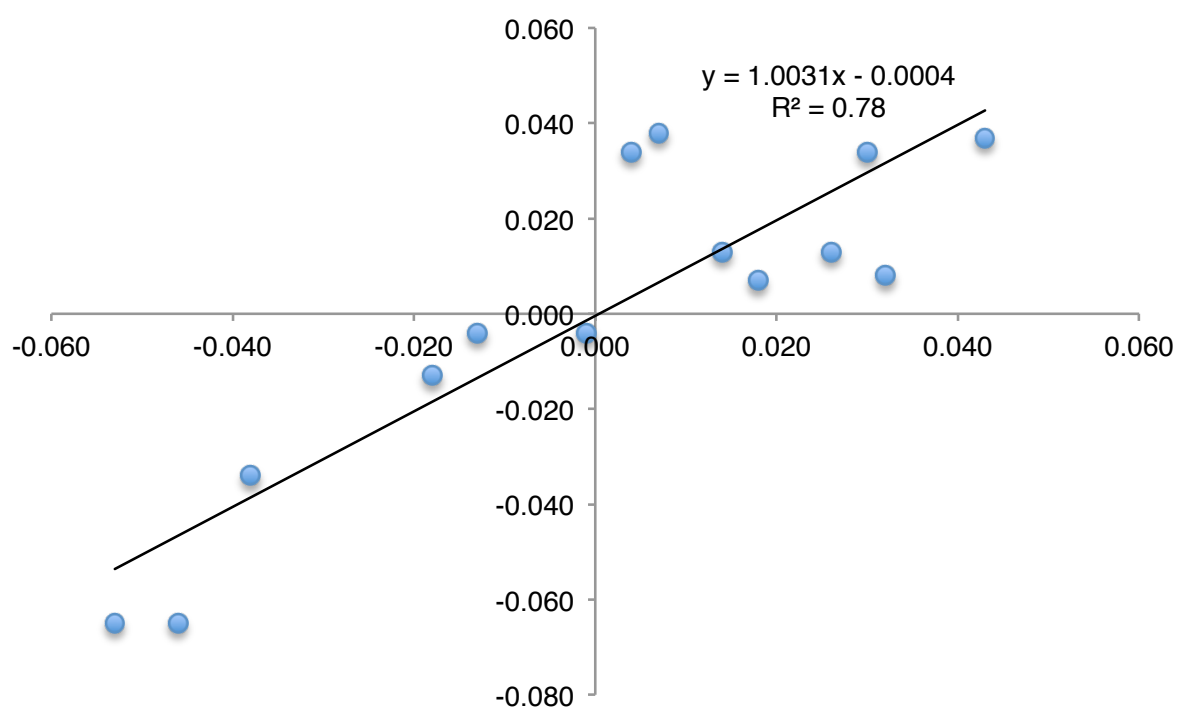

Figure S11. Comparison of the oxidation-induced bond length changes in ${ }^{\mathrm{M}} \mathbf{H E}$ obtained by means of X-ray crystallography (abscissa) and DFT calculations (ordinate). 


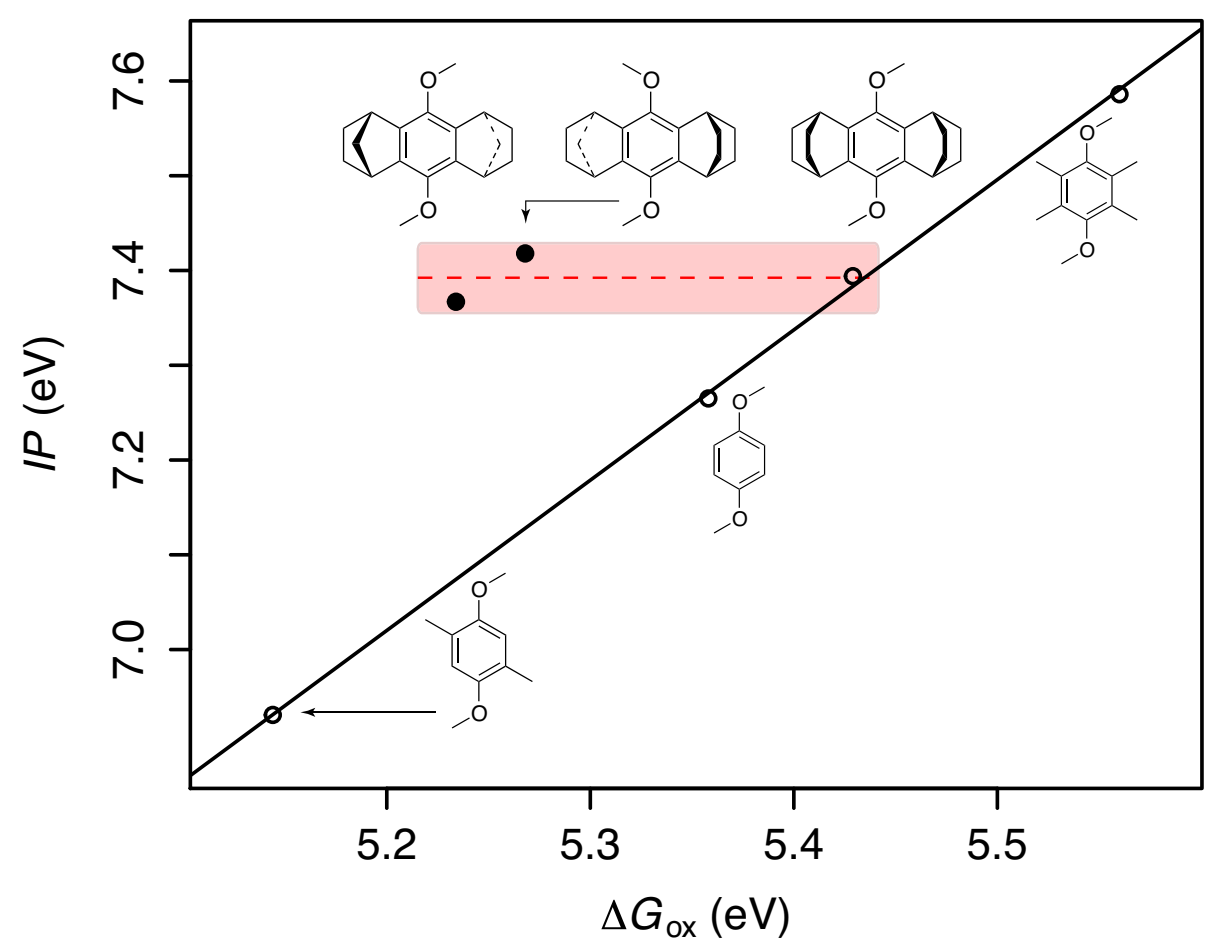

Figure S12. Calculated gas-phase ionization potentials vs solvent free energies of oxidation of HQEs obtained by means of B1LYP40/6-31G(d). The $\Delta G_{\text {ox }}$ values were computed using the polarized continuum model (PCM) with the parameters corresponding to dichloromethane. 


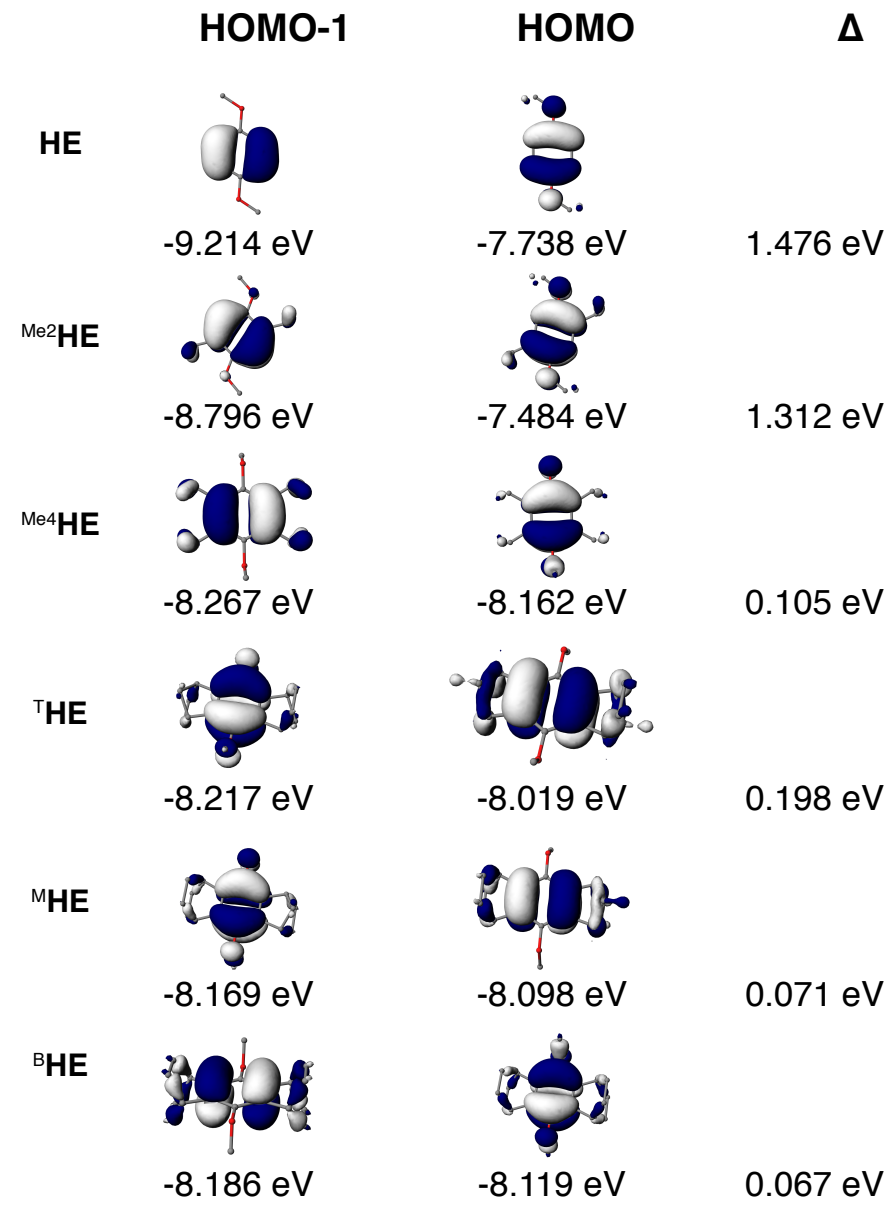

Figure S13. Isovalue (0.03 a.u.) plots and energies of the HQE HOMOs and HOMO-1 computed at the $\boldsymbol{H F / 6 - 3 1 G ( d )}$ level of theory. 

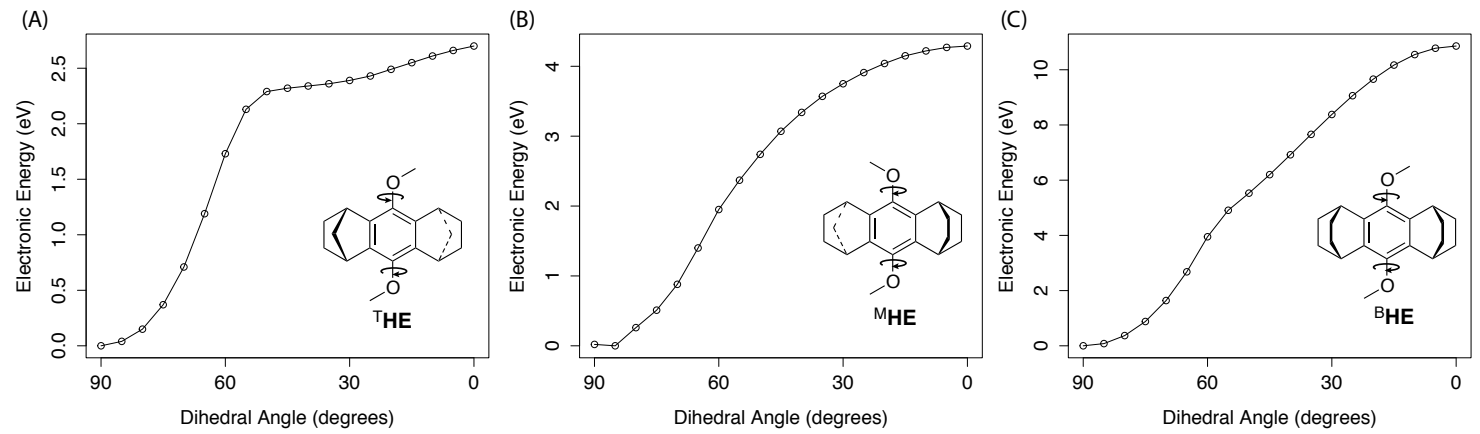

Figure S14. Electronic energies of ${ }^{\mathrm{T}} \mathrm{HE}$ (A), ${ }^{\mathrm{M}} \mathrm{HE}$ (B), and ${ }^{\mathrm{B}} \mathrm{HE}$ (C) as function of the dihedral angle between the methoxy groups and the aromatic plane, calculated by means of B1LYP40/6$31 \mathrm{G}(\mathrm{d})+\mathrm{PCM}$ (dichloromethane). Both methoxy groups were systematically rotated in such way that they had the same orientation toward the aromatic plane at every scan point. Other geometric parameters were optimized. 


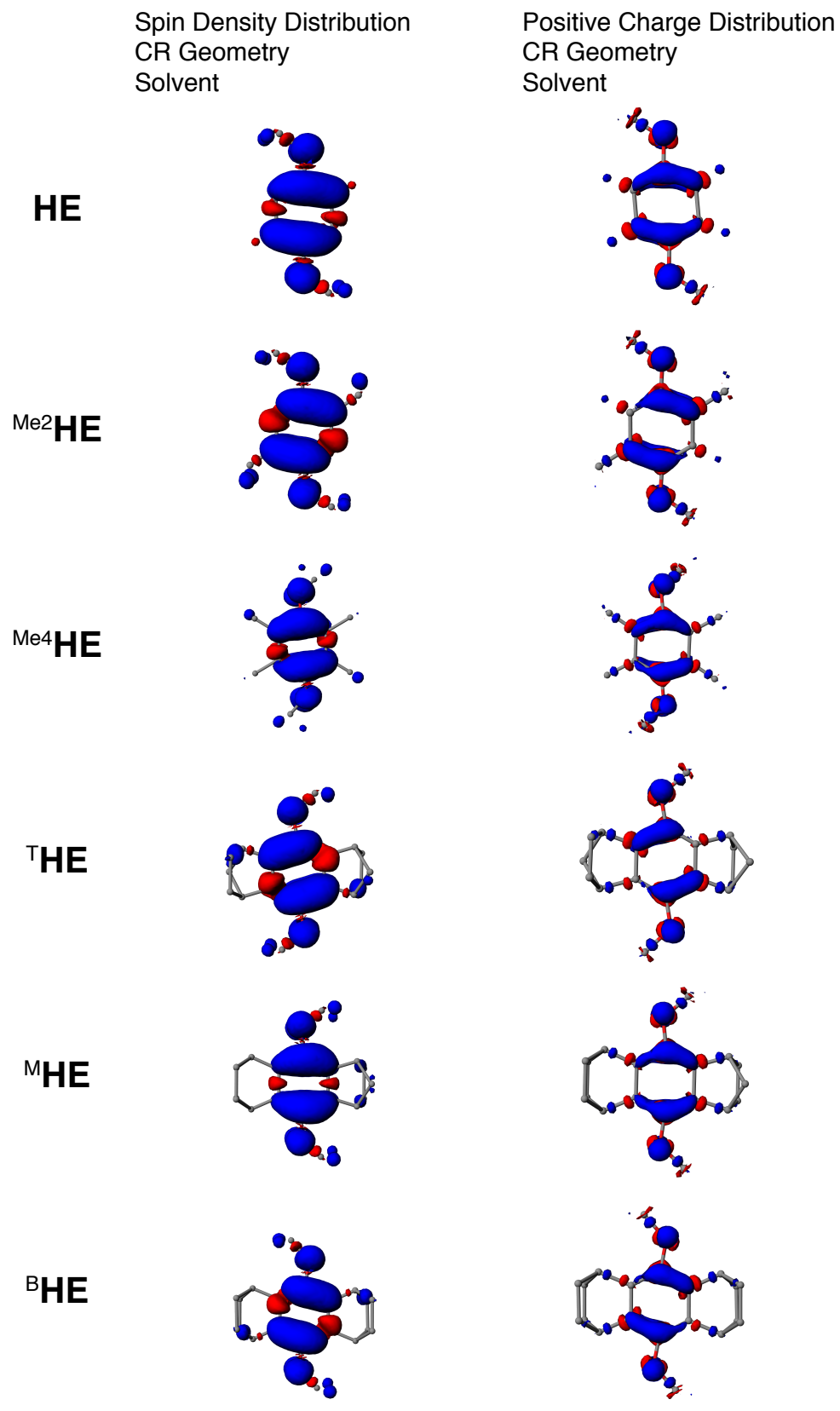

Figure S15. Comparison of the HQE CR spin density distribution (0.001 a.u.) and positive charge distribution (0.005 a.u.) isovalue plots obtained from the B1LYP-40/6$31 \mathrm{G}(\mathrm{d})+\mathrm{PCM}($ dichloromethane) calculations. 

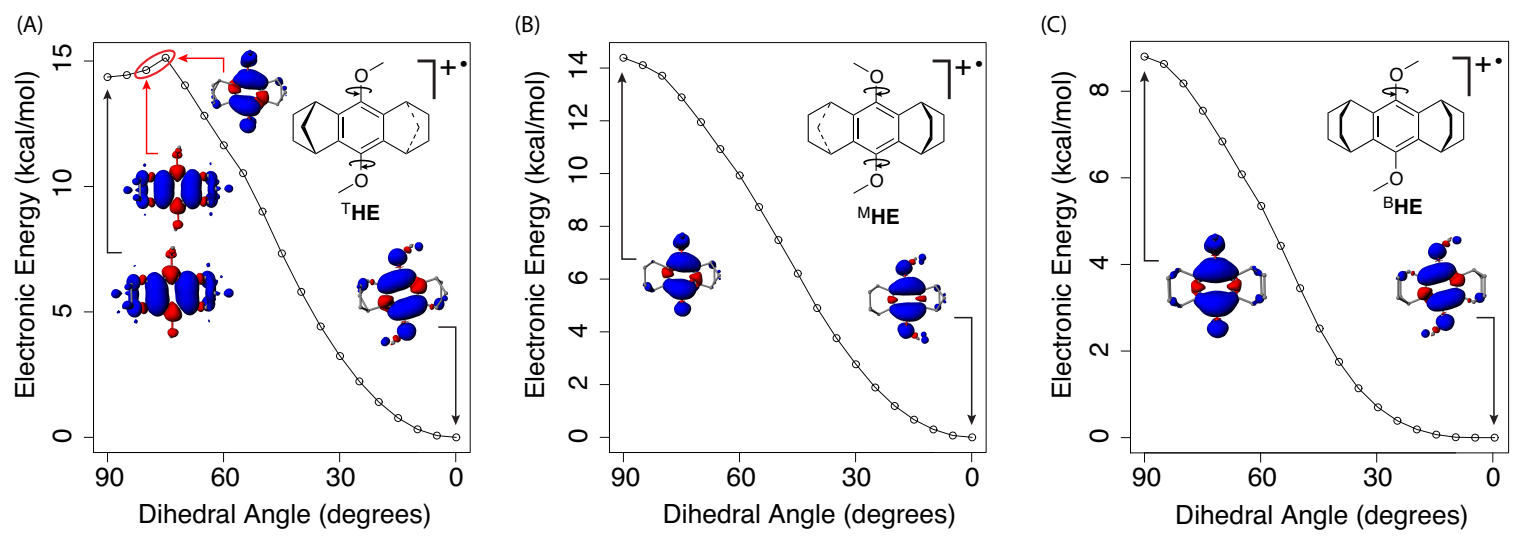

Figure S16. Electronic energies and spin density spatial distributions (0.001 a.u.) of ${ }^{\mathrm{T}} \mathbf{H E}(\mathrm{A})$, ${ }^{\mathrm{M}} \mathbf{H E}$ (B), and ${ }^{\mathrm{B}} \mathbf{H E}$ (C) cation radicals as function of the $\mathrm{CH}_{3}-\mathrm{O}-\mathrm{C}_{\mathrm{ar} 1}-\mathrm{C}_{\mathrm{ar} 2}$ dihedral angle [B1LYP40/6-31G(d)+PCM $\left.\left(\mathrm{CH}_{2} \mathrm{Cl}_{2}\right)\right]$. This scan revealed that only ${ }^{\mathrm{T}} \mathbf{H E}$ has a conformationallyinduced switchover, which occurs at $\sim 75^{\circ}$, whereas transformation of ${ }^{\mathrm{M}} \mathbf{H E}$ from the quinoidal to bisallylic state occurs even at $90^{\circ}$ due to the relaxation of non-fixed geometric parameters. Noteworthy, initial decrease of the dihedral angle from $90^{\circ}$ to $75^{\circ}$ leads to increase in energy of the CR state of ${ }^{\mathrm{T}} \mathbf{H E}$, which does not occur in the other annelated HQEs ${ }^{\mathrm{M}} \mathbf{H E}$ and ${ }^{\mathrm{B}} \mathbf{H E}$. Thus, relative orientation of the methoxy groups and aromatic ring in hydroquinone ethers occurs to control the electronic structure of the corresponding cation radicals with a switchover angle of $\sim 75^{\circ}$ thus representing the case of electronic isomerism that is unprecedented for the aromatic cation radicals. It is also noted that the obtained spin/charge distributions at every values of the dihedral angle $\mathrm{CH}_{3}-\mathrm{O}-\mathrm{C}_{\mathrm{ar} 1}-\mathrm{C}_{\mathrm{ar} 2}$ were found to be in close agreement with the shape of HOMO from the corresponding scans of neutral HQEs shown on Figure 3 in the main text.

(A)

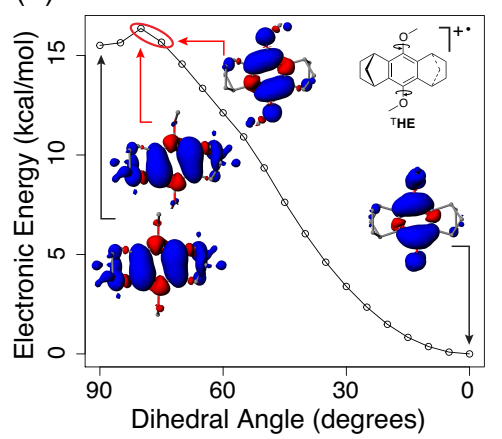

(B)

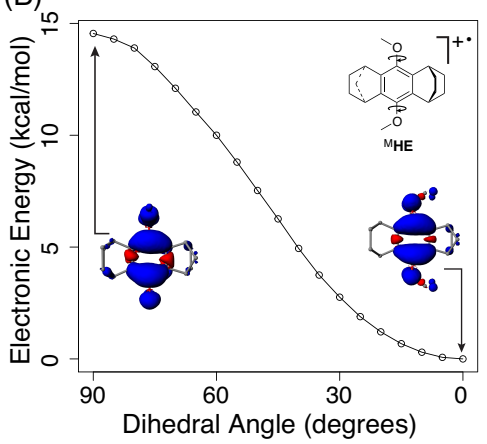

(C)

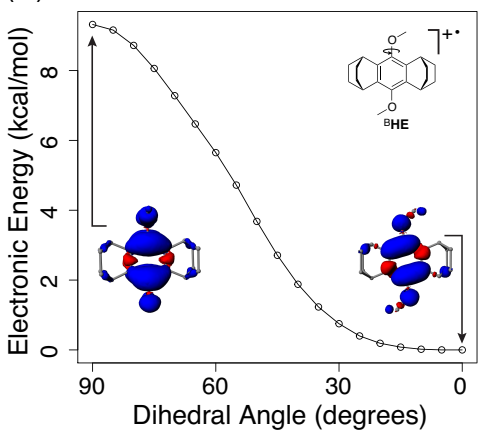

Figure S17. Gas-phase electronic energies and spin density spatial distributions (0.001 a.u.) of ${ }^{\mathrm{T}} \mathrm{HE}$ (A), ${ }^{\mathrm{M}} \mathrm{HE}$ (B), and ${ }^{\mathrm{B}} \mathrm{HE}$ (C) cation radicals as function of the dihedral angle between the methoxy groups and the aromatic plane, calculated by means of B1LYP40/6-31G(d) without solvent modeling. Both methoxy groups were systematically rotated in such way that they had the same orientation toward the aromatic plane at every scan point. Other geometric parameters were optimized. 
Spin Density in Cation Radical

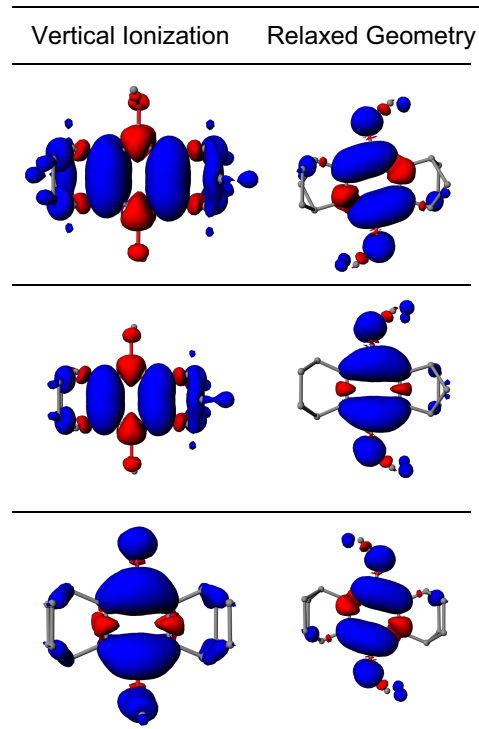

Figure S18. Isovalue plots of the full spin density spatial distributions (0.001 a.u.) in the HQE CRs [B1LYP40/6-31G(d)+PCM $\left.\left(\mathrm{CH}_{2} \mathrm{Cl}_{2}\right)\right]$. 


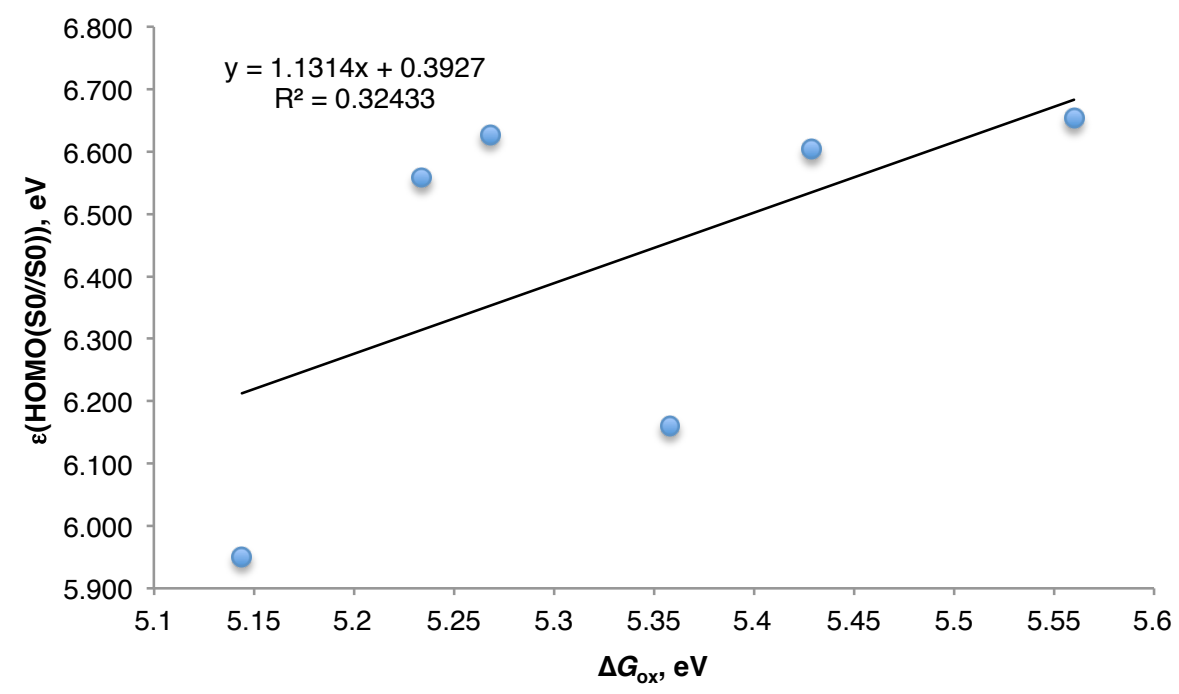

Figure S19. Relationship between $\Delta G_{\mathrm{ox}}$ vs HOMOs of the HQEs from Chart 1, denoted as $\mathrm{HOMO}(\mathrm{S} 0 / / \mathrm{S} 0)$ [B1LYP40/6-31G(d)+PCM $\left(\mathrm{CH}_{2} \mathrm{Cl}_{2}\right)$ ].

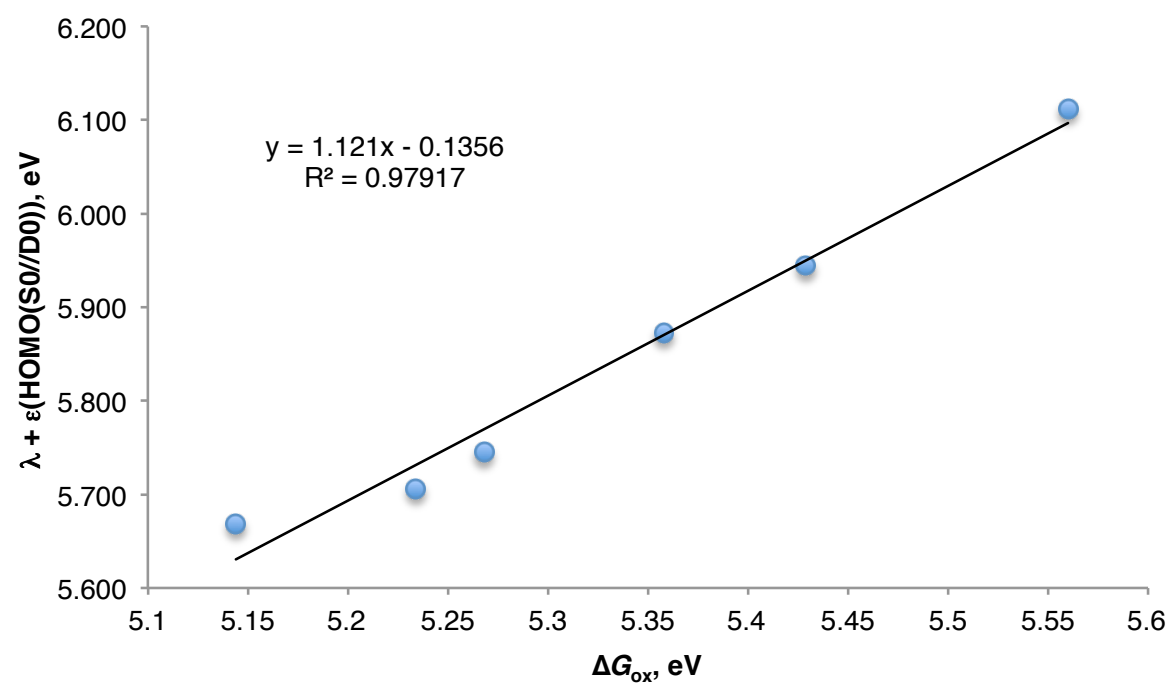

Figure S20. Relationship between $\Delta G_{\text {ox }}$ vs HOMOs of neutral HQEs that were structurally reorganized upon 1-electron oxidation [denoted as $\mathrm{HOMO}(\mathrm{S} 0 / / \mathrm{D} 0)$ ] with the structural reorganization energy taken into account $[\lambda=E(\mathrm{~S} 0 / / \mathrm{D} 0)-E(\mathrm{~S} 0 / / \mathrm{S} 0)]$, B1LYP40/6-31G(d)+PCM $\left(\mathrm{CH}_{2} \mathrm{Cl}_{2}\right)$. 


\section{S5. References}

(1) Navale, T. S.; Zhai, L.; Lindeman, S. V.; Rathore, R. Octamethoxydibenzochrysene: Isolation and X-ray Crystallographic Characterization of a Twisted Polyaromatic Cation Radical. Chem. Commun. 2009, 2857-2859.

(2) Banerjee, M.; Vyas, V. S.; Lindeman, S. V.; Rathore, R. Isolation and X-ray Structural Characterization of Tetraisopropylpyrene Cation Radical. Chem. Commun. 2008, 1889-1891.

(3) Chebny, V. J.; Navale, T. S.; Shukla, R.; Lindeman, S. V.; Rathore, R. X-ray Structural Characterization of Charge Delocalization onto the Three Equivalent Benzenoid Rings in Hexamethoxytriptycene Cation Radical. Org. Lett. 2009, 11, 22532256.

(4) Navale, T. S.; Thakur, K.; Vyas, V. S.; Wadumethrige, S. H.; Shukla, R.; Lindeman, S. V.; Rathore, R. Charge Delocalization in Self-assembled Mixed-valence Aromatic Cation Radicals. Langmuir 2012, 28, 71-83.

(5) Shukla, R.; Wadumethrige, S. H.; Lindeman, S. V.; Rathore, R. Synthesis, Electronic Properties, and X-ray Structural Characterization of Tetrarylbenzo[1,2-b:4,5-b']difuran Cation Radicals. Org. Lett. 2008, 10, 3587-3590.

(6) Chebny, V. J.; Shukla, R.; Lindeman, S. V.; Rathore, R. Molecular Actuator: Redoxcontrolled Clam-like Motion in a Bichromophoric Electron Donor. Org. Lett. 2009, 11, 1939-1942.

(7) Iuliucci, R.; Hoop, C. L.; Arif, A. M.; Harper, J. K.; Pugmire, R. J.; Grant, D. M. Redetermination of 1,4-dimethoxy-benzene. Acta. Crystallogr. Sect. E Struct. Rep. Online 2009, 65, o251.

(8) Wieczorek, M. W.; Bokii, N. G.; Struchkov, Y. T. Roczniki Chemii. Roczniki Chemii 1975, 49, 1737.

(9) Rathore, R.; Kochi, J. K. Isolation of Novel Radical Cations from Hydroquinone Ethers. Conformational Transition of the Methoxy Group upon Electron Transfer. J. Org. Chem. 1995, 60, 4399-4411. 
(10) Rosokha, S. V.; Kochi, J. K. Mechanism of Inner-sphere Electron Transfer via Charge-transfer (Precursor) Complexes. Redox Energetics of Aromatic Donors with the Nitrosonium Acceptor. J. Am. Chem. Soc. 2001, 123, 8985-8999.

(11) Frisch, M. J.; Trucks, G. W.; Schlegel, H. B.; Scuseria, G. E.; Robb, M. A.; Cheeseman, J. R.; Scalmani, G.; Barone, V.; Mennucci, B.; Petersson, G. A.; Nakatsuji, H.; Caricato, M.; Li, X.; Hratchian, H. P.; Izmaylov, A. F.; Bloino, J.; Zheng, G.; Sonnenberg, J. L.; Hada, M.; Ehara, M.; Toyota, K.; Fukuda, R.; Hasegawa, J.; Ishida, M.; Nakajima, T.; Honda, Y.; Kitao, O.; Nakai, H.; Vreven, T.; Montgomery, J. A.; Peralta, J. E.; Ogliaro, F.; Bearpark, M.; Heyd, J. J.; Brothers, E.; Kudin, K. N.; Staroverov, V. N.; Kobayashi, R.; Normand, J.; Raghavachari, K.; Rendell, A.; Burant, J. C.; Iyengar, S. S.; Tomasi, J.; Cossi, M.; Rega, N.; Millam, J. M.; Klene, M.; Knox, J. E.; Cross, J. B.; Bakken, V.; Adamo, C.; Jaramillo, J.; Gomperts, R.; Stratmann, R. E.; Yazyev, O.; Austin, A. J.; Cammi, R.; Pomelli, C.; Ochterski, J. W.; Martin, R. L.; Morokuma, K.; Zakrzewski, V. G.; Voth, G. A.; Salvador, P.; Dannenberg, J. J.; Dapprich, S.; Daniels, A. D.; Farkas; Foresman, J. B.; Ortiz, J. V.; Cioslowski, J.; Fox, D. J. Gaussian, Inc., Wallingford CT, 2009.

(12) Talipov, M. R.; Boddeda, A.; Timerghazin, Q. K.; Rathore, R. Key Role of EndCapping Groups in Optoelectronic Properties of Poly-p-phenylene Cation Radicals. $J$. Phys. Chem. C 2014, 118, 21400-21408.

(13) Adamo, C.; Barone, V. Toward Reliable Adiabatic Connection Models Free from Adjustable Parameters. Chem. Phys. Lett. 1997, 274, 242-250.

(14) Hehre, W. J.; Ditchfield, R.; Pople, J. A. Self-consistent Molecular Orbital Methods. XII. Further Extensions of Gaussian-type Basis Sets for Use in Molecular Orbital Studies of Organic Molecules. J. Chem. Phys. 1972, 56, 2257-2261.

(15) Renz, M.; Theilacker, K.; Lambert, C.; Kaupp, M. A Reliable Quantum-chemical Protocol for the Characterization of Organic Mixed-valence Compounds. J. Am. Chem. Soc. 2009, 131, 16292-16302.

(16) Renz, M.; Kess, M.; Diedenhofen, M.; Klamt, A.; Kaupp, M. Reliable Quantum Chemical Prediction of the Localized/Delocalized Character of Organic Mixed-Valence 
Radical Anions. From Continuum Solvent Models to Direct-COSMO-RS. J. Chem. Theory. Comput. 2012, 8, 4189-4203.

(17) Cohen, A. J.; Mori-Sánchez, P.; Yang, W. Insights into Current Limitations of Density Functional Theory. Science 2008, 321, 792-794.

(18) Cohen, A. J.; Mori-Sánchez, P.; Yang, W. Challenges for Density Functional Theory. Chem. Rev. 2011, 112, 289-320.

(19) Zhao, Y.; Truhlar, D. G. The M06 Suite of Density Functionals for Main Group Thermochemistry, Thermochemical Kinetics, Noncovalent Interactions, Excited States, and Transition Elements: Two New Functionals and Systematic Testing of Four M06class Functionals and 12 Other Functionals. Theor. Chem. Acc. 2008, 120, 215-241.

(20) Chai, J. -D.; Head-Gordon, M. Systematic Optimization of Long-range Corrected Hybrid Density Functionals. J. Chem. Phys. 2008, 128, 084106.

(21) Chai, J.-D.; Head-Gordon, M. Long-range Corrected Hybrid Density Functionals with Damped Atom-atom Dispersion Corrections. Phys. Chem. Chem. Phys. 2008, 10, 6615-6620.

(22) Miertus, S.; Scrocco, E.; Tomasi, J. Electrostatic Interaction of a Solute with a Continuum. A Direct Utilization of ab initio Molecular Potentials for the Prevision of Solvent Effects. Chem. Phys. 1981, 55, 117-129.

(23) Cances, M. T.; Mennucci, V.; Tomasi, J. A New Integral Equation Formalism for the Polarizable Continuum Model: Theoretical Background and Applications to Isotropic and Anisotropic Dielectrics. J. Chem. Phys. 1997, 107, 3032-3041.

(24) Cossi, M.; Barone, V.; Mennucci, V.; Tomasi, J. Ab Initio Study of Ionic Solutions by a Polarizable Continuum Dielectric Model. Chem. Phys. Lett. 1998, 286, 253-260.

(25) Tomasi, J.; Mennucci, B.; Cammi, R. Quantum Mechanical Continuum Solvation Models. Chem. Rev. 2005, 105, 2999-3093.

(26) Ribeiro, R. F.; Marenich, A. V.; Cramer, C. J.; Truhlar, D. G. Use of Solution-Phase Vibrational Frequencies in Continuum Models for the Free Energy of Solvation. J. Phys. Chem. B. 2011, 115, 14556-14562. 
(27) Seeger, R.; Pople, J. A. Self-consistent Molecular Orbital Methods. XVIII. Constraints and Stability in Hartree-Fock theory. J. Chem. Phys. 1977, 66, 3045-3050.

(28) Bauernschmitt, R.; Ahlrichs, R. Stability Analysis for Solutions of the Closed Shell Kohn-Sham equation. J. Chem. Phys. 1996, 104, 9047-9052.

(29) Sun, D.; Lindeman, S. V.; Rathore, R.; Kochi, J. K. Intramolecular (Electron) Delocalization Between Aromatic Donors and their Tethered Cation-radicals. Application of Electrochemical and Structural Probes. J. Chem. Soc. Perk. T. 2. 2001, 1585-1594.

(30) Lindeman, S. V.; Rosokha, S. V.; Sun, D.; Kochi, J. K. X-ray Structure Analysis and the Intervalent Electron Transfer in Organic Mixed-valence Crystals with Bridged Aromatic Cation Radicals. J. Am. Chem. Soc. 2002, 124, 843-855. 


\title{
Supporting Information: Archive Entries from the DFT Calculations
}

\section{Does Koopmans' Paradigm for 1-Electron Oxidation Always Hold? Breakdown of IP/Eox Relationship for $\mathrm{p}$-Hydroquinone Ethers and the Role of Methoxy Group Rotation}

\author{
Marat R. Talipov, Anitha Boddeda, Sergey V. Lindeman, Rajendra Rathore* \\ Department of Chemistry \\ Marquette University
}

P.O. Box 1881, Milwaukee, WI 53201-1881

\section{Corresponding Author}

*E-mail: rajendra.rathore@marquette.edu

\section{Table of Contents}

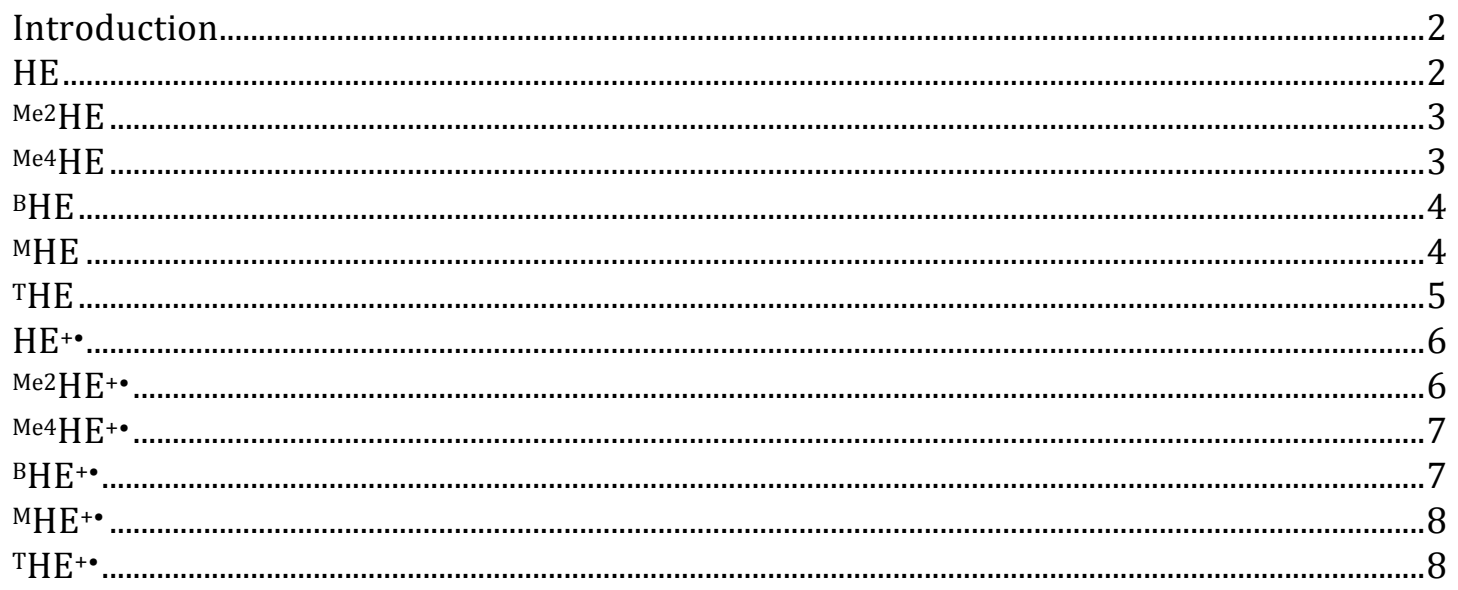




\section{Introduction}

The archive entries, formerly intended for the Browse Quantum Chemistry Database System, are organized as a simple list of data fields separated by backslash symbols, which is wrapped in 70-char text lines. The script 'Parse.Archive.pl', written in Perl, converts archive entry into human readable format. To use this script,

1. Check if the Perl interpreter is installed on the system. To do this, run the command 'perl $-\mathrm{v}$ ' in console. If console returns a message like 'command not found', please obtain and install a Perl interpreter (www.perl.org/get.html; Perl is Open Source software licensed under GNU GPL).

2. Save the script code, listed below, as a file named 'Parse.Archive.pl'.

3. Select an archive entry of interest and save it as another file (e.g. 'BXb.txt').

4. $\quad$ Run the command 'perl Parse.Archive.pl B-Xb.txt > B-Xb-parsed.txt' in console. The parsed archive entry will be stored in the file 'B-Xbparsed.txt' in this example. In some cases, absolute path to the Perl interpreter might need to be provided.

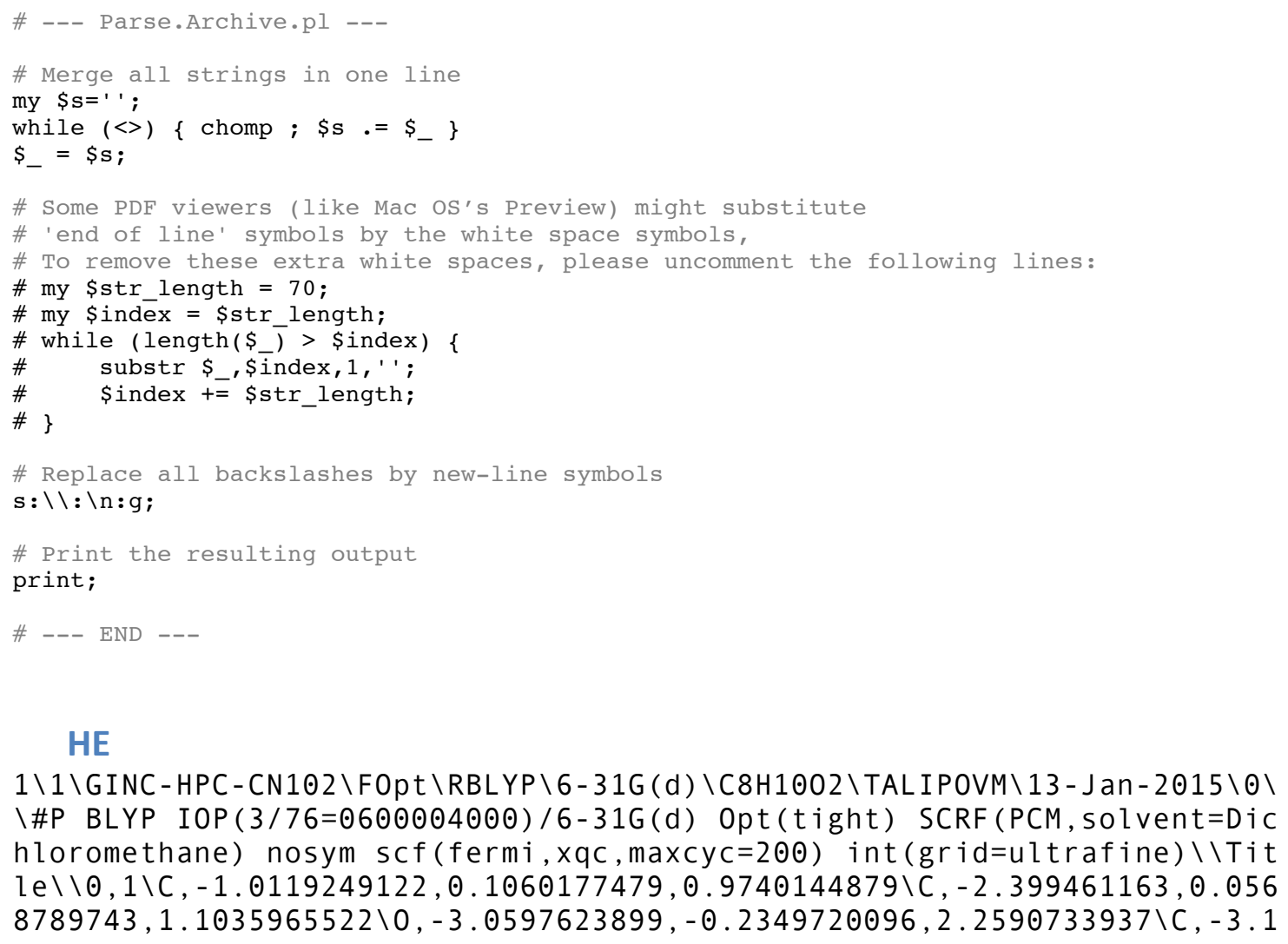


$928691051,0.3199190989,-0.0091310225 \backslash C,-2.622450493,0.6282968081,-1.23$ $67751274 \backslash C,-1.2349143545,0.6774370343,-1.36635639 \backslash 0,-0.5746165855,0.96$ $92826517,-2.5218356259 \backslash C,-0.4415062047,0.4143945497,-0.2536302205 \backslash C,-1$ $.3391461405,1.2434870039,-3.6766360431 \backslash C,-2.2952410624,-0.5091864851,3$ $.4138775243 \backslash \mathrm{H},-1.9564268203,0.3891721811,-3.9601825992 \backslash \mathrm{H},-0.6260360924$ $, 1.4478426413,-4.4692335301 \backslash \mathrm{H},-1.9789729377,2.11632282,-3.5351383663 \backslash \mathrm{H}$ $,-1.6554109986,-1.3820190181,3.2723751259 \backslash \mathrm{H},-3.0083562656,-0.713552824$ $6,4.2064676556 \backslash \mathrm{H},-1.6779649649,0.3451266856,3.6974387161 \backslash \mathrm{H},-0.36673714$ $71,-0.0922492265,1.8148604836 \backslash \mathrm{H},-4.2670473783,0.2800943165,0.097905225$ $8 \backslash H,-3.2676371192,0.8265611562,-2.0776230496 \backslash H, 0.6326721347,0.45421589$ $46,-0.3606671905 \backslash \backslash$ Vers ion $=E M 64 L-G 09 R e v D .01 \backslash H F=-461.0371381 \backslash R M S D=4.234 \mathrm{e}$ $-09 \backslash \mathrm{RMSF}=9.327 \mathrm{e}-07 \backslash \mathrm{D}$ i pol $\mathrm{e}=-0.00000018,-0.00000058,0.0000016 \backslash \mathrm{Quad}$ rupol $\mathrm{e}=-$ $3.8963118,-4.7070216,8.6033334,-1.0760225,4.4724128,-3.4166708 \backslash P G=C 01$ [X(C8H1002)] \\@

\footnotetext{
${ }^{\mathrm{Me} 2} \mathrm{HE}$
}

$1 \backslash 1 \backslash G I N C-H P C-C N 78 \backslash F 0 p t \backslash R B L Y P \backslash 6-31 G(d) \backslash C 10 H 1402 \backslash T A L I P O V M \backslash 14-J a n-2015 \backslash 0 \backslash$ $\backslash \# P$ BLYP IOP $(3 / 76=0600004000) / 6-31 \mathrm{G}(\mathrm{d})$ Opt (tight) SCRF (PCM, solvent=DiC hloromethane) nosym scf(fermi, $x q c$, maxcyc $=200)$ int (grid=ultrafine) $\backslash \backslash T i t$ le $\backslash \backslash 0,1 \backslash C,-1.0194153494,0.1548727189,0.9745928816 \backslash C,-2.4047904348,0.10$ $08769159,1.1017760528 \backslash 0,-3.0547966432,-0.1704670514,2.2714602082 \backslash \mathrm{C},-3$. $221957665,0.331456758,-0.0078870492 \backslash \mathrm{C},-2.6151087882,0.6134330384,-1.22$ $87533647 \backslash \mathrm{C},-1.2297309841,0.6674267298,-1.3559372027 \backslash 0,-0.5797278582,0$. $9387715191,-2.5256235808 \backslash \mathrm{C},-0.4125643696,0.4368480539,-0.2462749447 \backslash \mathrm{C}$, $-1.3490086223,1.1822552737,-3.6829064312 \backslash C,-2.2855179689,-0.4139553514$

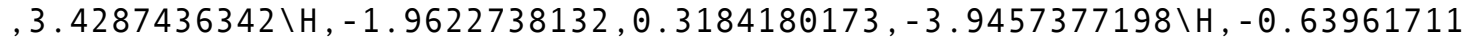
$93,1.3732928924,-4.4824295438 \backslash \mathrm{H},-1.9941074957,2.0539803946,-3.55926143$ $66 \backslash H,-1.6404158332,-1.2856772135,3.3050933673 \backslash H,-2.9949095196,-0.60500$ $09637,4.2282648603 \backslash H,-1.672255358,0.4498819101,3.6915812777 \backslash H,-0.38619$ $68311,-0.0229322007,1.8298482599 \backslash \mathrm{C},-4.7187036816,0.2732516362,0.126235$ $8174 \backslash H,-3.2483251751,0.7912425215,-2.0840089166 \backslash \mathrm{C}, 1.0841806537,0.49505$ $79956,-0.3803956634 \backslash \mathrm{H},-5.0489955582,-0.7086852365,0.4683561157 \backslash \mathrm{H},-5.20$ $21086138,0.4822033895,-0.8264566399 \backslash H,-5.0800791283,0.9965331068,0.858$ $6202365 \backslash H, 1.5675876262,0.2860939583,0.5722934922 \backslash H, 1.4144709603,1.4770$ $00939,-0.7225013301 \backslash H, 1.4455575706,-\odot .228209752,-1.1127923804 \backslash \backslash V e r s i o n$ $=E M 64 \mathrm{~L}-\mathrm{GO9}$ ReVD. $01 \backslash \mathrm{HF}=-539.6188686 \backslash \mathrm{RMSD}=8.796 \mathrm{e}-09 \backslash \mathrm{RMSF}=6.327 \mathrm{e}-07 \backslash \mathrm{D}$ i pole $=-0.0000027,-0.00000007,0.0000018 \backslash Q u a d r u p o l e=-3.5054497,-4.6289515,8.13$ $44012,-0.848712,4.0034848,-2.9036872 \backslash P G=C \odot 1[X(C 10 H 1402)] \backslash \backslash @$

${ }^{\mathrm{Me}} \mathrm{HE}$

$1 \backslash 1 \backslash G I N C-H P C-C N 90 \backslash F 0 p t \backslash R B L Y P \backslash 6-31 G(d) \backslash C 12 H 1802 \backslash T A L I P O V M \backslash 14-J a n-2015 \backslash 0 \backslash$ $\backslash \# P$ BLYP IOP $(3 / 76=0600004000) / 6-31 \mathrm{G}(\mathrm{d})$ 0pt (tight) SCRF (PCM, solvent=Dic hloromethane) nosym scf(fermi, xqc, maxcyc $=200$ ) int (grid=ultrafine) \\Tit le $\backslash \backslash \Theta, 1 \backslash C,-0.2819871912,-0.0294766773,2.3315551755 \backslash \mathrm{C},-1.0553649276,0.2$ $345444439,1.0660576082 \backslash C,-2.4521137607,0.2149795713,1.069319374 \backslash 0,-3.1$ $124213835,-0.0602859673,2.2510512106 \backslash C,-3.2031515243,0.4299431169,-0.0$ $887018838 \backslash \mathrm{C},-4.7080014109,0.3734814335,-0.048246182 \backslash \mathrm{C},-2.5332918362,0$. $6866812527,-1.2909804228 \backslash \mathrm{C},-3.3066766582,0.9506960824,-2.5564742958 \backslash \mathrm{C}$, $-1.1365441132,0.7062482958,-1.2942414221 \backslash 0,-0.4762319069,0.981512963$, $2.4759709069 \backslash \mathrm{C},-\odot .3855061052,0.4912872276,-\odot .1362186643 \backslash \mathrm{C}, 1.1193438229$ $, 0.5477564517,-0.176682453 \backslash H, 1.5108356842,1.1806629265,0.6203606404 \backslash H$, $1.4652478159,0.9456763991,-1.1256276308 \backslash H, 1.5634602037,-0.4412819569$, $0.0411832748 \backslash H,-0.9374578476,-0.3983020938,3.1143311652 \backslash H, 0.2104565033$ $, 0.874059901,2.6988413082 \backslash H, 0.5011362439,-0.7702107227,2.1667434703 \backslash H$, $-5.05391933,-\odot .0243368797,0.9007357608 \backslash H,-5.0994860025,-0.2595111247$, - 
$0.8452261414 \backslash H,-5.1521119752,1.3625057986,-0.1838622003 \backslash H,-4.089731243$ $, 1.6915097303,-2.3916853408 \backslash H,-3.7992123305,0.0471819332,-2.9236906076$ $\backslash H,-2.651196358,1.3194201621,-3.3392890405 \backslash \mathrm{C},-0.1634361562,-0.16563286$ $56,-3.2506068337 \backslash \mathrm{C},-3.4251501524,1.086853518,3.025723591 \backslash \mathrm{H}, 0.491916915$ $3,-0.8451636581,-2.7033044137 \backslash \mathrm{H}, 0.3484731941,0.1877546875,-4.141918068$ $4 \backslash H,-1.0669056262,-0.7035976882,-3.5423840239 \backslash H,-2.521652289,1.6247778$ $669,3.3174867766 \backslash \mathrm{H},-3.9370462329,0.733464393,3.9170418294 \backslash \mathrm{H},-4.0804940$ $218,1.7664214791,2.4784558962 \backslash \backslash$ Vers i on=EM64L-G09RevD . $01 \backslash \mathrm{HF}=-618.188235$ $2 \backslash \mathrm{RMSD}=7.505 \mathrm{e}-09 \backslash \mathrm{RMSF}=9.221 \mathrm{e}-07 \backslash \mathrm{D}$ i pol $\mathrm{e}=0.0000304,-0.0000025,0.0000164 \backslash$ Quadrupole $=1.485216,-4.508874,3.023658,-3.7420606,-0.1609776,5.9015255$ $\backslash P G=C O 1[X(C 12 H 1802)] \backslash \backslash @$

\section{${ }^{B} \mathrm{HE}$}

$1 \backslash 1 \backslash G I N C-H P C-C N 119 \backslash F 0 p t \backslash R B L Y P \backslash 6-31 G(d) \backslash C 20 H 2602 \backslash T A L I P O V M \backslash 14-J a n-2015 \backslash 0$ $\backslash \backslash \# P$ BLYP IOP $(3 / 76=0600004000) / 6-31 \mathrm{G}(\mathrm{d})$ Opt (tight) SCRF (PCM, solvent=Di chloromethane) nosym scf(fermi, xqc, maxcyc $=200)$ int (grid=ultrafine) $\backslash \backslash T i$ t le $\backslash \backslash 0,1 \backslash C,-0.0720603236,-0.0910634799,2.1512285623 \backslash \mathrm{C},-1.0664440851,0$. $1611721609,1.0475455159 \backslash \mathrm{C},-2.4538872455,0.1389434047,1.1617745614 \backslash 0,-3$ $.0463436604,-0.1601650683,2.3712485833 \backslash \mathrm{C},-3.2387297259,0.383567102,0 . \odot$ $380538647 \backslash \mathrm{C},-4.7444376318,0.3885904238,-0.0204736827 \backslash \mathrm{C},-2.637581139,0$. $6478213959,-1.1968513175 \backslash \mathrm{C},-3.6319646211,0.9000582887,-2.300534198 \backslash \mathrm{C},-$ $1.2501383211,0.6700500739,-1.3110805867 \backslash 0,-0.6576811288,0.9691583876$, $2.5205543316 \backslash C,-0.4652954801,0.4254260977,-0.1873598005 \backslash C, 1.0404125117$ $, 0.420403052,-0.1288323373 \backslash \mathrm{C},-0.3939031591,-0.1600811173,-3.33836989 \backslash \mathrm{C}$ $,-3.3101199831,0.9690739621,3.1890652277 \backslash \mathrm{H}, 0.2888836559,-0.8543507425$, $-2.8454192466 \backslash H, 0.0677426002,0.2124759296,-4.2491249768 \backslash \mathrm{H},-1.314599356$ $8,-0.6891665773,-3.5905671566 \backslash \mathrm{H},-2.3894298567,1.4981939953,3.441211077$ $7 \backslash \mathrm{H},-3.7717078005,0.5965105648,4.0998470839 \backslash \mathrm{H},-3.9929555985,1.66331474$ $6,2.6961410077 \backslash \mathrm{C},-5.1875138582,-0.6626366613,-1.0623499026 \backslash \mathrm{C},-4.533379$ $4852,-0.3473425526,-2.432811062 \backslash H,-6.2757975991,-0.6498048291,-1.14045$ $27859 \backslash \mathrm{H},-4.9056896052,-1.6576122802,-0.7186571898 \backslash \mathrm{H},-5.2943767745,-0.1$ $573463495,-3.1914066844 \backslash \mathrm{H},-3.9425863053,-1.1941657352,-2.782312124 \backslash \mathrm{C},-$ $4.5243339663,2.0888903602,-1.8794806272 \backslash \mathrm{H},-3.1308777177,1.1173375237$, $3.2409996371 \backslash \mathrm{C},-5.2034221204,1.7761539712,-0.5206687096 \backslash \mathrm{H},-5.271772895$ $8,2.2651066229,-2.6546626853 \backslash H,-3.9190957388,2.9925035968,-1.810888734$ $8 \backslash \mathrm{H},-5.1780702809,0.1643718586,0.9513524222 \backslash \mathrm{H},-6.290000767,1.776469849$ $2,-0.6208172856 \backslash \mathrm{H},-4.9536177499,2.5363725969,0.2195592454 \backslash \mathrm{C}, 0.82031090$ $7,-1.2798944504,1.73017667 \backslash \mathrm{C}, 1.4993979654,-0.967159433,0.3713642252 \backslash \mathrm{H}$, $0.2150745362,-2.1835091335,1.661586697 \backslash H, 1.5677499839,-1.4561077084,2$. $5053592583 \backslash \mathrm{H}, 1.2495935427,-1.7273792301,-0.3688626065 \backslash \mathrm{H}, 2.5859767125$, $0.9674744647,0.4715115567 \backslash \mathrm{C}, 0.8293527541,1.1563390569,2.2835042113 \backslash \mathrm{H},-$ $\odot .5731470482,-0.3083423275,3.0916941722 \backslash \mathrm{C}, 1.4834879168,1.4716317818,0$. $9130428786 \backslash \mathrm{H}, 1.4740449013,0.6446209053,-1.1006586864 \backslash \mathrm{H}, 1.2016636004,2$. $4666068699,0.5693488154 \backslash H, 2.5717715513,1.4588001234,0.9911469388 \backslash \mathrm{H}, 1.5$ $903499882,0.9663455132,3.0421005382 \backslash \mathrm{H}, 0.238557902,2.0031619258,2.63300$ $31316 \backslash \backslash$ Vers i on $=$ EM64L - GO9RevD . $01 \backslash \mathrm{HF}=-927.6833146 \backslash \mathrm{RMSD}=6.786 \mathrm{e}-09 \backslash \mathrm{RMSF}=8$. $299 \mathrm{e}-07 \backslash \mathrm{D}$ i pole $=0.0000048,-0.00000003,0.0000025 \backslash$ Quadrupole $=2.2782251,-5$. $0418543,2.7636293,-3.5907464,0.7027644,5.9570038 \backslash P G=C \odot 1 \quad[X(C 20 H 2602)] \backslash$ \@

\footnotetext{
${ }^{\mathrm{M}} \mathrm{HE}$
}

$1 \backslash 1 \backslash G I N C-H P C-C N 85 \backslash F 0 p t \backslash R B L Y P \backslash 6-31 G(d) \backslash C 19 H 2402 \backslash T A L I P O V M \backslash 14-J a n-2015 \backslash 0 \backslash$ $\backslash \# P$ BLYP IOP $(3 / 76=0600004000) / 6-31 \mathrm{G}(\mathrm{d})$ Opt (tight) SCRF (PCM, solvent=Dic hloromethane) nosym scf(fermi, xqc, maxcyc $=200$ ) int (grid=ultrafine) $\backslash \backslash T i t$ $\mathrm{le} \backslash \backslash \Theta, 1 \backslash \mathrm{C}, 0.0290133067,-0.0229661184,2.4489218843 \backslash \mathrm{C},-0.929110193,0.062$ $9513089,1.2891189521 \backslash \mathrm{C},-2.3216633869,0.1312552531,1.3749733525 \backslash 0,-2.94$ 
$66672399,0.1109454986,2.6030534437 \backslash \mathrm{C},-3.0547652385,0.1494898122,0.1995$ $526681 \backslash \mathrm{C},-4.5411798382,0.2153305005,-0.0758630246 \backslash \mathrm{C},-2.4174964421,0.12$ $16077872,-1.0457772421 \backslash \mathrm{C},-3.509263918,0.1697296047,-2.0923501324 \backslash \mathrm{C},-1$. $0358793881,0.0754062624,-1.1376128145 \backslash 0,-0.406519318,0.0006026438,-2.3$ $613895396 \backslash \mathrm{C},-0.2919211358,0.0353237836,0.0439930441 \backslash \mathrm{C}, 1.2074269352,-\Theta$. $0740090296,0.1465330049 \backslash \mathrm{C},-0.1540216862,1.2571843834,-2.969656076 \backslash \mathrm{C},-3$ $.2731377835,1.3921511738,3.1174716664 \backslash \mathrm{H},-1.0821964726,1.79713608,-3.16$ $44480359 \backslash \mathrm{H}, 0.3473806521,1.0545882237,-3.9124193021 \backslash \mathrm{H}, 0.4910242114,1.87$ $60940074,-2.3431114898 \backslash \mathrm{H},-2.3785783434,2.0036764722,3.2495737315 \backslash \mathrm{H},-3$. $745075672,1.2317599404,4.0832811087 \backslash \mathrm{H},-3.9678495825,1.9182128501,2.460$ $4836218 \backslash \mathrm{C},-4.6096747967,-0.6347205302,-1.3644659638 \backslash \mathrm{C},-4.1293690107,1$. $5959663739,-2.0440109484 \backslash \mathrm{C},-4.8382991628,1.6274240816,-0.6579855424 \backslash \mathrm{H}$, $-4.8466307402,1.7207258877,-2.8552052464 \backslash \mathrm{H},-3.3754823423,2.3743225791$, $-2.1481991539 \backslash \mathrm{H},-5.1839160799,-0.0775580502,0.7492885415 \backslash \mathrm{H},-5.91334093$ $27,1.7685257224,-0.7695061764 \backslash \mathrm{H},-4.4666797295,2.4224935185,-0.01394705$ $76 \backslash \mathrm{C}, 0.8348231196,-1.3338163636,2.3082550569 \backslash \mathrm{C}, 1.5410777438,-1.3644448$ $692,0.9280596608 \backslash \mathrm{H}, 0.1665167589,-2.1871893088,2.4204401146 \backslash \mathrm{H}, 1.5637090$ $576,-1.3922073097,3.1182695044 \backslash H, 1.2254400451,-2.2329836231,0.35058063$ $54 \backslash \mathrm{H}, 2.6232207381,-1.4383677204,1.0476591534 \backslash \mathrm{C}, 1.0200486168,1.15743537$ $23,2.3480052032 \backslash \mathrm{H},-0.5011223431,-0.0019048365,3.3982951781 \backslash \mathrm{C}, 1.7264004$ $715,1.1269611354,0.9675121893 \backslash \mathrm{H}, 1.6678728333,-0.0958823805,-0.83848523$ $16 \backslash H, 1.5449785255,2.0521810506,0.4203450291 \backslash H, 2.8072068796,1.036171449$ $6,1.086958889 \backslash \mathrm{H}, 1.7477407507,1.0815548995,3.157559898 \backslash \mathrm{H}, 0.4872562845,2$ $.0980128402,2.4885155137 \backslash H,-3.2216624153,-0.164445341,-3.0850081914 \backslash H$, $-5.579247377,-0.5808935259,-1.8618757397 \backslash \mathrm{H},-4.3413163616,-1.6778214897$ ,$-1.203504137 \backslash \backslash$ Vers i on $=E M 64 L-G 09 R e v D .01 \backslash H F=-888.3803292 \backslash R M S D=7.843 e-09$ $\backslash$ RMSF $=6.030 \mathrm{e}-07 \backslash \mathrm{D}$ i pol $\mathrm{e}=-0.0791962,1.1998422,-0.067043 \backslash \mathrm{Quad}$ rupole $=2.541$ $1003,-2.2410863,-0.300014,-4.3675341,1.7995449,0.0107811 \backslash P G=C 01$ [X(C19 H2402)] \\@

\section{THE}

$1 \backslash 1 \backslash G I N C-H P C-C N 116 \backslash F 0 p t \backslash R B L Y P \backslash 6-31 G(d) \backslash C 18 H 2202 \backslash T A L I P O V M \backslash 14-J a n-2015 \backslash 0$ $\backslash \backslash \# P$ BLYP IOP $(3 / 76=0600004000) / 6-31 \mathrm{G}(\mathrm{d})$ 0pt (tight) SCRF (PCM, solvent=Di chloromethane) nosym scf(fermi, $x q c$, maxcyc $=200)$ int (grid=ultrafine) $\backslash \backslash \mathrm{Ti}$ t le $\backslash \backslash \odot, 1 \backslash C, 0.0088725353,0.0466416258,2.1545700439 \backslash \mathrm{C},-1.1251231504,0.22$ $38832401,1.1683072426 \backslash \mathrm{C},-2.5027820006,0.1078816648,1.3071469695 \backslash 0,-3.0$ $701194813,-0.1933967561,2.5253154493 \backslash \mathrm{C},-3.2767176772,0.2661707805,0.16$ $35436672 \backslash \mathrm{C},-4.7740292318,0.2808518838,-0.0548058369 \backslash \mathrm{C},-2.6887369768,0$. $5218090524,-1.0807296724 \backslash \mathrm{C},-3.8227325106,0.6990510147,-2.0669923473 \backslash \mathrm{C}$, $-1.3110783784,0.6378113598,-1.2195694174 \backslash 0,-0.7437453667,0.9390921682$, $-2.4377392318 \backslash \mathrm{C},-0.5371424296,0.479521849,-0.0759659448 \backslash \mathrm{C}, 0.9601692207$ $, 0.4648409094,0.142383824 \backslash C,-0.3601824359,-0.1930151139,-3.2028600173 \backslash$ C, $-3.453629582,0.938714043,3.2904576089 \backslash \mathrm{H}, 0.4009275472,-0.7807278459$, $2.6867646514 \backslash \mathrm{H}, 0.0496440447,0.1834378081,-4.136400988 \backslash \mathrm{H},-1.2178523683$, $-0.8333406499,-3.4164323315 \backslash H,-2.5959315472,1.5789994461,3.5040370701 \backslash$ $\mathrm{H},-3.8634679966,0.5622629533,4.2239940824 \backslash \mathrm{H},-4.2147165883,1.5264680923$ $, 2.7743751329 \backslash \mathrm{C},-4.8431239023,-0.3028064097,-1.4833677454 \backslash \mathrm{C},-4.5193835$ $111,2.0459710883,-1.7191820883 \backslash \mathrm{C},-5.1770505385,1.7576229967,-0.3377804$ $292 \backslash \mathrm{H},-5.2722955693,2.284317825,-2.47054134 \backslash \mathrm{H},-3.811502157,2.871961779$ $9,-1.6869708702 \backslash H,-5.3652400711,-0.2093131717,0.7134077506 \backslash H,-6.262131$ $0611,1.8458119467,-0.392801394 \backslash H,-4.8305327358,2.4330682215,0.44239408$ $5 \backslash \mathrm{C}, 0.7055240191,-1.3002782159,1.8067601052 \backslash \mathrm{C}, 1.3631912851,-1.01193001$ $56,0.4253586533 \backslash \mathrm{H},-0.0023571364,-2.126269046,1.7745486689 \backslash \mathrm{H}, 1.45843587$ $43,-1.5386247525,2.5581196243 \backslash \mathrm{H}, 1.0166742752,-1.6873759213,-0.35481559$ $41 \backslash H, 2.4482718447,-1.1001182091,0.4803800546 \backslash C, 1.029263645,1.048499370$ $8,1.5709456603 \backslash \mathrm{H},-0.2549872543,0.1558624188,3.2024207095 \backslash \mathrm{H},-3.55887210$ $31,0.5898299612,-3.1148428214 \backslash \mathrm{H},-5.833279811,-0.2168490138,-1.93332769$ 
$92 \backslash H,-4.5076145212,-1.3375563465,-1.5389034043 \backslash H, 1.5513802511,0.955006$ $5168,-0.6258293501 \backslash H, 2.0194196026,0.9625422629,2.0209055592 \backslash H, 0.693753$ $9488,2.0832491882,1.6264812131 \backslash \backslash$ Vers i on $=E M 64 L-G 09 R e v D .01 \backslash H F=-849.07743$ $78 \backslash \mathrm{RMSD}=8.219 \mathrm{e}-09 \backslash \mathrm{RMSF}=1.074 \mathrm{e}-06 \backslash \mathrm{D}$ i pol $\mathrm{e}=0.0000293,0.0000009,0.000011 \backslash \mathrm{Q}$ uadrupole $=3.2600465,-5.2535663,1.9935198,-3.6386951,0.5262484,6.209564$ $2 \backslash P G=C O 1[X(C 18 H 2202)] \backslash \backslash @$

\section{$\mathrm{HE}^{+\bullet}$}

$1 \backslash 1 \backslash G I N C-H P C-C N 37 \backslash S$ tabil i ty $\backslash U B L Y P \backslash 6-31 G(d) \backslash C 8 H 1002(1+, 2) \backslash T A L I P O V M \backslash 14-J$ an-2015 $\backslash \backslash \backslash \# P$ BLYP IOP $(3 / 76=0600004000) / 6-31 G(d)$ stable (opt) pop (nbo) scrf(check) guess(read) geom(allcheck) nosym scf(fermi, xqc, maxcyc $=200$ ) int (grid=ultrafine) $\backslash \backslash T$ t t le $\backslash \backslash 1,2 \backslash C, 0,-0.9600118859,0.1072718024,0.9686$ $719418 \backslash \mathrm{C}, 0,-2.372692518,0.0570646795,1.1041859742 \backslash 0,0,-3.0025320204,-0$ $.224179705,2.2137097199 \backslash \mathrm{C}, 0,-3.2117734287,0.3232031477,-0.0189940462 \backslash \mathrm{C}$ $, 0,-2.6743658871,0.6269971342,-1.2314419019 \backslash \mathrm{C}, 0,-1.2616856614,0.677221$ $5554,-1.3669518125 \backslash 0,0,-0.6318483553,0.9585014323,-2.476467369 \backslash \mathrm{C}, 0,-\Theta$. $4226044407,0.411066348,-0.2437760286 \backslash C, 0,-1.3456297716,1.2468573492,-3$ $.6911928049 \backslash \mathrm{C}, 0,-2.2887549054,-0.5125090332,3.4284439221 \backslash \mathrm{H}, 0,-1.939571$ $1896,0.3860076127,-3.9848311337 \backslash H, 0,-0.5779860558,1.4427624644,-4.4281$ $459035 \backslash H, 0,-1.9712505921,2.1246035271,-3.5552237094 \backslash H, 0,-1.663116876$, $1.390245263,3.2924919023 \backslash \mathrm{H}, 0,-3.0564005476,-0.7084218554,4.16539289 \backslash \mathrm{H}$, $\odot,-1.6948310457,0.3483554456,3.7220749399 \backslash H, 0,-\odot .3188116853,-0.0919534$ $077,1.810554235 \backslash \mathrm{H}, 0,-4.2792477628,0.274990636,0.1275303368 \backslash \mathrm{H}, 0,-3.3155$ $653828,0.8262067891,-2.0733283684 \backslash \mathrm{H}, 0,0.6448700121,0.4592693409,-0.390$ $3027838 \backslash \backslash$ Version=EM64L - GO9RevD $.01 \backslash \mathrm{HF}=-460.8399693 \backslash \mathrm{S} 2=0.764304 \backslash \mathrm{S} 2-1=0 . \backslash$ $S 2 A=0.750062 \backslash R M S D=2.084 e-09 \backslash D$ i pol $e=-0.00000007,-0.000002,0.00000008 \backslash \mathrm{Quad}$ rupole $=0.9112031,-14.7414726,13.8302695,-2.5886603,1.9584722,-7.721445$ $8 \backslash P G=C \odot 1[X(C 8 H 1002)] \backslash \backslash @$

$$
{ }^{\mathrm{Me} 2} \mathrm{HE}^{+\bullet}
$$

$1 \backslash 1 \backslash G I N C-H P C-C N 29 \backslash S t a b i l$ i ty $\backslash U B L Y P \backslash 6-31 G(d) \backslash C 10 H 1402(1+, 2) \backslash T A L I P O V M \backslash 14-$

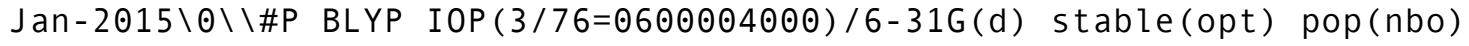
scrf(check) guess(read) geom(allcheck) nosym scf(fermi, xqc, maxcyc $=200$

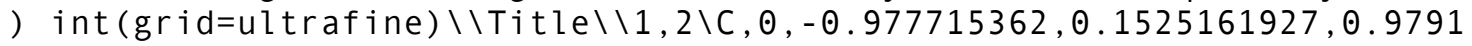
$243189 \backslash \mathrm{C}, 0,-2.3820118427,0.0978939489,1.1019601623 \backslash 0,0,-3.0103634721$, $0.1646651946,2.2214405165 \backslash \mathrm{C}, 0,-3.2418941942,0.3344011465,-0.0294081968$ $\backslash C, 0,-2.6568057057,0.6157940836,-1.2332835075 \backslash \mathrm{C}, 0,-1.2525124555,0.6704$ $081445,-1.3561218546 \backslash 0,0,-0.6241595522,0.9329614248,-2.4756026027 \backslash \mathrm{C}, 0$, $-0.3926269327,0.4339092175,-0.2247489528 \backslash C, 0,-1.3410217572,1.185440891$ $1,-3.693587271 \backslash \mathrm{C}, 0,-2.2935034382,-0.4171472625,3.4394262371 \backslash \mathrm{H}, 0,-1.935$ $5298212,0.316670767,-3.9628026814 \backslash \mathrm{H}, 0,-0.5768929548,1.3629417948,-4.43$ $91973221 \backslash \mathrm{H}, 0,-1.9692958011,2.0649082371,-3.5814483725 \backslash \mathrm{H}, 0,-1.665218040$ $3,-1.2966058086,3.3272823306 \backslash H, 0,-3.0576348582,-0.5946666129,4.1850289$ $745 \backslash H, 0,-1.6990088596,0.4516275534,3.7086555944 \backslash H, 0,-0.3552268238,-0.0$ $298498723,1.839016193 \backslash \mathrm{C}, 0,-4.7246526309,0.2653087322,0.1476733475 \backslash \mathrm{H}, 0$, $-3.2792956954,0.7981660825,-2.0931730738 \backslash \mathrm{C}, 0,1.0901292788,0.5030062086$ $,-0.4018367466 \backslash H, 0,-5.0229973571,-0.7190020988,0.5087503812 \backslash H, 0,-5.233$ $6208074,0.4649937535,-0.7909629045 \backslash H, 0,-5.0572879199,0.9899269252,0.89$ $09729852 \backslash H, 0,1.5991034024,0.3033391064,0.5368001246 \backslash H, 0,1.3884668001,1$ $.4873132477,-0.7629304462 \backslash H, 0,1.4227668009,-0.2216206087,-1.1451272334$ $\backslash \backslash$ Vers i on $=E M 64 L-G 09 R e v D .01 \backslash H F=-539.4298121 \backslash S 2=0.767035 \backslash S 2-1=0 . \backslash S 2 A=0.7$ $50118 \backslash$ RMSD $=4.982$ e $-09 \backslash \mathrm{D}$ i pole $=-0.00000041,-0.0000012,0.0000048 \backslash$ Quadrupole $=4.0366625,-15.6138484,11.5771859,-2.373478,1.0763964,-6.6285728 \backslash P G=C \Theta$ $1[\mathrm{X}(\mathrm{C} 10 \mathrm{H} 1402)] \backslash \backslash @$ 
${ }^{\mathrm{Me} 4} \mathrm{HE}^{+\bullet}$

$1 \backslash 1 \backslash G I N C-H P C-C N 42 \backslash S t a b i l$ ity $\backslash U B L Y P \backslash 6-31 G(d) \backslash C 12 H 1802(1+, 2) \backslash T A L I P O V M \backslash 14-$

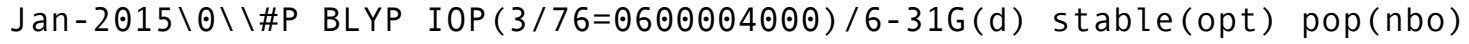
scrf(check) guess(read) geom(allcheck) nosym scf(fermi,xqc, maxcyc $=200$ ) int (grid=ultrafine) $\backslash \backslash T i t l e \backslash \backslash 1,2 \backslash C, 0,-0.0849580233,-0.0035625809,2.20$ $84581649 \backslash \mathrm{C}, \odot,-\odot .9206585891,0.2194766543,0.9801599594 \backslash \mathrm{C}, \odot,-2.3350650807$ $, 0.4189635136,1.1509094458 \backslash 0,0,-2.7049987605,0.4202277218,2.4149597962$ $\backslash \mathrm{C}, 0,-3.2232308588,0.594805542,0.047523193 \backslash \mathrm{C}, 0,-4.7208366026,0.5437703$ $261,0.2190427938 \backslash C, 0,-2.6679772298,0.7017563008,-1.2050734678 \backslash C, 0,-3.5$ $036761763,0.9248064287,-2.4333706634 \backslash C, 0,-1.2535740165,0.5022604679,-1$ $.3758234185 \backslash 0, \odot,-\odot .8836410912, \odot .5009816618,-2.6398739847 \backslash C, 0,-\odot .365406$ $1721,0.3264258748,-0.272436378 \backslash \mathrm{C}, 0,1.1321987922,0.3774693519,-0.443961$ $7555 \backslash H, 0,1.588200134,0.8460153162,0.4231706207 \backslash H, 0,1.4097966407,0.9734$ $553897,-1.3067824122 \backslash \mathrm{H}, 0,1.5765809855,-0.6122287263,-0.5545769804 \backslash \mathrm{H}, 0$, $-0.6423738866,-\Theta .5546958156,2.9589403696 \backslash H, \odot, 0.2086874632,0.9482692596$ $, 2.6568166524 \backslash \mathrm{H}, \odot, 0.8181592963,-0.5574562653,1.9724414312 \backslash \mathrm{H}, 0,-4.99844$ $29423,-0.052214113,1.0818614174 \backslash H, 0,-5.1768373362,0.0752273001,-0.6480$ $916168 \backslash \mathrm{H}, 0,-5.1652122481,1.5334715905,0.3296564623 \backslash \mathrm{H}, 0,-4.4067834156,1$ $.4787162482,-2.1973533046 \backslash H, 0,-3.7973391415,-0.0270208848,-2.881727263$ $3 \backslash \mathrm{H}, \odot,-2.9462517587,1.475928403,-3.1838549856 \backslash \mathrm{C}, \odot, 0.2001637785,-0.2637$ $105825,-3.1955945451 \backslash \mathrm{C}, 0,-3.788808431,1.184906004,2.9706914217 \backslash \mathrm{H}, \odot, 0.4$ $505795726,-1.1022792402,-2.5566058952 \backslash H, 0,1.0604089894,0.3774700567,-3$ $.3530146696 \backslash \mathrm{H}, 0,-0.1707653565,-0.6203743905,-4.1500243531 \backslash \mathrm{H}, 0,-3.41787$ $81265,1.5415614522,3.925123862 \backslash H, 0,-4.649048711,0.5437178493,3.1281076$ $517 \backslash \mathrm{H}, 0,-4.0392316976,2.0234798858,2.3317124517 \backslash \backslash$ Vers ion=EM64L - GO9RevD $.01 \backslash \mathrm{HF}=-617.9830631 \backslash S 2=0.766341 \backslash S 2-1=0 . \backslash S 2 \mathrm{~A}=0.750077 \backslash \mathrm{RMSD}=7.221 \mathrm{e}-09 \backslash \mathrm{Di}$ pole $=-0.0000099,-0.0000022,0.0000099 \backslash Q u a d r u p o l e=13.8005044,-16.0302393$ $, 2.229735,-7.4319595,-8.7218648,4.9661823 \backslash \mathrm{PG}=\mathrm{C} 01[\mathrm{X}(\mathrm{C} 12 \mathrm{H} 1802)] \backslash \backslash @$

\section{${ }^{\mathrm{B}} \mathrm{HE}^{+\bullet}$}

$1 \backslash 1 \backslash G I N C-H P C-C N 109 \backslash S t a b i l$ i ty $\backslash U B L Y P \backslash 6-31 G(d) \backslash C 20 H 2602(1+, 2) \backslash T A L I P O V M \backslash 14$

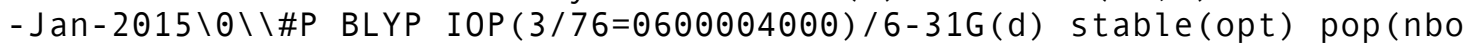
) $\operatorname{scrf}($ check) guess (read) geom(allcheck) nosym scf(fermi, xqc, maxcyc $=20$ $0)$ int (grid=ultrafine) $\backslash \backslash T i t l e \backslash \backslash 1,2 \backslash C, 0,0.2441046913,0.0445017393,2.225$ $6969288 \backslash \mathrm{C}, 0,-0.8239377481,0.1490068945,1.1550767891 \backslash \mathrm{C}, 0,-2.2384522041$, $0.208210409,1.2751055572 \backslash 0,0,-2.964463216,0.1303071475,2.3693988704 \backslash \mathrm{C}$, $\odot,-3.0470262474,0.3659078607,0.0963018317 \backslash \mathrm{C}, \odot,-4.5475243546,0.43430349$ $41,0.1425446993 \backslash \mathrm{C}, 0,-2.5091215667,0.4389142943,-1.1706752877 \backslash \mathrm{C}, 0,-3.57$ $71643652,0.5434167134,-2.2412956117 \backslash C, 0,-1.094606908,0.3797118882,-1.2$ $907039839 \backslash 0,0,-0.3685961057,0.4576151324,-2.3849976442 \backslash \mathrm{C}, 0,-0.28603286$ $36,0.2220149362,-0.1119004208 \backslash C, 0,1.2144652295,0.1536175849,-0.1581432$ $\odot 03 \backslash \mathrm{C}, \odot,-\odot .8230098387,0.755718807,-3.7082684055 \backslash \mathrm{C}, \odot,-2.5100520854,-\odot .1$ $67793673,3.6926710773 \backslash \mathrm{H}, \odot,-1.3978657699,-\odot .0739076702,-4.107509345 \backslash \mathrm{H}, 0$ $, 0.0853329934,0.8823035808,-4.2850597086 \backslash H, \odot,-1.3975665801,1.676483742$ $4,-3.7176019719 \backslash \mathrm{H}, 0,-3.4183962412,-0.2943704503,4.2694620486 \backslash \mathrm{H}, 0,-1.93$ $51912775,0.6618308815,4.091909111 \backslash \mathrm{H}, 0,-1.9355009822,-1.0885621205,3.70$ $20090898 \backslash \mathrm{C}, \odot,-5.1001822456,-\odot .7448395705,-\odot .6902316493 \backslash \mathrm{C}, 0,-4.50254396$ $69,-0.6888746648,-2.1127948966 \backslash H, 0,-6.1868432258,-0.6662368137,-0.7162$ $879961 \backslash \mathrm{H}, 0,-4.8596617114,-1.6870590144,-0.2001679973 \backslash \mathrm{H}, 0,-5.2871376111$ $,-0.6054377927,-2.8644077559 \backslash \mathrm{H}, 0,-3.9399242273,-1.5938696501,-2.337526$ $8731 \backslash \mathrm{C}, 0,-4.4134166882,1.8137099011,-1.9663667316 \backslash \mathrm{H}, 0,-3.1767890358,0$. $581017206,-3.2427436244 \backslash \mathrm{C}, 0,-4.9808135858,1.7564210465,-0.5307126955 \backslash \mathrm{H}$ $, 0,-5.2151180988,1.8607141809,-2.7029023195 \backslash H, 0,-3.7972412007,2.700516$ $8269,-2.1087033396 \backslash \mathrm{H}, 0,-4.9137143241,0.3872828405,1.1613527002 \backslash \mathrm{H}, 0,-6$. $0697114183,1.7976688669,-0.5368916891 \backslash \mathrm{H}, 0,-4.632371327,2.6007259998,0$. 
$0622242082 \backslash \mathrm{C}, \odot, 1.0803563823,-1.2257915749,1.9507661863 \backslash \mathrm{C}, \odot, 1.647750487$ , - $1.1685030682,0.5151109957 \backslash H, 0,0.4641812738,-2.1125985188,2.093104358$ $2 \backslash H, 0,1.8820592477,-1.2727952923,2.6873002794 \backslash H, 0,1.299302628,-2.01280$ $52898,-0.0778265767 \backslash \mathrm{H}, 0,2.7366480992,-1.2097563409,0.5212875214 \backslash \mathrm{C}, 0,1$. $1694851258,1.2767925706,2.0971983142 \backslash H, 0,-0.156270822,0.0068992913,3.2$ $27144722 \backslash \mathrm{C}, 0,1.7671262246,1.3327568396,0.6746361799 \backslash \mathrm{H}, 0,1.5806554408,0$ $.2006401611,-1.1769510327 \backslash \mathrm{H}, 0,1.5266113958,2.2749782967,0.1845736105 \backslash \mathrm{H}$ $, 0,2.8537867633,1.2541485474,0.7006943747 \backslash \mathrm{H}, 0,1.9540771695,1.193356251$ $2,2.8488128638 \backslash \mathrm{H}, 0,0.6068646912,2.1817875721,2.3219284392 \backslash \backslash$ Version=EM6 $4 L-G \odot 9 R e v D .01 \backslash H F=-927.4849703 \backslash S 2=0.766765 \backslash S 2-1=0 . \backslash S 2 A=0.7501 \backslash R M S D=2.36$ $5 e-09 \backslash$ D i pole $=0.0000001,0.000001,0.0000006 \backslash$ Quadrupole $=5.2893925,-17.924$ $6796,12.6352871,-2.0817694,1.8779858,-4.3287853 \backslash P G=C 01 \quad[X(C 20 H 2602)] \backslash \backslash$ @

\section{${ }^{\mathrm{M}} \mathrm{HE}^{+\bullet}$}

$1 \backslash 1 \backslash G I N C-H P C-C N 28 \backslash S t a b i l$ ity $\backslash U B L Y P \backslash 6-31 G(d) \backslash C 19 H 2402(1+, 2) \backslash T A L I P O V M \backslash 14-$

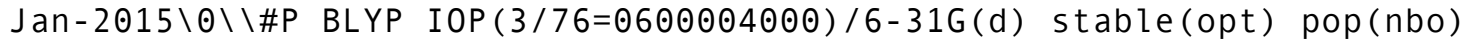
scrf(check) guess(read) geom(allcheck) nosym scf(fermi,xqc, maxcyc $=200$ ) int (grid=ultrafine) $\backslash \backslash T$ Ttle $\backslash \backslash 1,2 \backslash C, 0,0.1394889975,0.1682241254,2.2966$ $088119 \backslash \mathrm{C}, 0,-0.8762243147,0.2428307738,1.1912107954 \backslash \mathrm{C}, 0,-2.2908492311,0$ $.3539989103,1.3750806255 \backslash 0,0,-2.6593367531,0.432963922,2.6330147434 \backslash C$, $\odot,-3.131570054,0.3536092537,0.2275795997 \backslash \mathrm{C}, 0,-4.6373437003,0.451105923$ $9,0.0482615081 \backslash \mathrm{C}, 0,-2.58244012,0.324874684,-1.0447401919 \backslash \mathrm{C}, 0,-3.743559$ $1863,0.3996101426,-2.0218899625 \backslash C, 0,-1.1712924624,0.3011553308,-1.2201$ $781724 \backslash 0,0,-0.5098057313,0.3370542794,-2.3541590345 \backslash \mathrm{C}, 0,-0.3355041774$, $0.2165417902,-0.0622678911 \backslash C, 0,1.1642216564,0.1183860176,-0.0796729026$ $\backslash \mathrm{C}, 0,-1.1007862342,0.5017161653,-3.6482589263 \backslash \mathrm{C}, 0,-4.0058455245,0.6009$ $156762,3.0906293588 \backslash \mathrm{H}, 0,-1.6260370171,-0.4037973888,-3.9357454583 \backslash \mathrm{H}, 0$, $-0.2637358655,0.6692305261,-4.3148158312 \backslash H, 0,-1.7635592176,1.360794284$ $,-3.660436042 \backslash \mathrm{H}, 0,-4.4679768293,1.4603234446,2.6157094815 \backslash \mathrm{H}, 0,-3.91560$ $92094,0.770701652,4.1564451433 \backslash H, 0,-4.5767203059,-0.3042159167,2.90810$ $85781 \backslash \mathrm{C}, 0,-4.8047342495,-0.3832223919,-1.231921725 \backslash \mathrm{C}, 0,-4.3117083962,1$ $.8477479464,-1.9211014176 \backslash \mathrm{C}, 0,-4.9263146798,1.8835067082,-0.4958408048$ $\backslash H, \odot,-5.0741993945,1.990034037,-2.6847116982 \backslash H, 0,-3.5457614195,2.60544$ $39169,-2.0718143946 \backslash H, \odot,-5.2497676458,0.1576845628,0.8883079084 \backslash H, \odot,-6$ $.0022949963,2.0438315288,-0.533181932 \backslash \mathrm{H}, 0,-4.496500851,2.6610753954,0$. $1316862507 \backslash \mathrm{C}, 0,0.9449787394,-1.1386144611,2.104632542 \backslash \mathrm{C}, 0,1.5570903721$ $,-1.168883477,0.6832028306 \backslash \mathrm{H}, 0,0.2958907814,-1.9978201071,2.2674550407$ $\backslash \mathrm{H}, 0,1.723329407,-1.1777707715,2.8663557788 \backslash \mathrm{H}, 0,1.2148860373,-2.042510$ $3358,0.1302279865 \backslash \mathrm{H}, 0,2.6445642931,-1.2245933086,0.7269175695 \backslash \mathrm{C}, 0,1.11$ $0225908,1.3607512106,2.1234787917 \backslash \mathrm{H}, 0,-0.3307386146,0.1922404211,3.274$ $2696568 \backslash \mathrm{C}, 0,1.7237661316,1.3304439767,0.7027992106 \backslash \mathrm{H}, 0,1.5520349842,0$. $1007558829,-1.0929822925 \backslash \mathrm{H}, \Theta, 1.5025298773,2.2501458793,0.1629713247 \backslash \mathrm{H}$, $\odot, 2.8088595373,1.2396014757,0.7475286938 \backslash H, 0,1.8856015474,1.2864577291$ $, 2.8856656738 \backslash H, 0,0.5788386479,2.2951155084,2.2987494619 \backslash H, 0,-3.556553$ $3588,0.0588943081,-3.0298844489 \backslash H, 0,-5.8004017259,-0.2962347441,-1.664$ $1230248 \backslash \mathrm{H}, 0,-4.554205652,-1.4337744865,-1.0975412149 \backslash \backslash$ Vers i on=EM64L $-\mathrm{G} \odot$ $9 R e v D .01 \backslash H F=-888.1890296 \backslash S 2=0.765231 \backslash S 2-1=0 . \backslash S 2 A=0.75006 \backslash R M S D=3.506 \mathrm{e}-\Theta$ $9 \backslash \mathrm{Dipole}=-1.5449486,0.1501331,-0.6597614 \backslash \mathrm{Quadrupol} e=17.9882383,-20.837$ $2442,2.8490059,-6.0030822,-1.2288276,-0.7538861 \backslash P G=C 01 \quad[X(C 19 H 2402)] \backslash \backslash$ @

\section{${ }^{\mathrm{T}} \mathrm{HE}^{+\bullet}$}

$1 \backslash 1 \backslash G I N C-H P C-C N 21 \backslash S t a b i l$ ity $\backslash U B L Y P \backslash 6-31 G(d) \backslash C 18 H 2202(1+, 2) \backslash T A L I P O V M \backslash 14-$

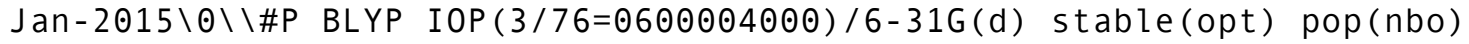
scrf(check) guess (read) geom(allcheck) nosym scf(fermi, xqc, maxcyc $=200$ ) int (grid=ultrafine) $\backslash \backslash T i t l e \backslash \backslash 1,2 \backslash C, 0,0.1625527462,0.1851660005,2.0125$ 
$570598 \backslash \mathrm{C}, \odot,-\odot .9961546651, \odot .3354622271,1.0652103939 \backslash \mathrm{C}, \odot,-2.3894723058, \odot$ $.4134606366,1.3821832331 \backslash 0,0,-2.6394372643,0.440178029,2.6714440389 \backslash C$, $\odot,-3.3102350763,0.4470393222,0.3088215049 \backslash \mathrm{C}, 0,-4.8163579758,0.63518467$ $69,0.1737179526 \backslash \mathrm{C}, 0,-2.817695698,0.410238724,-0.9776287214 \backslash \mathrm{C}, 0,-3.9764$ $023054,0.5605428154,-1.9249752246 \backslash \mathrm{C}, 0,-1.4243780121,0.3322324514,-1.29$ $46015566 \backslash 0,0,-1.1744145317,0.3054999908,-2.5838625235 \backslash \mathrm{C}, 0,-0.503615255$ $9,0.2986593625,-0.2212398146 \backslash C, 0,1.0025084251,0.1105206238,-0.08613600$ $06 \backslash \mathrm{C}, 0,0.149526785,0.2496576152,-3.1279034953 \backslash \mathrm{C}, 0,-3.9633805974,0.4959$ $927574,3.2154827366 \backslash \mathrm{H}, 0,0.6989870357,1.1478490568,-2.8622025199 \backslash \mathrm{H}, 0,0$. $009266068,0.2037376901,-4.2006074296 \backslash \mathrm{H}, 0,0.664413915,-0.6408408587,-2$. $7808955078 \backslash \mathrm{H}, \Theta,-4.4782767973,1.3864937511,2.8684948352 \backslash \mathrm{H}, 0,-3.82312365$ $64,0.5418883206,4.2881882009 \backslash \mathrm{H}, 0,-4.5128298383,-0.4021985476,2.9497577$ $945 \backslash \mathrm{C}, 0,-5.0681317829,-0.1678009699,-1.1178778764 \backslash \mathrm{C}, 0,-4.450483756,2.0$ $410374056,-1.7832585873 \backslash \mathrm{C}, 0,-5.0309356912,2.0895747315,-0.3433428338 \backslash \mathrm{H}$ $, 0,-5.2176261202,2.2445514891,-2.5282696071 \backslash \mathrm{H}, 0,-3.6392024231,2.748056$ $2125,-1.941070362 \backslash H, 0,-5.4236312172,0.368825991,1.0277878374 \backslash H, 0,-6.09$ $54357002,2.31696855,-0.3541117475 \backslash \mathrm{H}, \Theta,-4.5405638534,2.8279719453,0.287$ $2563764 \backslash C, 0,0.6366412881,-1.2953267019,1.8708457459 \backslash \mathrm{C}, 0,1.2170932119$, $1.3438664734,0.4309301108 \backslash \mathrm{H}, 0,-0.1746365471,-2.0023488928,2.0286602556$ $\backslash \mathrm{H}, \Theta, 1.4037848035,-1.4988343689,2.6158573401 \backslash \mathrm{H}, 0,0.7267246469,-2.08226$ $83148,-0.1996661904 \backslash \mathrm{H}, 0,2.2815942887,-1.5712552165,0.441699577 \backslash \mathrm{C}, 0,1.2$ $542787039,0.9135121705,1.2054568902 \backslash H, 0,-0.0206070852,0.5087701335,3.0$ $304028813 \backslash H, 0,-3.7932436219,0.2369414948,-2.9428221562 \backslash H, 0,-6.06779206$ $83,-0.013136234,-1.5212316167 \backslash \mathrm{H}, 0,-4.8809117899,-1.2340035971,-1.00410$ $82881 \backslash H, 0,1.6097802276,0.376878894,-\odot .9402070999 \backslash H, 0,2.2539398296,0.75$ $88536089,1.6088109406 \backslash \mathrm{H}, 0,1.0670536614,1.9797134973,1.0916834535 \backslash \backslash V e r s$ ion $=E M 64 \mathrm{~L}-\mathrm{G} 09 \mathrm{ReVD} .01 \backslash \mathrm{HF}=-848.8877312 \backslash \mathrm{S} 2=0.767644 \backslash \mathrm{S} 2-1=0 . \backslash \mathrm{S} 2 \mathrm{~A}=0.750121 \backslash$ RMSD $=3.734 \mathrm{e}-09 \backslash \mathrm{D}$ i pole $=-0.000001,-0.0000147,0.0000031 \backslash$ Quadrupole $=18.389$ $6706,-18.4432766,0.053606,-5.8319317,-9.1153957,-0.2481487 \backslash P G=C 01$ [X(C 18H2202)] \\@ 